\title{
Final Report Full-Scale Test of DWPF Advanced Liquid-Level and Density Measurement Bubbler $\mathbf{S}$

$$
\text { CONF-990702-- }
$$

by

M. R. Duignan

Westinghouse Savannah River Company

Savannah River Site

Aiken, South Carolina 29808

G. E. Weeks

\section{MASTERYT}

IMRTHEUTION OF THIS DOCUMENT IS UNLAMTED

A document prepared for AMERICAN SOCIETY OF MECHANICAL ENGINEERS FLUIDS ENGINEERING DIVISION SUMMER MEETING at San Francisco, CA, USA from 7/18/99 - 7/23/99.

DOE Contract No. DE-AC09-96SR18500

This paper was prepared in connection with work done under the above contract number with the U.S.

Department of Energy. By acceptance of this paper, the publisher and/or recipient acknowledges the U. S. Government's right to retain a nonexclusive, royalty-free license in and to any copyright covering this paper, along with the right to reproduce and to authorize others to reproduce all or part of the copyrighted paper. 


\section{DISCLAIMER}

This report was prepared as an account of work sponsored by an agency of the United States Government. Neither the United States Government nor any agency thereof, nor any of their employees, makes any warranty, express or implied, or assumes any legal liability or responsibility for the accuracy, completeness, or usefulness of any information, apparatus, product, or process disclosed, or represents that its use would not infringe privately owned rights. Reference herein to any specific commercial product, process, or service by trade name, trademark, manufacturer, or otherwise does not necessarily constitute or imply its endorsement, recommendation, or favoring by the United States Government or any agency thereof. The views and opinions of authors expressed herein do not necessarily state or reflect those of the United States Government or any agency thereof.

This report has been reproduced directly from the best available copy.

Available to DOE and DOE contractors from the Office of Scientific and Technical Information, P.O. Box 62, Oak Ridge, TN 37831; prices available from (615) 576-8401.

Available to the public from the National Technical Information Service, U.S. Department of Commerce, 5285 Port Royal Road, Springfield, VA 22161. 


\section{DISCLAIMER}

Portions of this document may be illegible in electronic image products. Images are produced from the best available original document. 
EES

ENGINEERED EQUIPMENT \& SYSTEMS DEPARTMENT and WTT

WASTE TREATMENT TECHNOLOGY DEPARTMENT

WSR C-TR-97-0103

TTR NO.: HLW/DWPF/TTR-960068

KEYWORDS:

LEVEL SENSING INSTRUMENTS

HIGH-LEVEL WASTES

BUBBLER SYSTEM

AIR PRESSURE

FEEDTANKS

PLUGGAGE

SLURRIES

SLUDGE

SRAT

AIR

RETENTION:

PERMANENT

FINAL REPORT: FULL-SCALE TEST OF DWPF ADVANCED LIQUID-LEVEL AND DENSITY MEASUREMENT BUBBLERS (U)

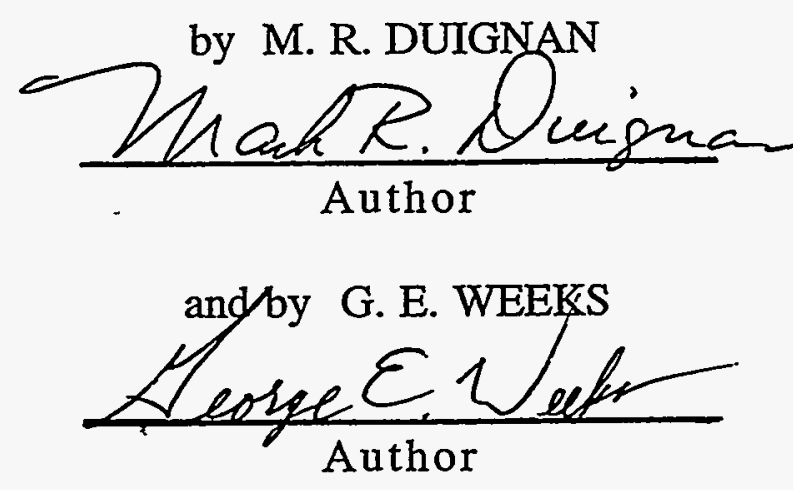

ISSUED: April, 1997

SRTC SAVANNAH RIVER TECHNOLOGY CENTER, AIKEN, SC 29808

Westinghouse Savannah River Company

Prepared for the U.S. Department of Energy under

Contract DE-AC09-96SR18500 
Document: WSRC-TR-97-0103

Title:

Final Report: Full-scale Test of DWPF

Advanced Liquid-level and Density

TTR No:

Measurement Bubblers (U)

TTR Date: $\quad 02 / 23 / 96$

Approvals

$\frac{\text { Athentes }}{\text { J. L. Steimke, Technical reviewer }} \frac{\varphi / 2 / 97}{\text { Date }}$

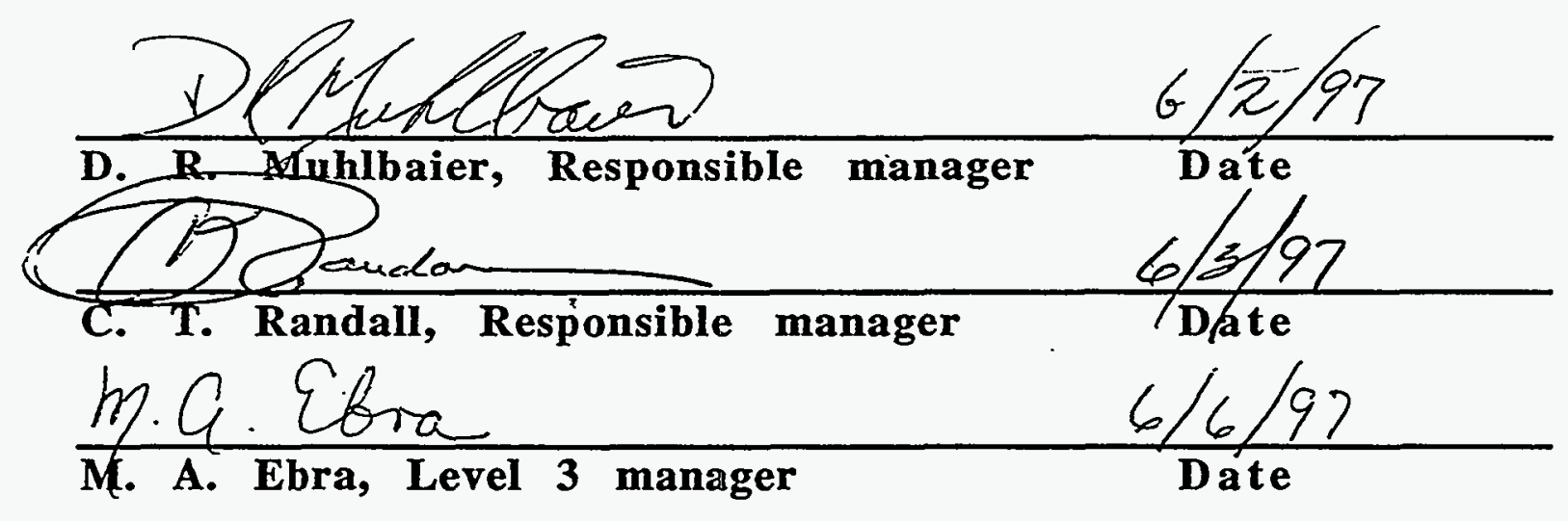




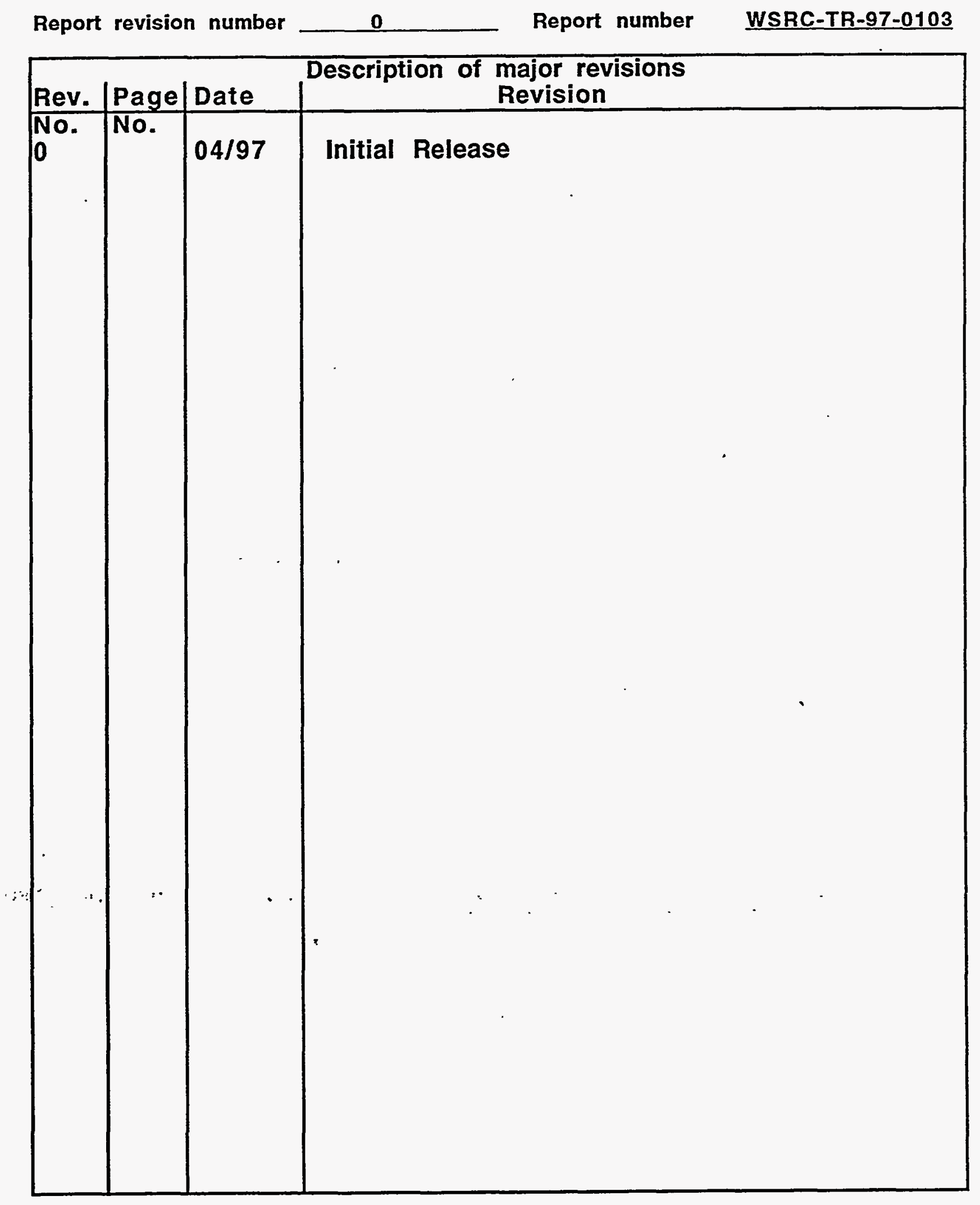


Final Report: Full-scale Test of DWPF Advanced Liquid-level and Density Measurement Bubblers (U)- WSRC-TR-97-0103, Rev. 0

PAGE INTENTIONALLY LEFT BLANK 
Final Report: Full-scale Test of DWPF Advanced Liquid-level and Density Measurement Bubblers (U)- WSRC-TR-97-0103, Rev. 0

\section{Executive Summary}

As requested by the Technical Task Request (1), a full-scale test was carried out on several different liquid-level measurement bubblers as recommended from previous testing (2). This final report incorporates photographic evidence (Appendix B) of the bubblers at different stages of testing, along with the preliminary results (Appendix $C$ ) which were previously reported (3), and instrument calibration data (Appendix D); while this report contains more detailed information than previously reported (3) the conclusions remain the same. The test was performed under highly prototypic conditions from November 26, 1996 to January 23, 1997 using the full-scale SRAT/SME tank test facilities located in the 672-T building at TNX. Two different types of advanced bubblers were subjected to approximately 58 days of slurry operation; 14 days of which the slurry was brought to boiling temperatures.

The test showed that the large diameter tube bubbler (2.64 inches inside diameter) operated successfully throughout the 2-month test by not plugging with the glass-frit ladened slurry which was maintained at a minimum temperature of $50^{\circ} \mathrm{C}$ and several days of boiling temperatures. However, a weekly blow-down with air or water is recommended to minimize the slurry which builds up.

The small diameter porous tube bubbler ( 0.62 inch inside diameter; water flow > 4 milliliters/hour $=1.5$ gallons/day) operated successfully on a daily basis in the glass-frit ladened slurry which was maintained at a minimum temperature of $50^{\circ} \mathrm{C}$ and several days of boiling temperatures. However, a daily blow-down with air, or air and water, is necessary to maintain accurate readings.

For the small diameter porous tube bubbler $(0.62$ inch inside diameter; water flow $<4$ milliliters/hour $=1.5$ gallons/day) there were varying levels of success with the lower water-flow tubes and these tubes would have to be cleaned by blowing with air, or air and water, several times a day to maintain them plug free. This may be too labor intensive for practical use.

All of the large diameter bubbler tubes tested could be readily cleaned in place by either blowing them down with just high pressure air or water $\approx$ $90 \mathrm{psig})$. While the use of both air and water produced the cleanest bubbler, using just air removed most of the slurry build-up, and the use of 
Final Report: Full-scale Test of DWPF Advanced Liquid-level and

Density Measurement Bubblers (U)- WSRC-TR-97-0103, Rev. 0

water resulted in basically a slurry free surface. For the small diameter bubbler tubes it was necessary to use high pressure air and water $(\approx 90$ psig) to effectively clean them. The water was only sent through the porous jacket and not introduced down the air line. However, even under these conditions there was one case where a plug was not removed when both air and water were used.

Primary recommendation: The large diameter probe is the best choice since none of the three tested plugged during the 2-mouth test period to the point which compromised liquid-level measure. However, after a week's operation at boiling temperatures several inches of a soft sludge builds up within the tubes. This sludge can be easily removed in place with either high pressure air or water $(\approx 90 \mathrm{psig})$. A full-scale verification test should be carried out in S-area to confirm the conclusion.

Secondary recommendation: The small-diameter porous tube bubbler is recommended when an access port cannot accommodate the larger diameter probe. Bubbler \#1 operated accurately during most of the test period. This probe had the highest water flow rate $(\approx 1.6$ gallons/day) and had the least distance from the slurry upper surface ( 37 inches). This probe can be made to accurately operate at lower depths if the 8-inchlong porous tube is made longer and the water flow rate made higher.

Substituting the current level and density probes (Holledge) with bubbler probes will result in a significant cost savings (inexpensive materials, less labor to manufacture, less labor to maintain, less down time due to less frequent instrument replacement).

(Table 1 is reproduced from page 8 of report.)

\begin{tabular}{|c|c|c|c|c|}
\hline \multicolumn{5}{|c|}{ Table 1: Summary of Test Results (seo Appendix C for Specific Results) } \\
\hline $\begin{array}{l}\text { Bubbler } \\
\text { No. }\end{array}$ & Bubbler Type & $\begin{array}{l}\text { Air Flow Rate } \\
\text { CFH *1* }\end{array}$ & $\begin{array}{c}\text { Water Flow Rate } \\
\mathrm{ml} / \mathrm{min}{ }^{*}{ }^{*}\end{array}$ & $\begin{array}{l}\text { Time to Plug } \\
\text { Days } 3^{*}\end{array}$ \\
\hline 1 & porous tube & 1.5 & 4.4 & 7 \\
\hline 2 & porous tube & 1.7 & 2 & 3 \\
\hline 3 & porous tube & 1.6 & 1.2 & 5 \\
\hline 4 & porous tube & 1.5 & 0.3 & 1 \\
\hline 5 & porous tube & 1.5 & 0.5 & 3 \\
\hline 6 & porous tube & 1.6 & 0.3 & 2 \\
\hline 7 & porous tube & 1.5 & 4.2 & 7 \\
\hline 8 & porous tube & 1.5 & 2 & \\
\hline 9 & porous tube & 1.8 & 1.3 & 2 \\
\hline 10 & large diameter tube & 1.4 & $4^{*}$ & No Plugggage \\
\hline 11 & large diameler tube & 1.5 & $\cdot 4^{*}$ & No Pluggage \\
\hline 12 & large diameter tube & 1.5 & $\cdot 4^{*}$ & No Pluggage \\
\hline \multicolumn{5}{|c|}{ 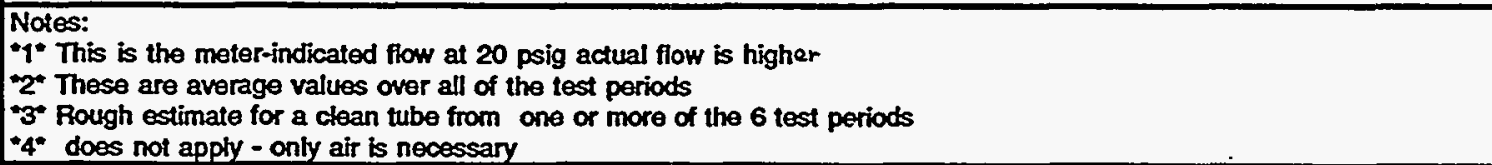 } \\
\hline
\end{tabular}


Final Report: Full-scale Test of DWPF Advanced Liquid-level and Density Measurement Bubblers (U)- WSRC-TR-97-0103, Rev. 0

\section{Acknowledgments}

We would like to thank all of the TNX and ETF personnel who assisted in this task. Specifically we would like to thank: R. C. Odom for his procedural development and day-to-day hands-on help; T. K. Snyder, J. W. Duvall, M. L. Johnson, and A. P. Jarrett for their painstaking job of transcribing the analog data into a spreadsheet; J. W. Corbett and S. T. Hargett for their design and drafting assistance; and L. J. Pattison for cleaning up the last version of this report. The work was funded by the U. S. Department of Energy under Contract DE-AC09-96SR18500. 
Final Report: Full-scale Test of DWPF Advanced Liquid-level and Density Measurement Bubblers (U)- WSRC-TR-97-0103, Rev. 0

\section{Nomenclature}

$\begin{array}{ll}\text { DWPF } & \text { - Defense Waste Process Facility } \\ \text { DWPT } & \text { - Defense Waste Process Technology } \\ \text { ETF } & \text { - Experimental Thermal Fluids (group or laboratory) } \\ \text { MFT } & \text { - Melter Feed Tank } \\ \text { PHA } & \text { - Precipitate Hydrolysis Aqueous } \\ \text { SME } & \text { - Slurry Melter Evaporator } \\ \text { SRAT } & \text { - Sludge Receipt and Adjustment Tank } \\ \text { SRTC } & \text { - Savannah River Technology Center } \\ \text { SRS } & \text { - Savannah River Site } \\ \text { TNX } & \text { - Full-scale Demonstration Facility } \\ \text { WSRC } & - \text { Westinghouse Savannah River Company } \\ \rho & - \text { Density } \\ \sigma & - \text { Surface Tension }\end{array}$


Final Report: Full-scale Test of DWPF Advanced Liquid-level and Density Measurement Bubblers (U)- WSRC-TR-97-0103, Rev. 0

\section{Table of Contents}

Executive Summary

Page

Acknowledgments

vii

Nomenclature

viii

1.0. Introduction 1

2.0 Experimental Setup 2

3.0 Instrumentation 3

4.0 General Operation 4

5.0 Discussion Results 4

6.0 Conclusions and Recommendations ‘ 9

$\begin{array}{lll}7.0 & \text { References } & 10\end{array}$

Appendices

Appendix A: Photographic and Drawings of the Experimental Apparatus

Appendix B: Photographic Evidence 24

\begin{tabular}{cc} 
Appendix C: & $\begin{array}{c}\text { Explanation of Experimental } \\
\text { Measurement Data }\end{array}$ \\
\hline
\end{tabular}

Appendix D: Instrument Uncertainty Analysis 57 
Final Report: Full-scale Test of DWPF Advanced Liquid-level and Density Measurement Bubblers (U)-WSRC-TR-97-0103, Rev. 0

\section{PAGE INTENTIONALLY LEFT BLANK}




\subsection{Introduction}

\section{The need}

The instrument originally used to measure liquid level and density in DWPF mixing tanks [e.g., Slurry Receipt and Adjustment Tank (SRAT), Slurry Mixture Evaporator (SME) Tank, Melter Feed Tank (MFT)] was the fundamentally simple and rugged bubbler. The advantage of a bubbler is in its construction and maintenance, i.e., it is simply a straight tube with the open end located were a measurement is needed. Being just a tube it is easily replaced and calibrated, inexpensive to manufacture, has no moving parts to wear out, and contains no elastomers which will break down in a radioactive environment. Unfortunately, since one end of the tube is exposed to the medium that it is measuring, one problem was encountered. In tanks that contain glass frit and sludge (i.e., SME and the MFT) the tube becomes readily plugged, and the higher the temperature the faster it plugs. In the SME plugging can occur within hours! In a typical bubbler tube, which has a 0.5 -inch to 1.0-inch inside-diameter tube, the liquid enters the tube because of the tank agitation and a typical plug is approximately two inches recessed inside the tube and is approximately two inches thick. Because of the drying effect of the heat and air the plug becomes a hard solid that can only be removed by mechanical means (e.g., metal lance).

In 1983 (4), the bubbler-type level sensors were replaced with a similar, but more complicated pressure sensing device, a Holledge Diaphragm Probe. This device works like a bubbler tube in that air flows through a tube and the medium to be measured provides a back pressure, but instead of the air entering the medium it presses against a diaphragm which then presses against the medium. After the air leaves the tube end and flows past the diaphragm it returns through a concentric tube that surrounds the downflowing air tube. That is, the air does not enter the liquid being measured but returns via an outside jacket on the tube through which it originally came. The end of this probe is sealed and no liquid can enter. Unfortunately, besides the fact that each probe is relatively expensive $(\$ 50,000)(5)$ the operational experience with Holledge Probes has not been satisfactory. Several problems occurred since their introduction. Some of those problems are: 1 ) in the low pressure range of interest there are linearity problems, 2) highly sensitive to temperature, 3) diaphragms fail readily from stress, 4) cannot be recalibrated once put in use, 5) a diaphragm's limited movement creates a measurement threshold. In 1989 (6) a check of fifteen probes in five different tanks showed only one Holledge probe functioning properly. 
In 1993 (5) a proposal was made to search the literature and vendors for liquid level indicators as a replacement for the Holledge Probe. From the results of the search (4) two main recommendations were given: 1) To study a radar liquid-level indicator, because it can operate in a radioactive environment and is medium independent. 2) To develop a modified bubble tube to utilize all the advantages a bubbler type indicator while minimizing its plugging problem.

\section{Path Forward}

To pursue the second recommendation, given above, some modifications on bubbler tubes were suggested (7). The basic idea was to keep the inside of the tube from drying out and therefore the slurry may not be able to stick and build up. One idea was to have concentric tubes to allow cooling water to flow and prevent the slurry from evaporating inside the tube. Another was to have the concentric tubing, but the inside wall of the tube would be porous to allow water to seep through and keep the surface wet. In this case, a small flow of water would enter the slurry.

In 1994, a bench-top experiment was carried out to test several different bubbler tube alternatives, to include a large diameter tube bubbler. It was thought that the large diameter would provide a larger free surface within the bubbler to allow internal wave action to keep the bubbler tube plug free. Of the five alternative bubbler tube tested the results (2) indicated that two types may operate successfully in DWPF slurries without pluggage: a small diameter ( 0.6 inch i.d.) porous tube with water flowing through the porous wall and a large diameter (3.4 inch i.d.) tube. Those suggestions were the basis for issuing a Technical Task Request (1) to carry out a full-scale test in the SRAT/SME tank at TNX so that the alternate technologies could be tested under prototypic conditions. This resulted in a Task Technical and QA Plan (8) to construct and do testing of the two types of bubblers. The testing began at TNX in November 1996 and ended in January 1997.

\subsection{Experimental Setup}

To satisfy the TTR (1) a set of twelve probes were constructed, Appendix A. The "probe tree" on the lower left hand side in Fig. A1 [WSRC Photograph No. 96-1569-1] shows the orientation of nine porous tube probes. Figure A2 [WSRC Photograph No. 96-1569-4] is a close-up of three of the pre-installed porous-tube bubblers, with Fig. A7 showing a profile drawing of this probe construction. All nine probes were exactly 
Final Report: Full-scale Test of DWPF Advanced Liquid-level and

Density Measurement Bubblers (U)- WSRC-TR-97-0103, Rev. 0

the same, only the water flow rate would vary*. Figure A3 [WSRC Photograph No. 96-1569-6] is a close-up of the pre-installed large diameter bubblers, with Fig. A4 showing a profile of this probe construction ${ }^{\star *}$.

["The bench-top test (2) showed that a water flow of $1.67 \mathrm{~m} / \mathrm{min}$ ( 0.6 gallons/day) maintained the tube plug free for 19 hours in slurry at $90^{\circ} \mathrm{C}$, but this full-scale test was to determine if lower flow rates would also work so as to minimize the amount of water additions to waste tanks. For this test an equivalent water flow rate would be 1.67 $\mathrm{m} / \mathrm{min} \times 8 / 6=2.2 \mathrm{ml} / \mathrm{min}$ ( $0.8 \mathrm{gaV}$ day), since the porous-tube length was increased to 8 inches, from 6 inches; the length was increased because the slurry was found to splash up to approximately 6 inches in the bench-top test

(2). Therefore, the water flow rates were chosen to be multiples of the bench-top value, i.e., $2 x, 1 x, 0.5 x, 0.25 x$, and $0.125 \times 2.2 \mathrm{ml} / \mathrm{min}$, (see Figs. C1 to $\mathrm{C} 9$ for the actual flow rates used).]

["The large tube has an inside diameter of 2.64 inches (2.5 sch 10 pipe) instead of the 3.4 inches used previously (2). It would have been better to use the larger diameter, but the access port on the S-area tanks for level probes only have 3 -inch diameter openings. Combining this limitation with the fact that the tube must have significant structural strength to withstand the highly agitated slurry, led to this smaller dimension, i.e., 2.5 sch 10 pipe (2.88 o.d., 2.64 i.d.). The reduced diameter was expected to build up slurry much faster and have a higher potential to plug, but it was hoped that there was still sufficient flow area to maintain the bubbler operational over significantly longer time periods than the $4-8$ hours that standard bubblers are known to plug.]

Figure A4 gives the relative distances of the probes along the probe trees. These distances are also valid for the small diameter probes since the vertical probe-to-probe distances were the same for either the small or large diameter probes. Using Section A-A from Fig. A9 and the Front Elevation View from Fig. A4 the distances from the bottom of the flange plate to each probe opening are shown to be 185.125 inches, 161.125 inches, and 130.125 inches (which takes into account that a probe's opening is at the apex of the "V" notch to allow air bubbles to easily escape into the tank; it is $1 / 8$ inch high). The entire probe assembly rig shown in Fig. A1 was placed in a large tank opening (19.50 inches) shown in Fig. A11 (Ref. 9) on the right side of the tank, i.e., opposite the side that has the mercury sump. The distance from the top of that opening to the bottom of the tank, at the center of that opening, is approximately 186.5 inches $(9,10)$. Therefore, the distances between the probe openings and the bottom of the tank were 1.4 inch, 25.4 inches, and 56.4 inches, respectively. During the second week of testing, the probe assembly was raised 42 inches higher in the tank (see $A 10$ ), which increased the distance from the tank bottom to the probe opening to 43.4 inches, 67.4 inches, and 98.4 inches, respectively. This was done to keep the top-most probes out of the slurry for a fixed period to simulate empty tank conditions. The goal was to see if probes, with some sludge accumulation but still operational, would continue to function after their reintroduction into the slurry.

\subsection{Instrumentation}

Each of the twelve bubbler tubes had a pressure gauge and an air flow meter. Each of the nine porous bubbler tubes also had a water flow meter. Specifics and calibrations for each of the devices are given in Appendix D. 
Final Report: Full-scale Test of DWPF Advanced Liquid-level and

Density Measurement Bubblers (U)- WSRC-TR-97-0103, Rev. 0

\subsection{General Operation}

Details of the actual operating procedure can be found in the test procedures (11). The general procedure was:

- pre-calibrate the instruments

- install the twelve probes in the full-scale SRAT/SME tank

- monitor the twelve probes on an hourly basis

- when scheduled, raise the slurry to boiling temperature

- on a weekly basis remove the probes to document conditions

- after the first period with some days of boiling temperatures: raise the probes out of the slurry sufficiently to maintain the top set out of the slurry

- after the next period with some days of boiling temperatures: lower the probes to the original height

- after the next period with some days of boiling temperatures: document the condition in the morning, replace the probes in the slurry, blow down the probes, remove the probes for documentation

- after the last period with some days of boiling temperatures: remove and document

- post-calibrate the instruments..

\subsection{Discussion of Results}

\section{Definition of Pluggage}

Pluggage of a tube simply means that a bubbler is sufficiently clogged with a combination of dried sludge, slurry, and glass frit that a level measurement is no longer practical, for example see Fig. B9. In fact, the inner tube of a bubbler could have a significant build-up of sludge and still function properly, Figs. B2 to B6. Only when the level measurement is affected, is it considered plugged. Moreover, during the tests once a tube became plugged it always re- 
Final Report: Full-scale Test of DWPF Advanced Liquid-level and

Density Measurement Bubblers (U)-WSRC-TR-97-0103, Rev. 0

opened to temporarily indicated level again, however, it would begin to successively, replug and unplug to the point that made the instrument useless.

\section{General Observations of the Probes During Testing}

Because of the labor necessary to install and remove the test probes from the full-scale tank, these activities were kept to a minimum with at least one week between removals. Therefore, daily sludge accumulations in the probes were not recorded. However, whether the probes were clean of slurry, or not, a week's time was sufficient to allow the slurry to build up in all the probes to the point that some appeared to be plugged (see Figs. $\mathrm{B} 2$ and $\mathrm{B} 6$ ), even though the data still did not indicate a pluggage (see Fig. $\mathrm{C} 12$, which corresponds to Figs. B2 to B5, and Figs. C7, C8, and C9 for test period 1, which correspond to Fig. B6).

Another feature common to all probes was that the location of the highest concentration of slurry build-up, in each probe, was a function of a probe's depth in the slurry. Probe 12, which was located 92 inches under the surface of the slurry, had a slurry plug recessed approximately 10 inches into the tube. Probe 11, which was located 68 inches under the surface of the slurry, had a slurry plug recessed approximately 6 inches into the tube. Probe 10, which was located 37 inches under the surface of the slurry, had slurry plugs recessed approximately 3 inches into the tube. This effect can be seen by comparing Figs. B2 with B3. These figures are of the same probe, 12 , but after the first period of testing the probe was raised 42 inches (or to $92-42=50$ inches under the surface of the slurry) and held there for one week. The 10-inch plug depth was reduced to between 4 to 5 inches.

The smaller diameter porous-tube probes: 7,8 , and 9 at the same level as probe $12 ; 4,5$, and 6 at the same level as probe 11 ; and 1,2, and, 3 at the same level as probe 10, had differences in the plug depths into the tubes similar to the large diameter probes. However, the actual plug depths were about one-half that of the large diameter probes. For example, the plug depth for probes 7,8 , and 9 was about $5^{n}$ (Fig. B6) compared to the $10^{\prime \prime}$ of probe 12 (Fig. B2). This is possible because, for equal pressure (tensile stress) and liquid wall shear stress, only geometry is important. $A$ ratio of the forces, that result from these stresses, indicates that as the tube diameter decreases the force due to wall shear stress become more important which acts against the upward movement of a liquid plug, thus reducing its height. 
Final Report: Full-scale Test of DWPF Advanced Liquid-level and Density Measurement Bubblers (U)- WSRC-TR-97-0103, Rev. 0

These different plug locations exist because of the submerged wave heights within the liquid depend upon pressure. The importance here is if liquid level in a tank changes significantly over time, then the change in submerged wave heights will cause slurry plugs to occur at different locations. [As an illustration on the effect of pressure on these wave heights see Fig C13. A careful examination of the data between periods 1 and 2 shows that as pressure increases (increasing depth) there appears to be more variation in the data (Quantitatively, one standard deviation of those data increases from 1.2 inches $\mathrm{H}_{2} \mathrm{O}$, for lower pressure, to 2.9 inches $\mathrm{H}_{2} \mathrm{O}$, for the higher pressure. By comparing all the graphs, this same height effect is always present.]

\section{Specific Features of the Data}

Bubble Probes \#1, \#2, and \#3 Porous Tubes [Figs. C1, C2, and C3]

Height from Tank Bottom: 56.4 inches

Out of all the small diameter tube bubblers, these three, as a group, showed the most success in operation without pluggage. This occurred for two reasons which must be taken together. They had the highest water flow rates and were the least submerged in the slurry (37 inches from the upper surface). This means that inner tubes had the most water lubricating the tube wall while having a slurry plug pulsating less than 3 inches into the bottom of the tubes. In fact, bubbler probe 1 which had at least twice the water flow rate as the other two probes remained fairly stable and accurate until the last period. The increase in the last period is thought to have occurred because of an unsuccessful attempt to dislodge significant slurry build-up on $1 / 16 / 97$.

Bubble Probes \#4 \#5, and \#6 Porous Tubes [Figs. C4, C5, and C6] Height from Tank Bottom: 25.4 inches

With significantly lower water flow rates, and being twice as deep in the slurry (68 inches), than bubblers 1,2, and 3, these three bubblers only needed a day or two to begin to plug once boiling temperatures were reached. At the beginning of period 6 they were shown to operate accurately after being blown down, but began to plug once several days past. A daily blow down would probably keep them operating successfully. Bubble Probes \#7, \#8, and \#9 Porous Tubes [Figs. C7, C8, and C9] 
Final Report: Full-scale Test of DWPF Advanced Liquid-level and

Density Measurement Bubblers (U)- WSRC-TR-97-0103, Rev. 0

\section{Height from Tank Bottom: 1.4 inches}

Once again, the bubbler with the highest water flow rate $(4.2 \mathrm{~mL} / \mathrm{min}=$ 1.6 gallons/day) operated the longest without plugging, bubbler 7 . On Fig. C7 it appears that between periods 1 and 2 and between periods 5 and 6 bubbler 7 operated several days accurately but with the onset of boiling temperatures, the pressure would increase. A daily blown down with air or air and water would probably keep the probes operating accurately indefinitely. However bubblers 8 and 9 showed a higher tendency to plug and would therefore be a less desirable choice.

The photographic evidence indicates that waiting more than couple of days to blow down a porous tube may allow enough sludge to build up to prevent a complete plug removal. Figure $\mathrm{B} 6$ shows a one-week build up of sludge. The probes were still functional (see test period 1 on Figs. C7, C8, and C9) but there was only a small hole in the center of the plug to allow operation. On 1/16/97 these probes were blown down with water, see Fig. B13. Initially these probes were operational but the data in Figs. C7, C8, and $\mathrm{C} 9$ indicate that pluggage began almost immediately after one more week of operation. Figure B9 shows the plugs near the end of the tubes. This indicates that the original plugs were not totally removed and therefore the sludge accumulation simply continued where it left off. These probes should be blown down often enough to prevent accumulation to occur.

Bubble Probes \#10, \#11, \#12 Large Diameter Tubes [Figs. C10, C11, C12, and 13]

Height from Tank Bottom: 56.4 inches, 25.4 inches, 1.4 inches, respectively

Outside of the increased variance in the data as a probe is located deeper in the slurry, these three probes never indicated an onset of pluggage. After one week of operation there was enough slurry build-up in the probes to almost completely block the opening, however, there was always a channel to let it communicate hydraulically with the tank liquid, as can be seen in the center of the accumulated sludge in Figs. B2, B4, and B5. After two weeks of operation the probe appeared to be completely plugged when visually observed, e.g., see Fig. B3, but as the data show, see Fig $\mathrm{C13}$, they all continued to measure accurately. This is verified by the independent measurement indicated on the graphs and by the fact that the relative distance between the probes are accurately shown in the data. That is, the physical distance between the two top-most probes was 31 inches [Fig. A4] and when accounting for the SpG, then $31 * 1.3=40$ inches 
Final Report: Full-scale Test of DWPF Advanced Liquid-level and

Density Measurement Bubblers (U)- WSRC-TR-97-0103, Rev. 0

$\mathrm{H}_{2} \mathrm{O}$. On Fig. $\mathrm{C} 13$ the data show approximately $78-37=41$ inches. The physical distance between the two bottom-most probes was 24 inches [Fig. A4] and when accounting for the SpG, then $24^{*} 1.3=31$ inches $\mathrm{H}_{2} \mathrm{O}$. On Fig. $\mathrm{C} 13$ the data show approximately $110-78=32$ inches. Since the measurement uncertainty is considerably larger than $32-31=1$ inch, this difference is insignificant, see Fig. D24, D25, D26.

While sludge accumulations never affected the level measurement during any of the test periods for the large diameter probes, Figs. B2, B3, B4, and $B 5$ indicate significant accumulations that may eventually build to the point where readings could be affected. Therefore, two of the test periods (5 and 6) began with a blowdown with water. Fig. B10 shows an almost totally clean probe and Fig. B11 shows similar results. Fig. B4 shows what the tube looked like before being blown down and Fig. B11 shows it after cleaning on the same day, 1/16/97. This was done by removing the probe after a week's worth of operation to document in the morning; replacing it in the full-scale tank, blowing it down with water in the afternoon, and then immediately removing it again for documentation.

\begin{tabular}{|c|c|c|c|c|}
\hline $\begin{array}{l}\text { Bubbler } \\
\text { No. }\end{array}$ & Bubbler Type & $\begin{array}{c}\text { Air Flow Rate } \\
\text { CFH * } 1^{*}\end{array}$ & $\begin{array}{c}\text { Water Flow Rate } \\
\mathrm{ml} / \mathrm{min}{ }^{\star} 2^{*}\end{array}$ & $\begin{array}{l}\text { Time to Plug } \\
\text { Days: }{ }^{*} 3^{\star}\end{array}$ \\
\hline 1 & porous tube & 1.5 & 4.4 & 7 \\
\hline 2 & porous tube & 1.7 & 2 & 3 \\
\hline 3 & porous tube & 1.6 & 1.2 & 5 \\
\hline 4 & porous tube & 1.5 & 0.3 & 1 \\
\hline 5 & porous tube & 1.5 & 0.5 & 2 \\
\hline 6 & porous tube & 1.6 & 0.3 & 2 \\
\hline 7 & porous tube & 1.5 & 4.2 & 7 \\
\hline 8 & porous tube & 1.5 & 2 & 3 \\
\hline 9 & porous tube & 1.8 & 1.3 & 2 \\
\hline 10 & large diameter tube & 1.4 & ${ }^{*} 4^{*}$ & No Pluggage \\
\hline 11 & large diameter tube & 1.5 & $* 4$ * & No Pluggage \\
\hline 12 & large diameter tube & 1.5 & * $4^{*}$ & No Pluggage \\
\hline \multicolumn{5}{|c|}{$\begin{array}{l}\text { Notes: } \\
{ }^{*} 1^{*} \text { This is the meter-indicated flow at } 20 \text { psig actual flow is higher } \\
{ }^{*} 2^{*} \text { These are average values over all of the test periods } \\
{ }^{*} \text {. Rough estimate for a clean tube from one or more of the } 6 \text { test periods } \\
{ }^{*} 4^{*} \text { Does not apply - only air is necessary }\end{array}$} \\
\hline
\end{tabular}


Final Report: Full-scale Test of DWPF Advanced Liquid-level and

Density Measurement Bubblers (U)- WSRC-TR-97-0103, Rev. 0

\subsection{Conclusions and Recommendations}

\section{Large Diameter Tube Bubbler (2.64 inches inside diameter)}

Operated successfully throughout the 2-month test by not plugging with the glass-frit ladened slurry which was maintained at a minimum temperature of $50^{\circ} \mathrm{C}$ and several days of boiling temperatures. However, a weekly blow-down with air or water is recommended to minimize the slurry which builds up. [Figs. C10, C11, C12 and B2, B3, B4, B5 vs. B10, B11] [Limitation: Because of the physical size of this bubbler it is probably not practical to place measurement locations closer than 24 inches, when they are located on top of each other. For example, see Figs. $A 1, A 3$, and $A 4]$

2. Small Diameter Porous Tube Bubbler (0.62 inch inside diameter) (water flow $>4$ milliliters/hour $=1.5$ gallons $/$ day)

Operated successfully on a daily basis in the glass-frit ladened slurry which was maintained at a minimum temperature of $50^{\circ} \mathrm{C}$ and several days of boiling temperatures. However, a daily blow-down with air, or air and water, is necessary to maintain accurate readings. [Figs. $\mathrm{C1}, \mathrm{C} 7$ and $\mathrm{B} 6, \mathrm{~B} 7$ vs. $\mathrm{B} 12, \mathrm{~B} 13$ (the tube closest to the bottom of the photographs)]

3. Small Diameter Porous Tube Bubbler ( 0.62 inch inside diameter) (water flow $<4$ milliliters/hour $=1.5$ gallons/day)

There were varying levels of success with the lower water-flow tubes but these tubes would have to be cleaned by blowing with air, or air and water, several times a day to maintain them plug free. This may be too labor intensive for practical use. [Figs. C2, C3, C4, C5, C6, C8, C9 and B6, $B 7$ vs. $B 12, B 13$ (the two tube closest to the top of the photographs)]

\section{Clean with Air or Air and Water}

All of the large diameter bubbler tubes tested could be readily cleaned in place by either blowing them down with just high pressure air or water $\approx$ 90 psig). While using just air removed most of the slurry build-up, the use of water resulted in basically a slurry free surface, see Figs. B10 and B11. For the small diameter bubbler tubes it was necessary to use high pressure air and water $(\approx 90 \mathrm{psig})$ to effectively clean them. The water was only sent through the porous jacket and not introduced down the air line. However, even under these conditions there were some tubes where plugs were not removed when both air and water were used, see. Figs. B12 
Final Report: Full-scale Test of DWPF Advanced Liquid-level and Density Measurement Bubblers (U)- WSRC-TR-97-0103, Rev. 0

and B13 (on Fig. B12 only the two of the three tubes shown were blown down).

\section{Recommendations}

1. Replace all standard bubbler that plug and all Holledge probes with large diameter probes were the larger size probe can be tolerated.

The large diameter probe is the best choice since none of the three tested plugged during the 2-mouth test period to the point which compromised liquid-level measure. However, after a week's operation at boiling temperatures several inches of a soft sludge builds up within the tubes. This sludge can be easily removed in place with either high pressure air or water $(\approx 90 \mathrm{psig})$. A full-scale verification test should be carried out in $S$-area to confirm the conclusion. [Note: When testing, it should be remembered that the TNX tank agitator runs at 100 RPM and the S-area SME tank runs at 130 RPM. Since level (and density) are measured by pressure differences these reading may be affected by the increase velocity of the tank liquid by a factor of $(130 / 100) 2=1.7$. However, within the measurement uncertainty of this test such dynamic pressure affects were not significant.]

2. Replace all standard bubbler that plug and all Holledge probes with small-diameter porous tube probes were the larger size probe cannot be tolerated.

The small-diameter porous tube bubbler is recommended when an access port cannot accommodate the larger diameter probe. Testing showed that bubbler \#1 (Fig. C1) operated accurately during most of the test period. This probe had the highest water flow rate $(\approx 1.6$ gallons/day) and had the least distance from the slurry upper surface ( 37 inches). 'Therefore, this probe can be made to accurately operate at lower depths if the 8-inchlong porous tube is made longer and the water flow rate made higher.

\subsection{References}

1. Occhipinti, J. E., "Alternate liquid level measurement for DWPF Canyon vessels," Technical Task Request No. HLW/DWPF/TTR-960068, February 23, 1996.

2. Duignan, M. R., and A. B. Barnes, "Final Report: Development of Liquid Level and Density Bubbler for DWPF Canyon Vessels," Report No. WSRCTR-94-0509, October, 1994. 
3. Duignan, M. R. and G. E. Weeks, "DWPF Advanced Liquid-level Measurement Bubblers: Preliminary Test Results (U)

4. Spatz, T. L., "Liquid Level Indicator Study (U)," Inter-office Memorandum No. SRT-ETF-940002, January 11, 1994.

5. Steeper, T. J. "Proposal for Holledge Probe Alternative Background," Inter-office Memorandum No. SRT-ETF-930233, October 7, 1993.

6. Dillman, B., "Holledge Gauge Applications in the DWPF," presentation to Stone and Webster Engineering, November 1, 1989.

7. Randall, C. T., "Alternate Liquid Level Probe Idea," Inter-office Memorandum, February 14, 1994.

8. Weeks, G. E. and M. R. Duignan, "Evaluation of Advanced Bubblers for Liquid Level Measurement in the DWPF," Technical and QA Plan No. WSRCRP-96-0015, Rev. 0, for Task No. DWPT-96-0043.

9. Drawing, "Tank Assembly - SME/SRAT/MFT/DWTT," SRS Engineering Drawing No. W752193, Rev. 5, 7/19/85.

10. Drawing, "Test Tank Vessel Arrangement and Data," SRS Engineering Drawing No. PV182698, Rev. 35, 9/22/83.

11. WSRC Field Procedures to operate test: SP-672T-96-10-1, SP672T-96-10-2, SP-672T-96-10-3, SP-672T-96-10-4.

12. Weeks, G. E., Task Notebook No. WSRC-NB-94-1440, issued 4/20/94. 
Final Report: Full-scale Test of DWPF Advanced Liquid-level and Density Measurement Bubblers (U)- WSRC-TR-97-0103, Rev. 0

\section{APPENDIX A}

Photographs and Drawings of the Experimental Apparatus

[Figures $A 1, A 2$, and $A 3]$

Figure A1 (No. 96-1569-1, taken 11/96): This photograph shows the entire probe assembly before installation for the first time. The bottom left tree contained the nine porous-tube probes, the bottom right tree contained the three large diameter probes, the top tree was a support pipe to make the entire structure rigid.

Figure A2 (No. 96-1569-4, taken 11/96): This photograph shows the bottom 3 porous-tube bubblers before installation for the first time. The small tube connected at the side was one of the tubes which carried water to the concentric water tube channel. The tubes on top carried air to the center tube.

Figure A3 (No. 96-1569-6, taken 11/96): This photograph depicts the bottom large diameter tube before installation for the first time.

[Figures A4 to A10]

These figures are reductions of the developmental drawings used to construct the experimental apparatus that was installed in the full-scale SRAT/SME tank at TNX.

[Figure A11]

This figure shows the full-scale SRAT/SME tank at TNX (taken from Ref. 9). 
Final Report: Full-scale Test of DWPF Advanced Liquid-level and

Density Measurement Bubblers (U)- WSRC-TR-97-0103, Rev. 0

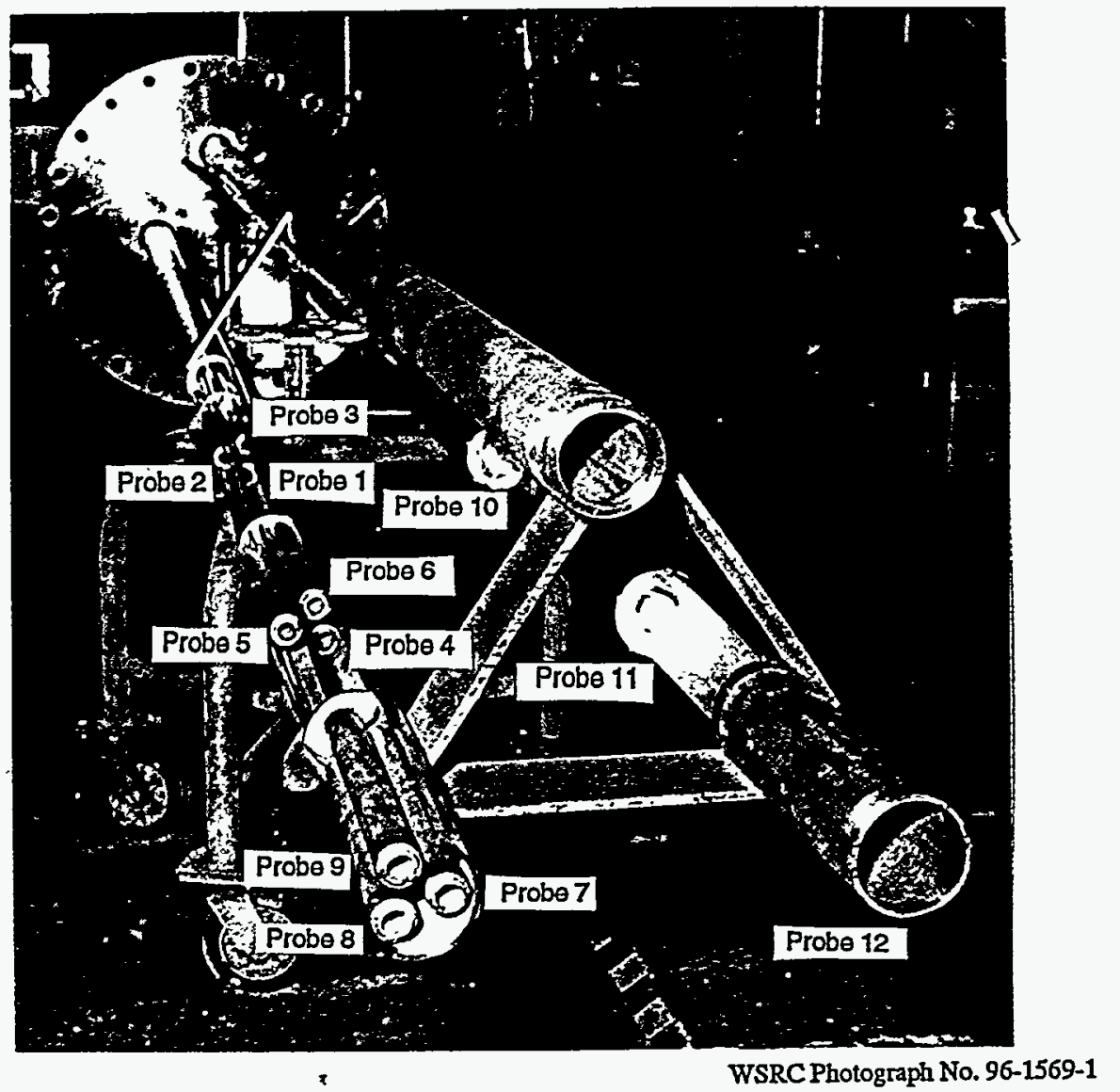

Figure A1 (No. 96-1569-1, taken 11/96): Overall Test Apparatus 
Final Report: Full-scale Test of DWPF Advanced Liquid-level and Density Measurement Bubblers (U)- WSRC-TR-97-0103, Rev. 0

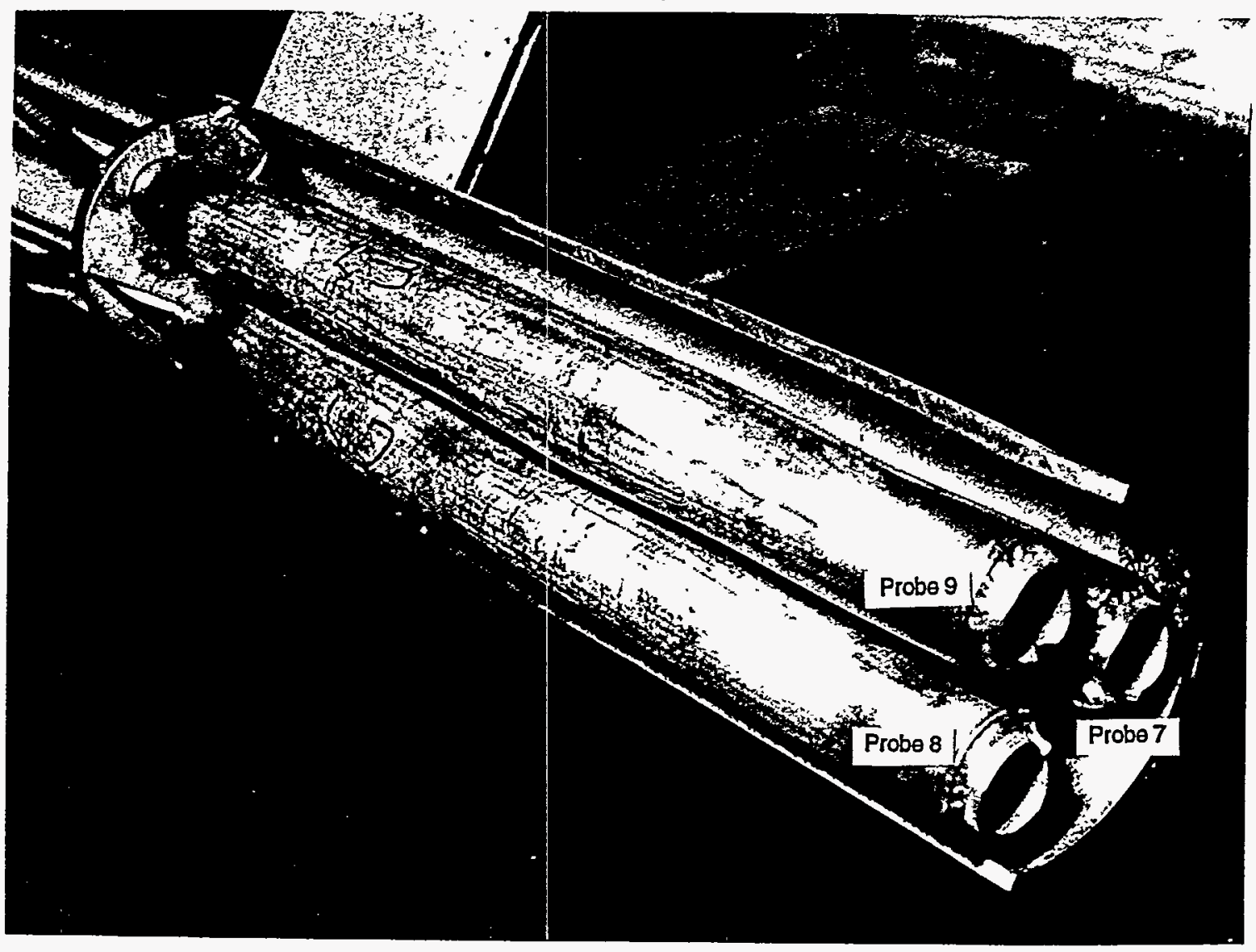

WSRC Photograph No. 96-1569-4 
Final Report: Full-scale Test of DWPF Advanced Liquid-level and

Density Measurement Bubblers (U)- WSRC-TR-97-0103, Rev. 0

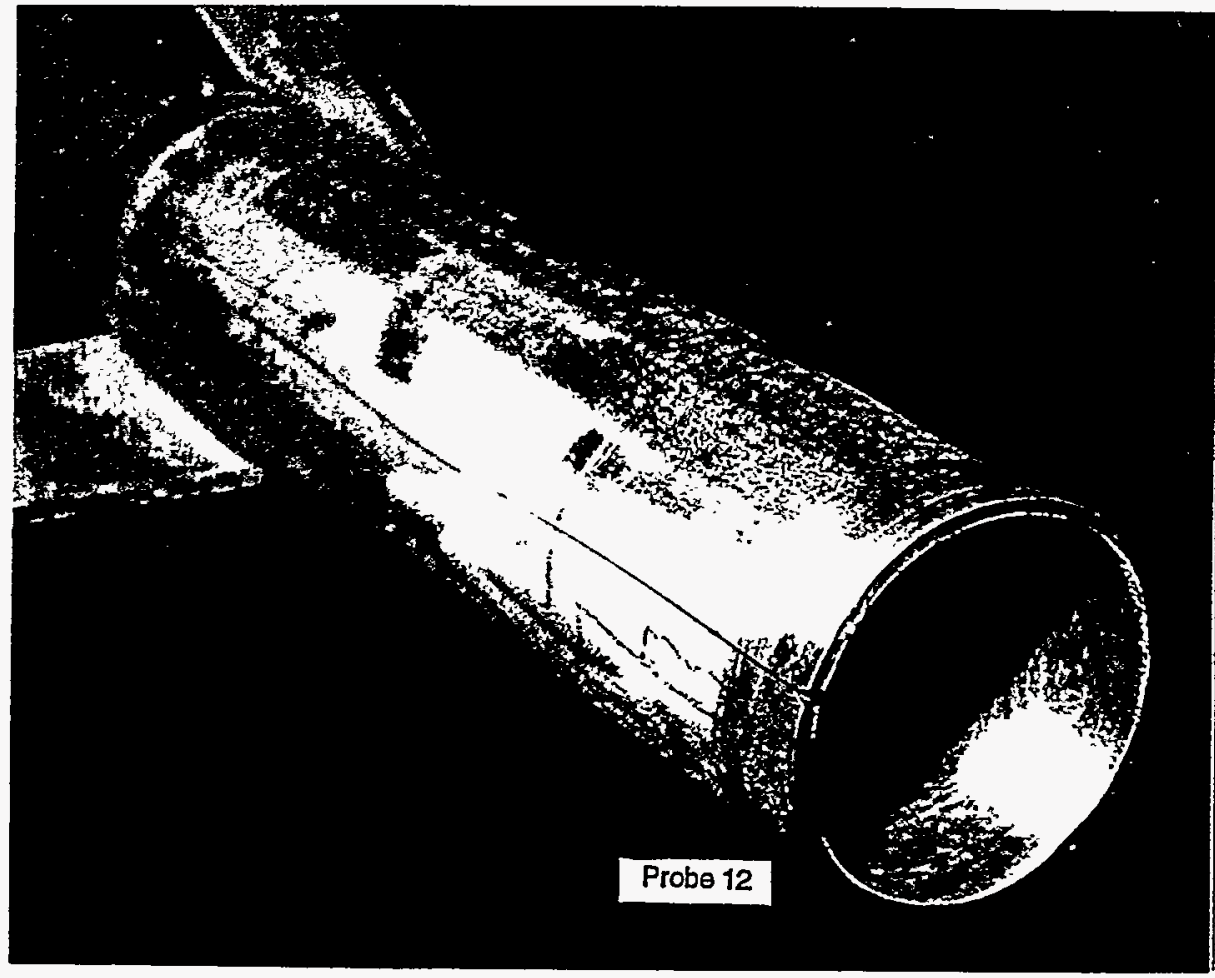

WSRC Photograph No. 96-1569-6

Figure A3 (No. 96-1569-6, taken 11/96): Large-diameter Bubbler Probe 
Final Report: Full-scale Test of DWPF Advanced Liquid-level and Density Measurement Bubblers (U)- WSRC-TR-97-0103, Rev. 0

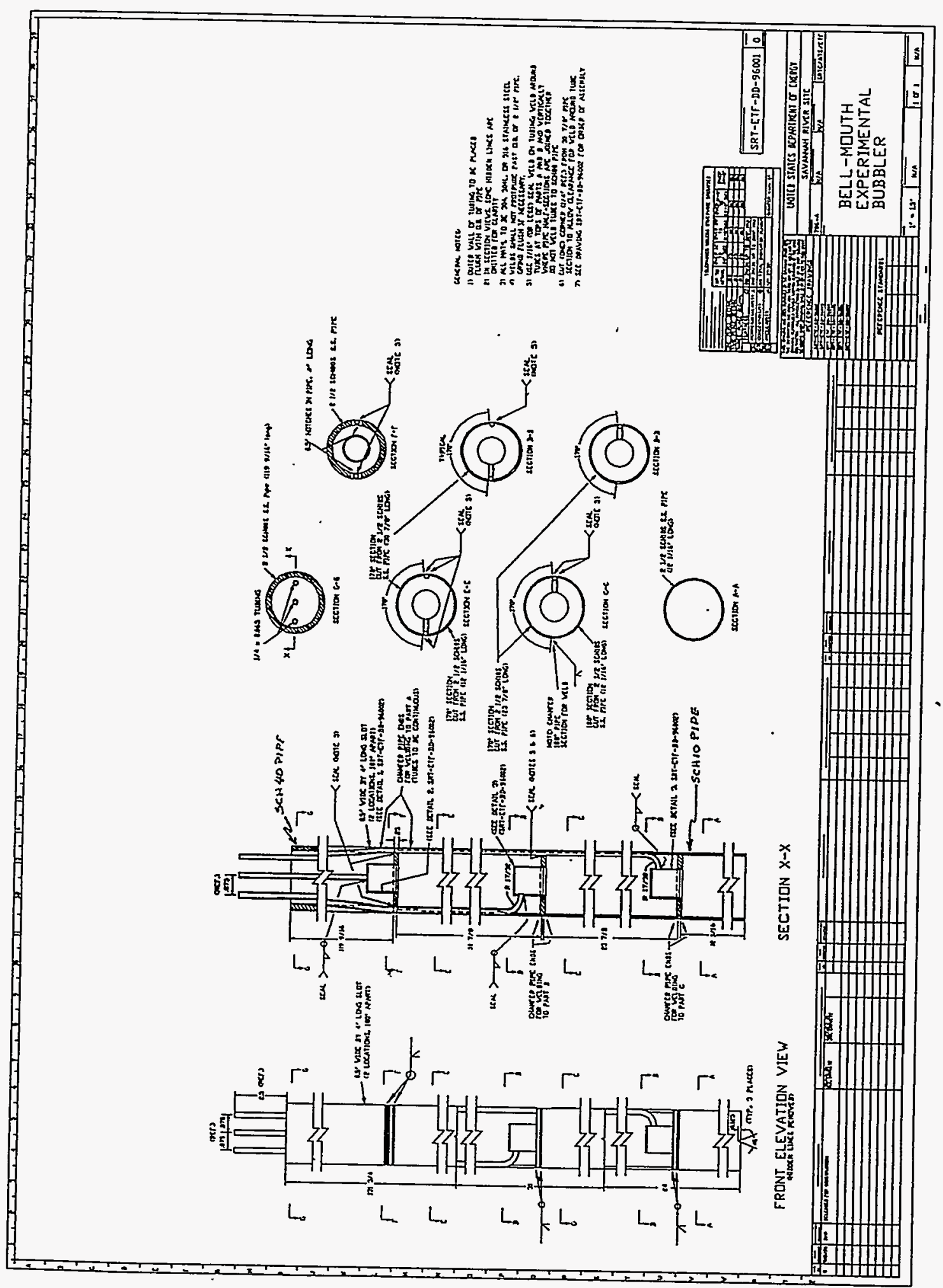

Figure A4: Development Drawing Number SRT-ETF-DD-96001, Rev. 0 
Final Report: Full-scale Test of DWPF Advanced Liquid-level and Density Measurement Bubblers (U)- WSRC-TR-97-0103, Rev. 0

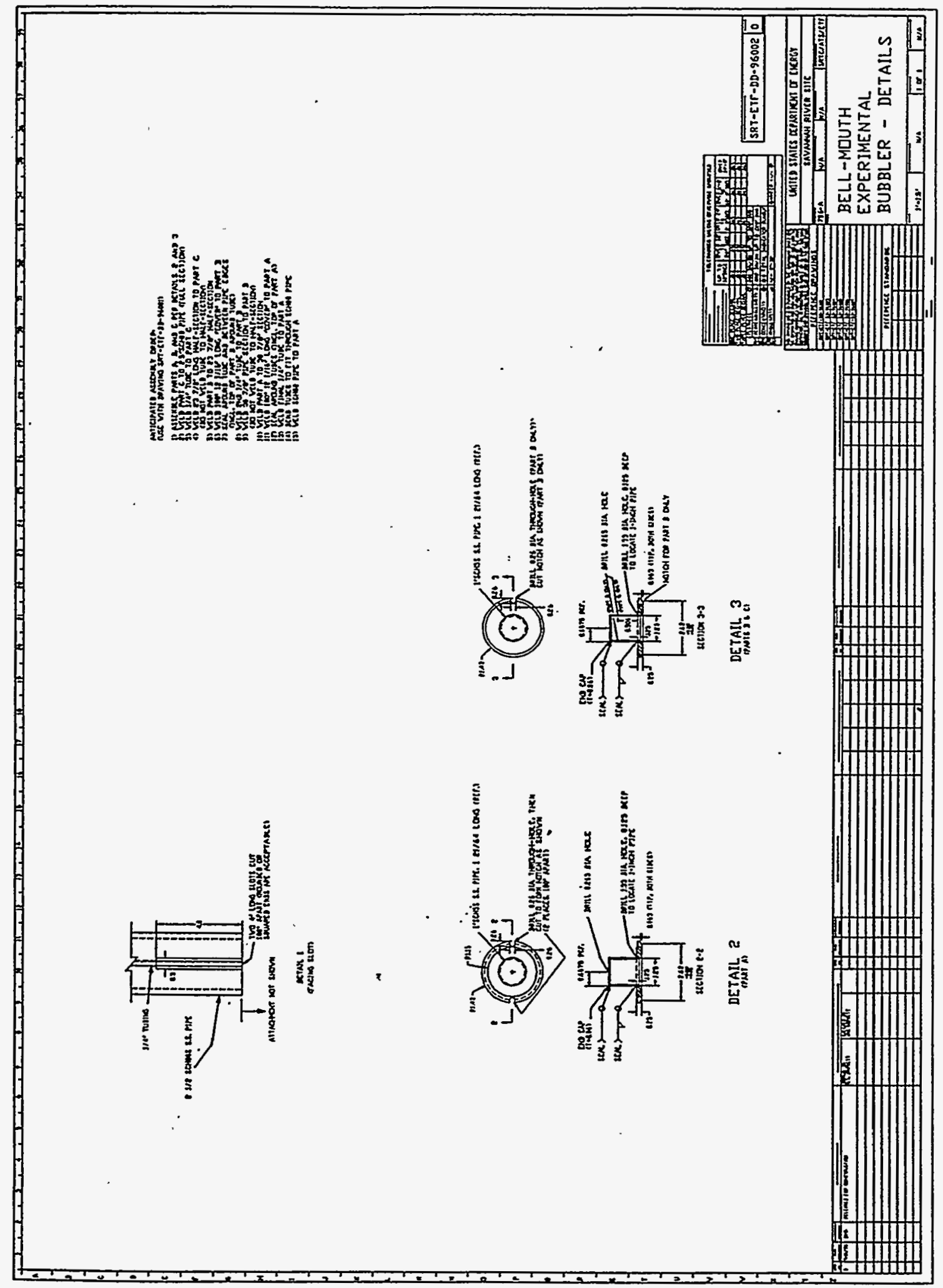

Figure A5: Development Drawing Number SRT-ETF-DD-96002, Rev. 0 


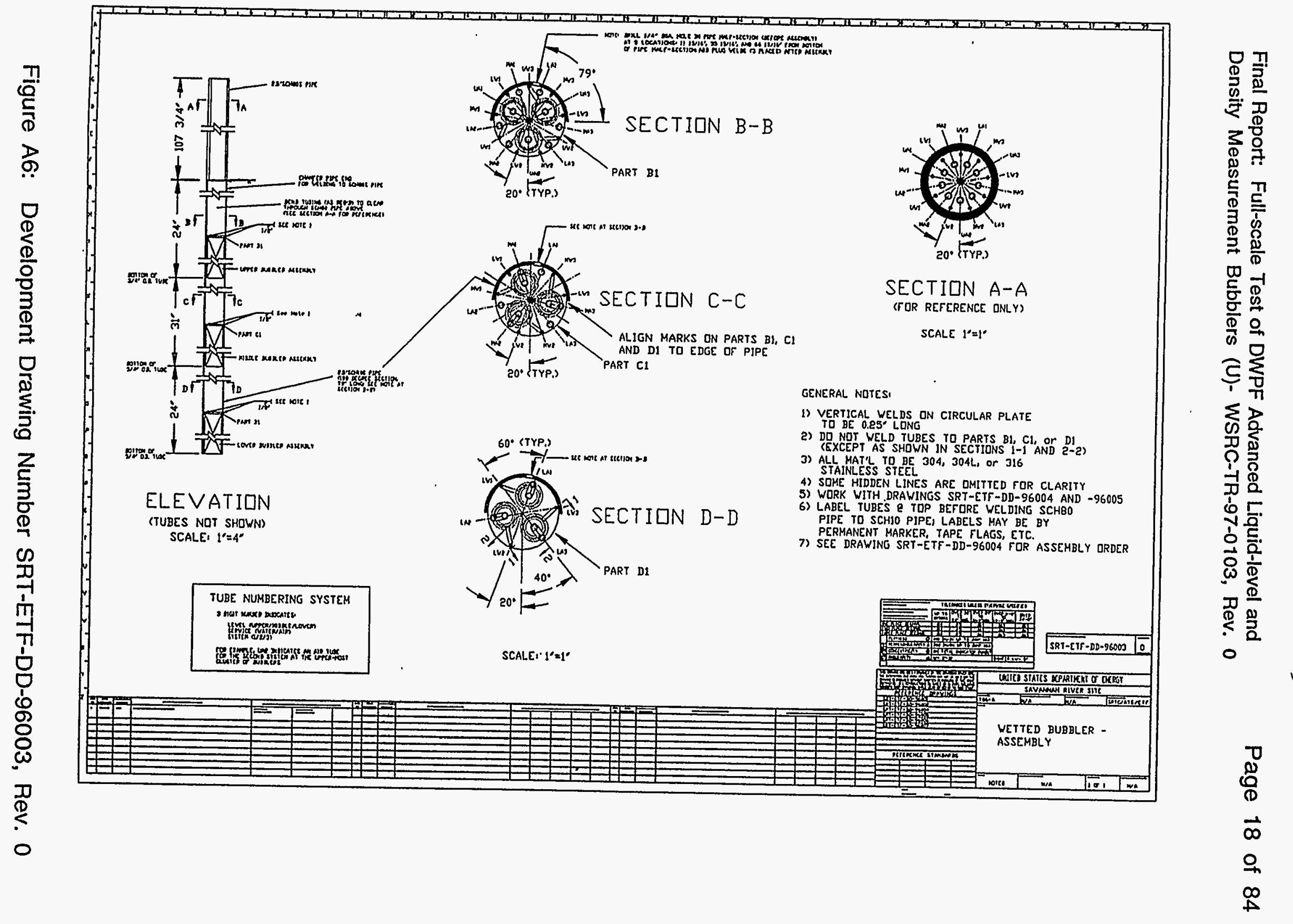


Final Report: Full-scale Test of DWPF Advanced Liquid-level and

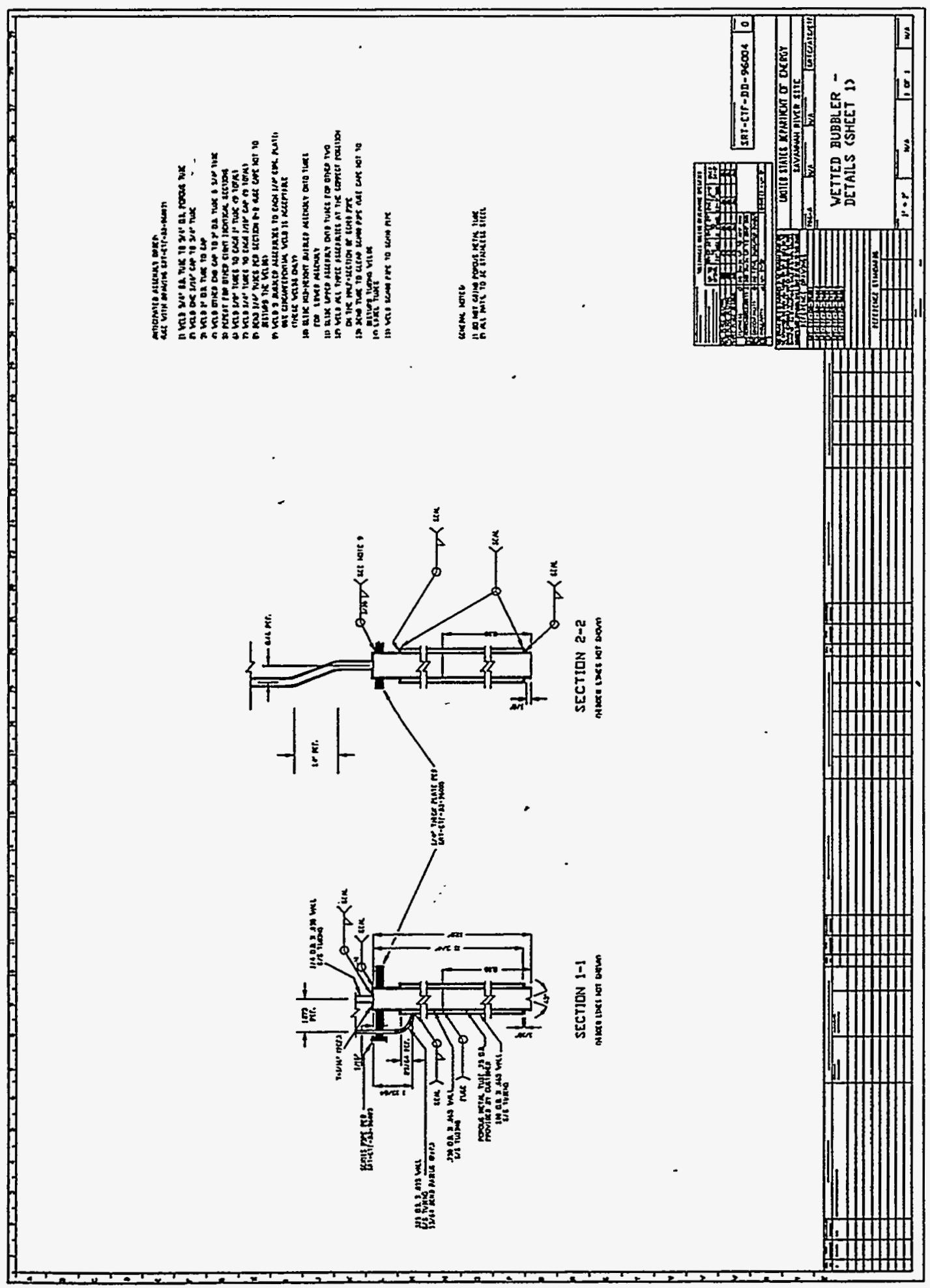

Figure A7: Development Drawing Number SRT-ETF-DD-96004, Rev. 0 


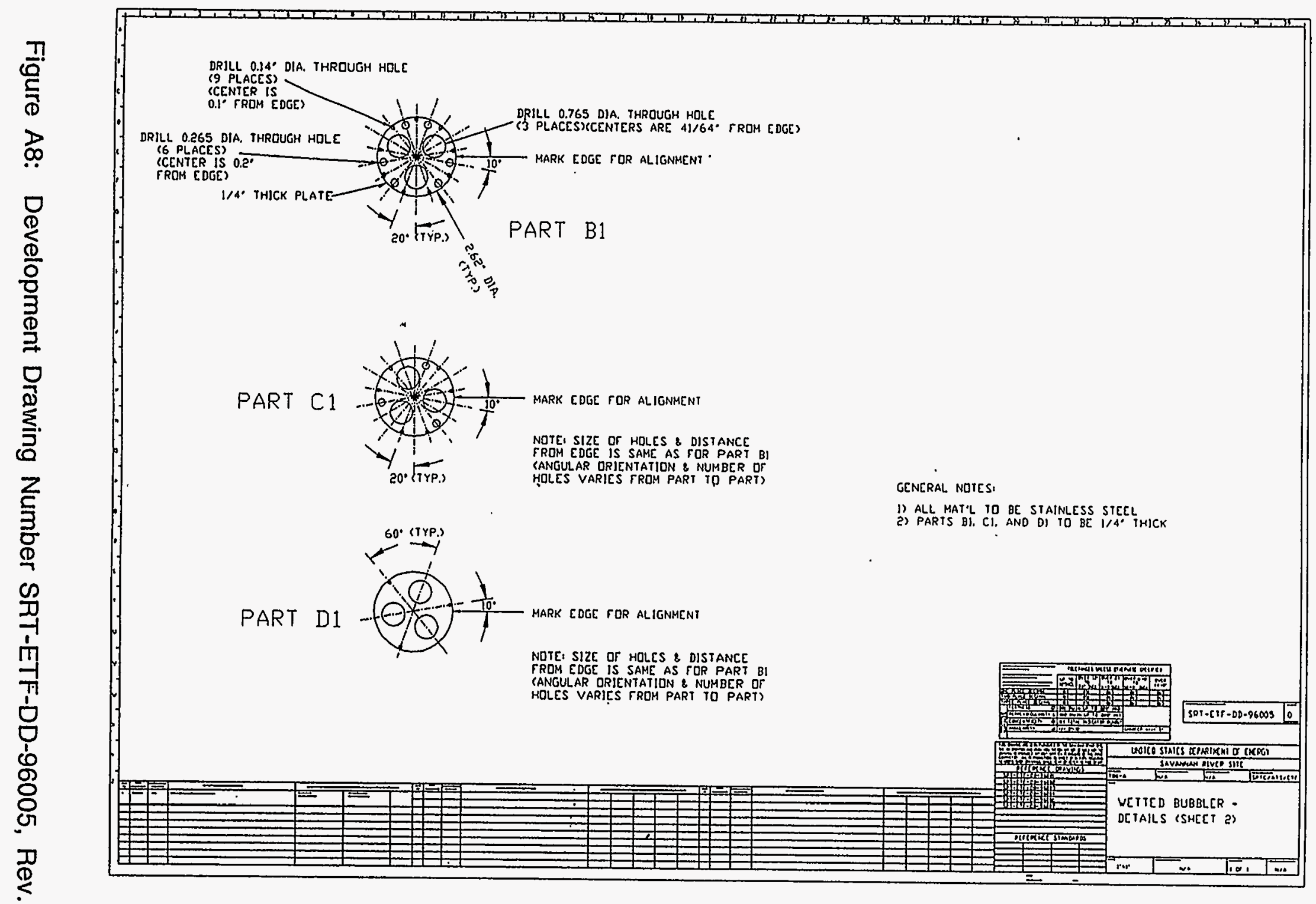


Final Report: Full-scale Test of DWPF Advanced Liquid-level and

Density Measurement Bubblers (U)- WSRC-TR-97-0103, Rev. 0

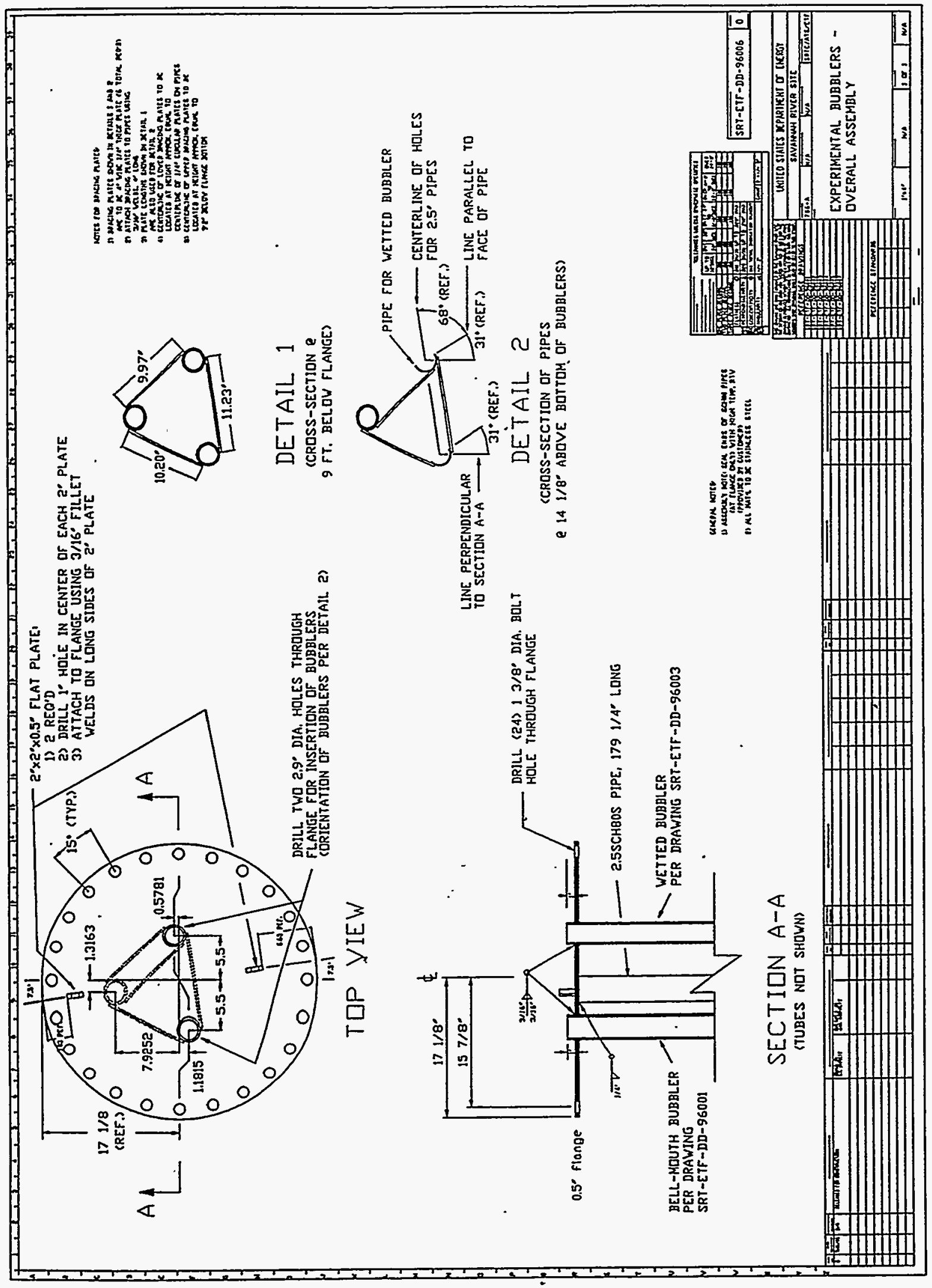

Figure A9: Development Drawing Number SRT-ETF-DD-96006, Rev. 0 
Final Report: Full-scale Test of DWPF Advanced Liquid-level and Density Measurement Bubblers (U):- WSRC-TR-97-0103, Rev. 0

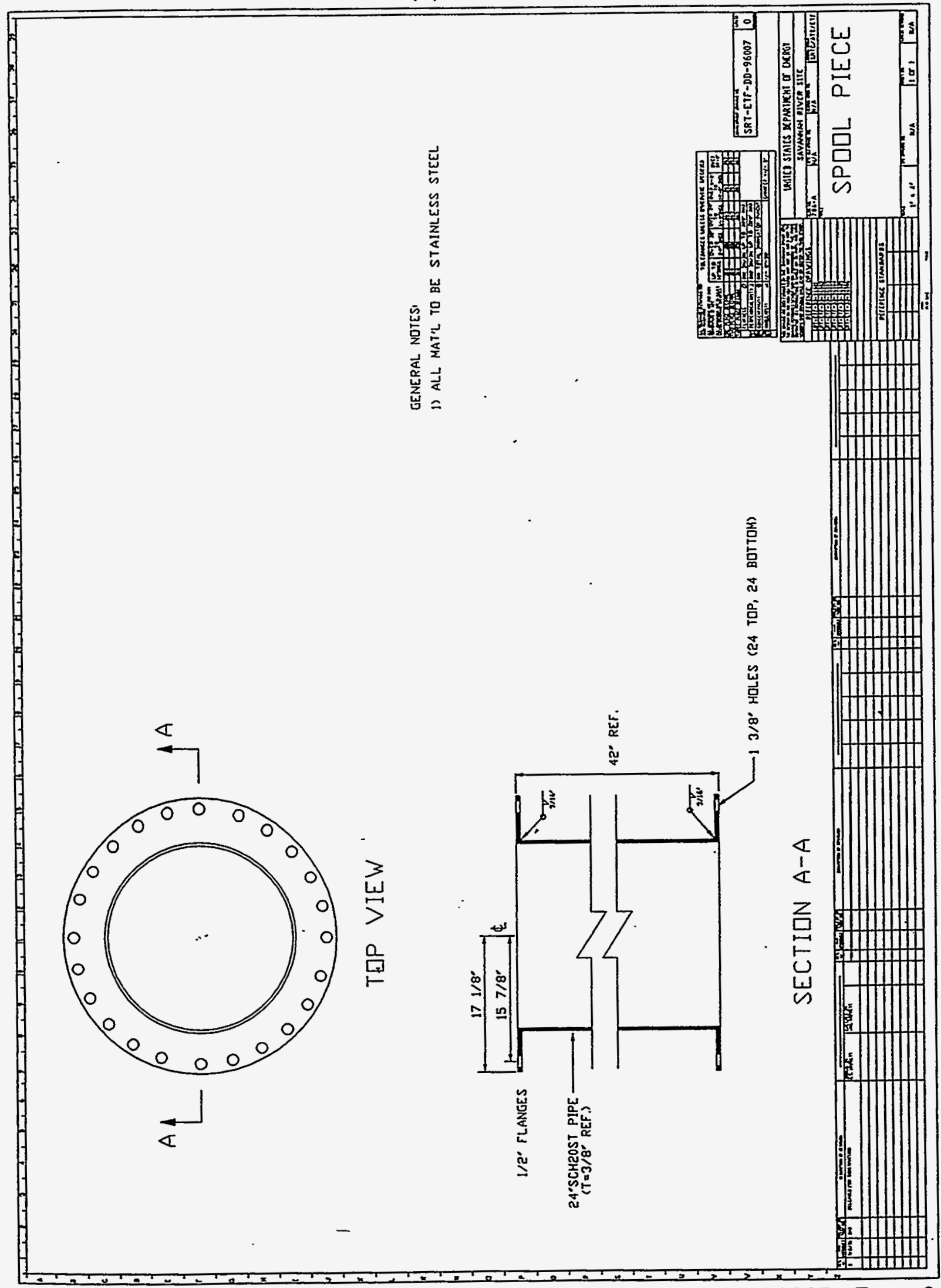

FigureA10: Development Drawing Number SRT-ETF-DD-96007, Rev. 0 
Final Report: Full-scale Test of DWPF Advanced Liquid-level and Density Measurement Bubblers (U)- WSRC-TR-97-0103, Rev. 0

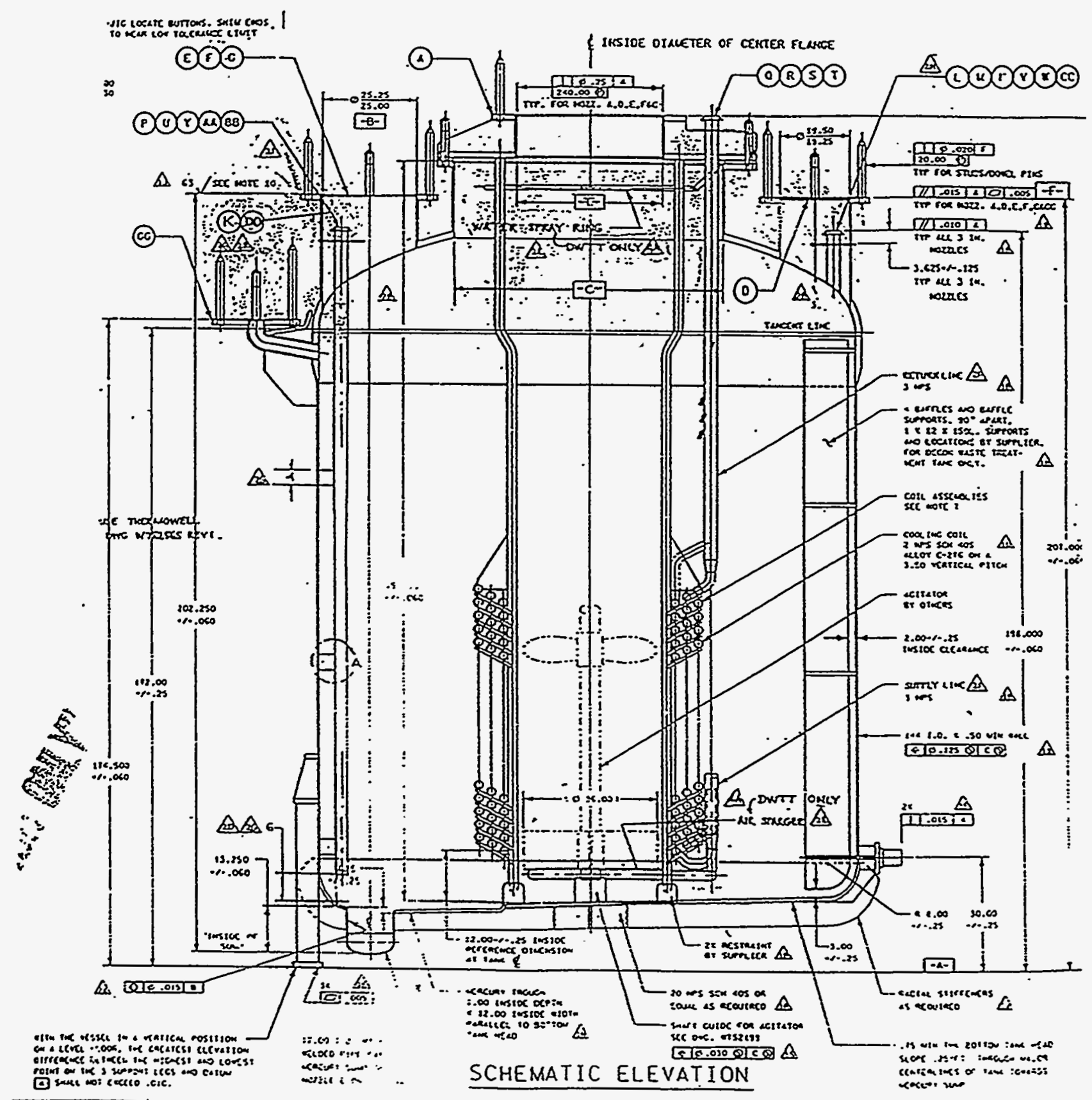

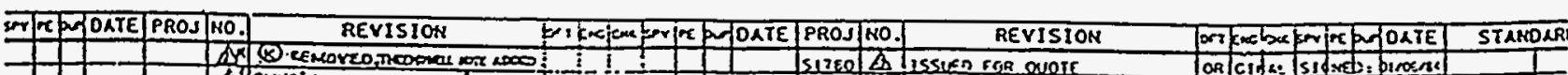

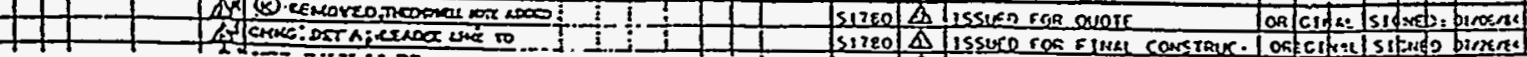

Figure A11: Full-scale SRÀT/SME Tank at TNX (see Ref. 9) 
Final Report: Full-scale Test of DWPF Advanced Liquid-level and

Density Measurement Bubblers (U)- WSRC-TR-97-0103, Rev. 0

\section{APPENDIX B}

\section{Photographic Evidence}

In pursuit to better understand the characteristics of the bubbler probes during operation more than 75 photographs were taken and are available through SRS Publications. The document numbers are listed below:

\section{WSRC Photographs}

Date Number Comment

11/96 96-1569-1 to -17 Probes before installation

12/05/96 96-1687-1 to -7 After 1st week of testing

12/12/96 96-1705-1 to -16 After 2nd week of testing

$12 / 19 / 9696-1717-1$ to -10 After 3rd week of testing

01/07/97 97-1002-1 to -6 After 2 weeks hiatus

$01 / 16 / 97$ 97-1022-1 to -7 After 6th week of testing(before blowdown)

$01 / 16 / 97$ 97-1023-1 to -6 After 7 th week of testing(after blowdown)

$01 / 23 / 97$ 97-1039-1 to -7 After 8th week of testing(end of test)

To better describe the test apparatus and what was observed during the test some photographic highlights were chosen for inclusion in this report. The fourteen photographs included here are referred to in the body of the report but brief explanation are given below to facilitate understanding.

\section{Test Apparatus}

Figure B1 (No. 96-1705-14, taken 12/12/96): This photograph shows the entire probe apparatus after being subjected to two weeks of hot slurry operation. It was removed for one of the weekly inspections of the individual bubbler probes.

Sludge Build Up

- Large-diameter Bubbler Tube

[Figures B2, B3, B4, and B5]

Figure B2 (No. 96-1687-2, taken on 12/5/96): Starting from the new probe, this photograph shows the extent of the sludge accumulation that occurred during one week of operation in bubbler probe No. 12. Notice that 
Final Report: Full-scale Test of DWPF Advanced Liquid-level and Density Measurement Bubblers (U)- WSRC-TR-97-0103, Rev. 0

several air holes are present with the largest at the center. The build-up was located approximately 10 inches up into the tube. This particular probe was located 1.4 inches from the bottom of the tank that was filled with approximately 93 inches of slurry. For the probes located higher in the slurry the accumulated sludge was found to be located closer to the probe opening. For mid-height probe, located 25.4 inches from the bottom, the build-up was located approximately 6 inches within the tube and for the probe located 56.4 inches from the tank bottom the sludge build-up was only recessed in the probe by 3 inches.

Figure B3 (No. 96-1705-2, taken on 12/12/96): Comparing this figure with Fig. B2, this is a result from a second week of operation. Notice that the accumulation appears closer to the end of the tube, between 4 and 6 inches. This occurred because the entire probe assembly was maintained 42 inches higher in the slurry. Despite the considerable build-up the probe was still functioning well.

Figure B4 (No. 96-1022-2, taken on 1/16/97): This is the accumulation that occurred after one week of operation after it was blown down with air and water. On several of the days the slurry temperature was increased to create boiling. The probe was still operational.

Figure B5 (No. 96-1039-1, taken on 1/23/97): Only again, this is similar to Fig. B4. The figure shows the sludge build-up after one week of operation from being blown down with water. The texture seems a little drier than seen in Fig. B4 possibly because during the last week of operation the largest number of days at boiling temperatures occurred.

- Porous-tube Bubbler Tube

[Figures B6, B7, B8, and B9]

Figure B6 (No. 96-1687-3, taken on 12/5/96): Starting from the new probe, this photograph shows the extent of the sludge accumulation that occurred during one week of operation in bubbler probes Nos. 7, 8, and 9 . They were all still functioning properly at the end of the week despite the appearance of sludge plugs. An air passage is visible in the center in two of the probes, the third was similar.

Figure B7 (No. 96-1705-5, taken on 12/12/96): After two weeks of operation these probes seemed to be totally plugged. However, while the level measurements being made by these probes was beginning to be 
Final Report: Full-scale Test of DWPF Advanced Liquid-level and

Density Measurement Bubblers (U)- WSRC-TR-97-0103, Rev. 0

affected by the sludge they were still giving fairly accurate results one day before this photograph was taken.

Figure B8 (No. 97-1022-1, taken on 1/16/97): These probes became plugged after approximately 3 days of operation and after the slurry temperature was raised from $50^{\circ} \mathrm{C}$ to $101^{\circ} \mathrm{C}$.

Figure B9 (No. 97-1039-2, taken on 1/23/97): These probes became plugged after being blown down with air and water and were subjected to boiling conditions for most of the preceding week.

Sludge Removal

- Large-diameter Bubbler Tube

[Figures B10 and B11]

Figure B10 (No. 97-1002-2, taken 1/7/97) [this photograph shows the probe after being cleaned with a blowdown of air at 90 psig for several minutes, and then cleaned with a. blowdown of water at 90 psig for several minutes] and Figure B11 (No. 97-1023-2, taken on 1/16/97) [this photograph shows the probe after being cleaned with only a blowdown of air at $90 \mathrm{psig}$ for five minutes]: After operating the bubbler probes for several weeks, and being held at different levels in the slurry, they were blown down with air and water to determine the effectiveness. Before being blown down the accumulation in this probe looked similar to Figs. B2 to B5. This probe appeared to be mostly clean of sludge after only an air blowdown but appeared to be almost sludge free after cleaning with air and then water.

- Porous-tube Bubbler Tube

[Figures B12 and B13]

Figure B12 (No. 97-1002-2, taken 1/7/97) [this photograph shows probes 7,8 , and 9 after probes 7 and 9 (the two lower tubes) were blown down with air at 90 psig (through their central channel) and water at 90 psig (through the porous tube)] and Figure B13 (No. 97-1023-1, taken 1/16/97) [this photograph shows probes 7,8 , and 9 after all the probes were blown down with air at 90 psig (through the central channel) and water at 90 psig (through the porous tube)]: After operating the bubbler probes for several weeks, and being held at different levels in the slurry, they were blown down with water to determine the effectiveness. Before being blown down 
the accumulation in these probes looked similar to Fig. B6 to B9. For these smaller diameter tubes the success of cleaning was varied. On 1/7/97 a few of the probes were selected for cleaning. The two, of the three bottom tubes, that were selected for cleaning successfully dislodged the sludge, as shown in Fig. B12. A combination of air (through the central port) and water (through the porous jacket) was used. On 1/16/97 all of the probes were cleaned, but not all of the porous-tube probes cleaned successfully. Fig. B13 shows that two of the three bottom probes ( 8 and 9 ) still had significant sludge deposits after cleaning occurred. More frequent cleaning would be necessary if these. smaller diameter probes are to be employed.

\section{Typical Sludge Accumulation}

Figure B14 (No. 96-1705-15, taken on 12/12/96): Close to the center of this photograph, sitting on one of the supporting member, part of a typical sludge accumulation. It fell out of the central large-diameter probe (No 11) as the probe assembly was being removed from the mixing tank for documentation, after two weeks of operation. Notice that it is several inches thick* and the side which faced the liquid is an oval with the lowest part of the oval close to where there was an exit hole which permitted the probe to continue to operate accurately. [ ${ }^{*}$ For scale, the plug was sitting on a bracing plate which was 4 inches wide, as described in the notes on Fig. A9.] 
Final Report: Full-scale Test of DWPF Advanced Liquid-level and

Page 28 of 84

Density Measurement Bubblers (U)- WSRC-TR-97-0103, Rev. 0

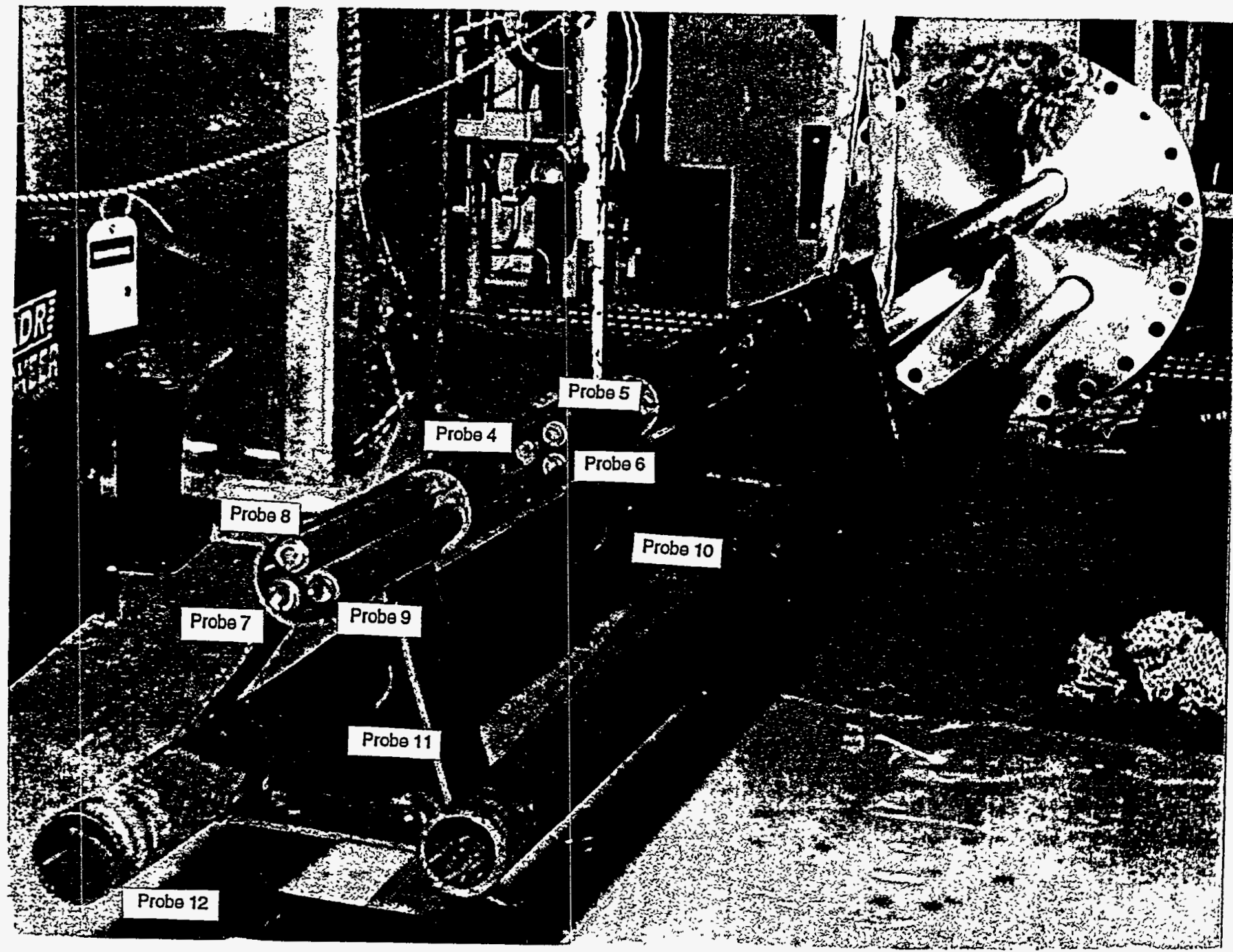

WSRC Photograph No. 96-1705-14

Figure B1: Test Apparatus During an Inspection on 12/12/96 
Final Report: Full-scale Test of DWPF Advanced Liquid-level and

Density Measurement Bubblers (U)- WSRC-TR-97-0103, Rev. 0

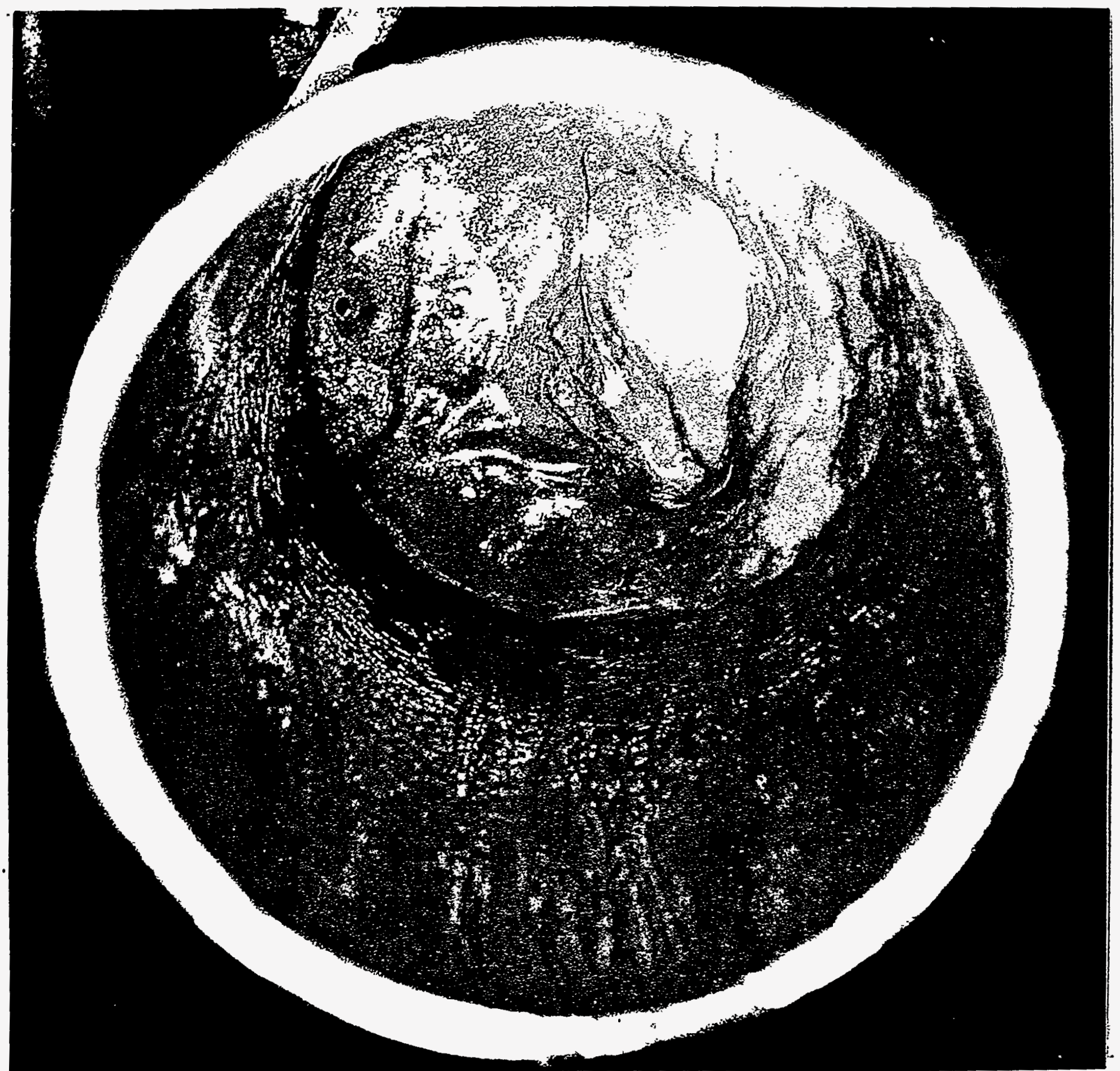

WSRCPhotograph No. 96-1687-2

Figure B2: Probe 12 After One Week of Operation, 12/5/96 
Final Report: Full-scale Test of DWPF Advanced Liquid-level and Density Measurement Bubblers (U)- WSRC-TR-97-0103, Rev. 0

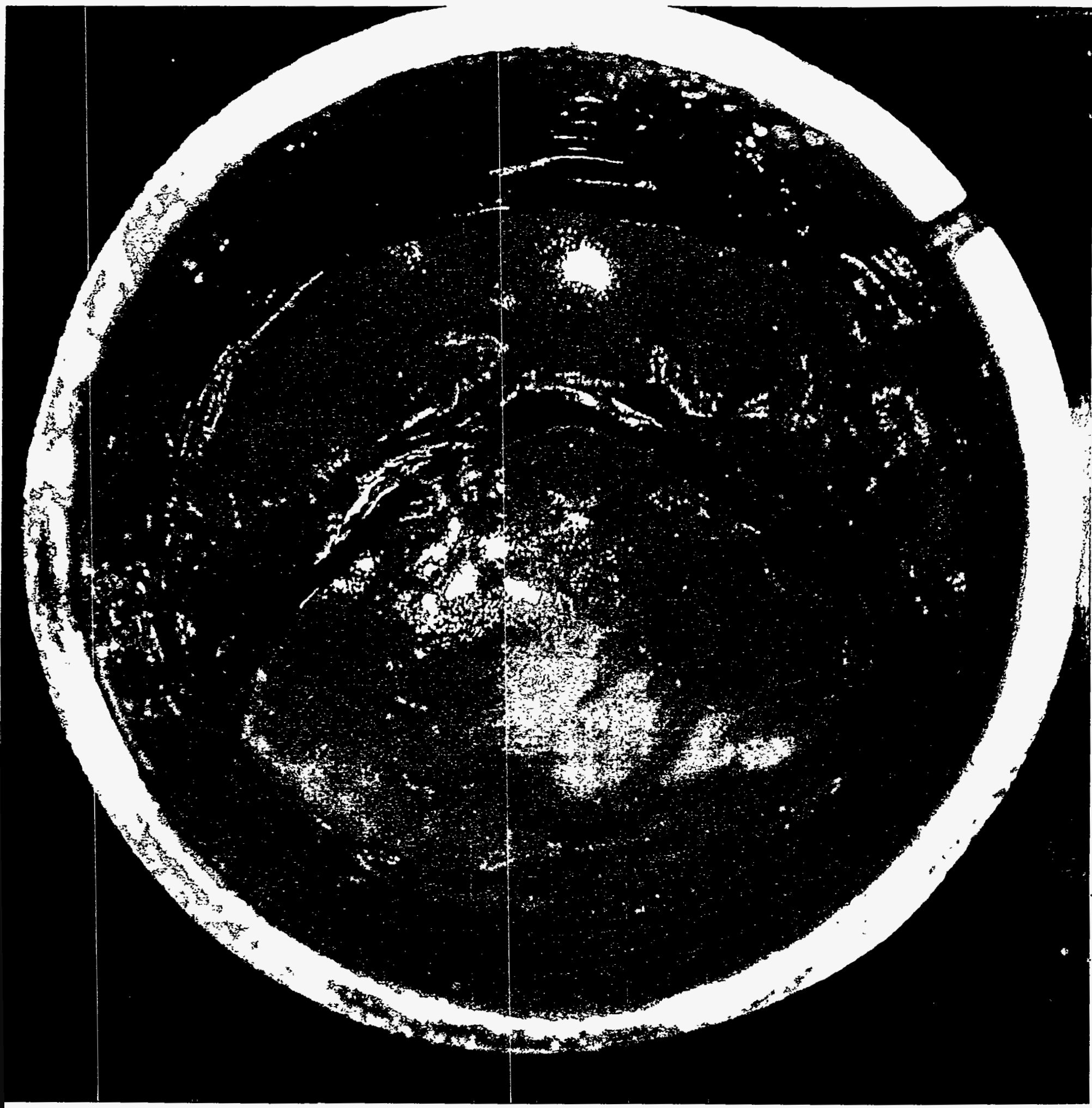

WSRC Photograph No. 96-1705-2

Figure B3: Probe 12 After Two Weeks of Operation, 12/12/96 
Final Report: ' Fullescale Test of DWPF Advän'céd'Liquid-level and Page 32 of 84 Density Measurement Bubblers (U)- WSRC-TR-97-0103, Rev. 0

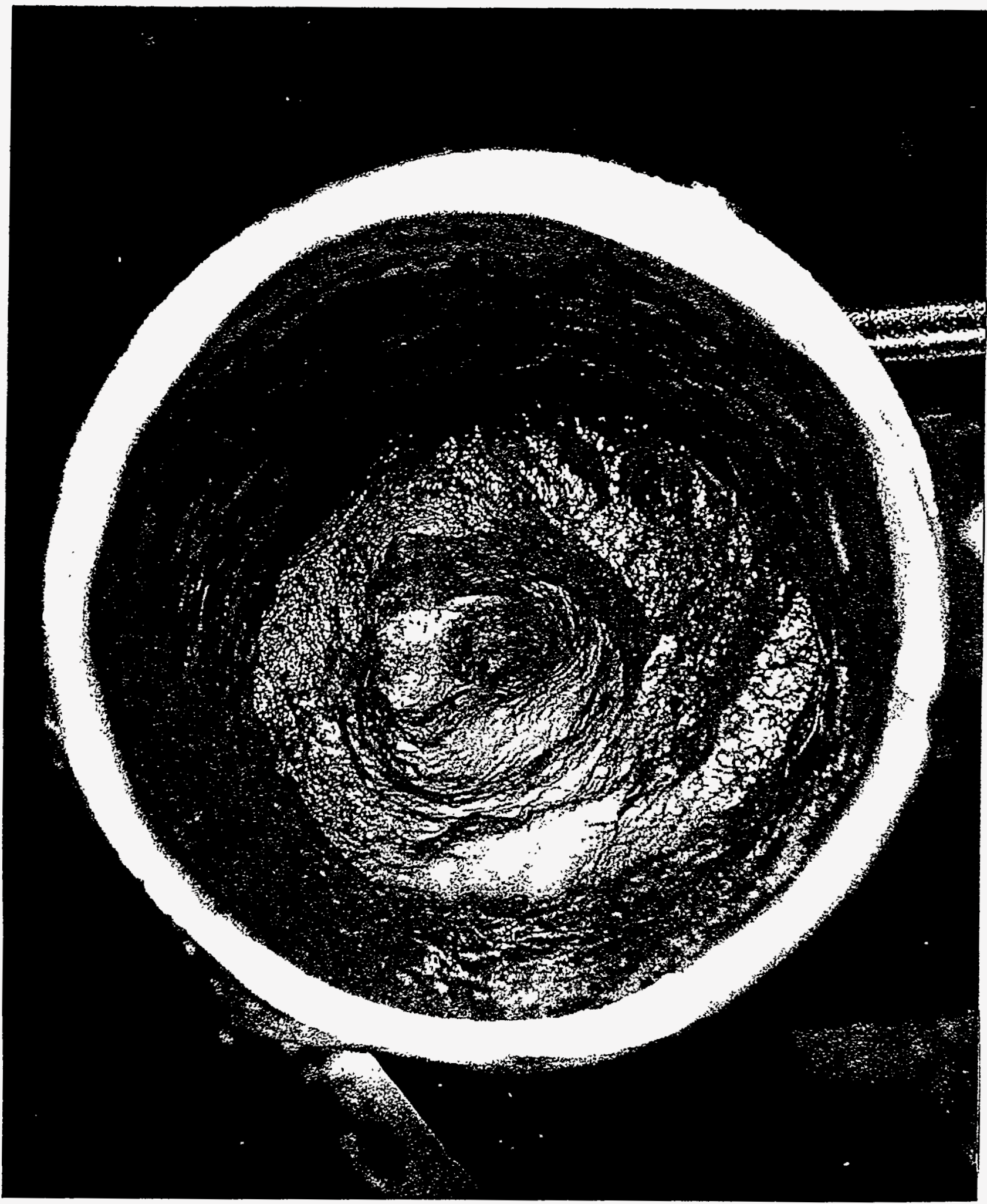

WSRC Photograph No. 97-1039-2

Figure B5: Probe 12 One Week of Operation From a Blowdown 1/23/97 
Final Report: Full-scale Test of DWPF Advanced Liquid-level and

Density Measurement Bubblers (U)- WSRC-TR-97-0103, Rev. 0

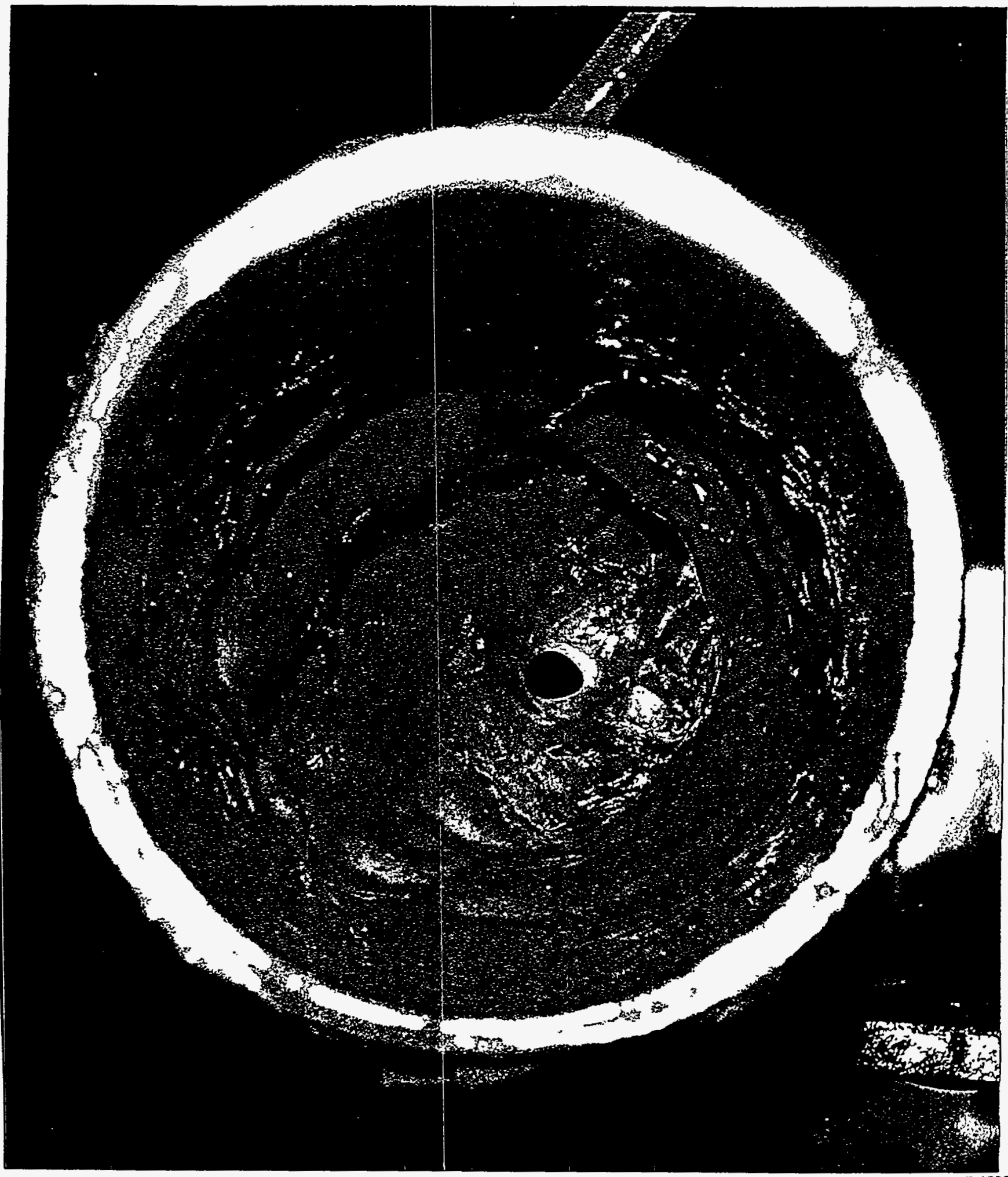

WSRC Photograph No. 97-1022-2

Figure B4: Probe 12 One Week of Operation From a Blowdown 1/16/97 
Final Report: Full-scale Test of DWPF Advanced Liquid-level and

Density Measurement Bubblers (U)- WSRC-TR-97-0103, Rev. 0

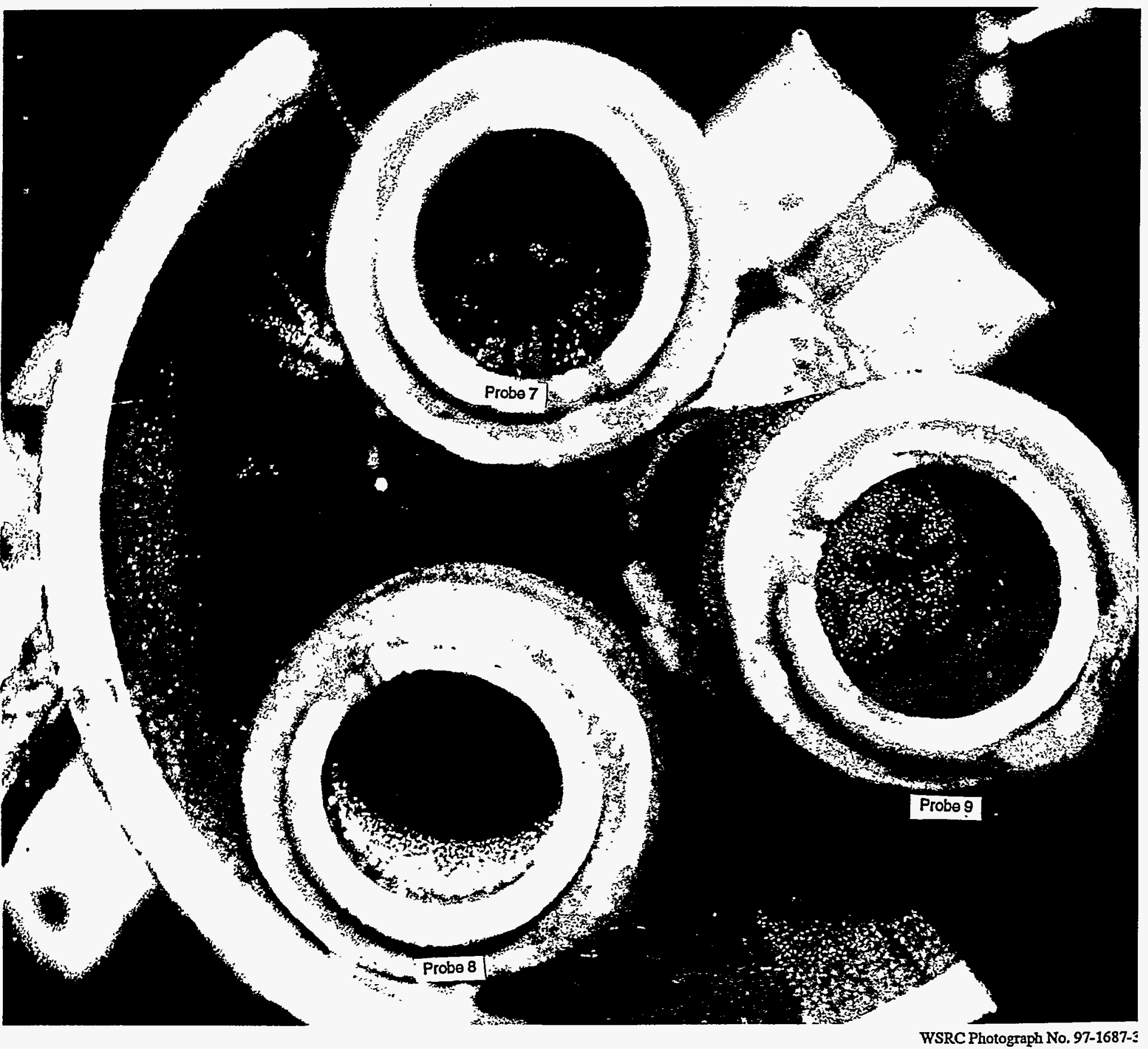

Figure B6: Probes 7,8,9 One Week of Operation From New Probes 12/5/96 
Final Report: Full-scale Test of DWPF Advanced Liquid-level and
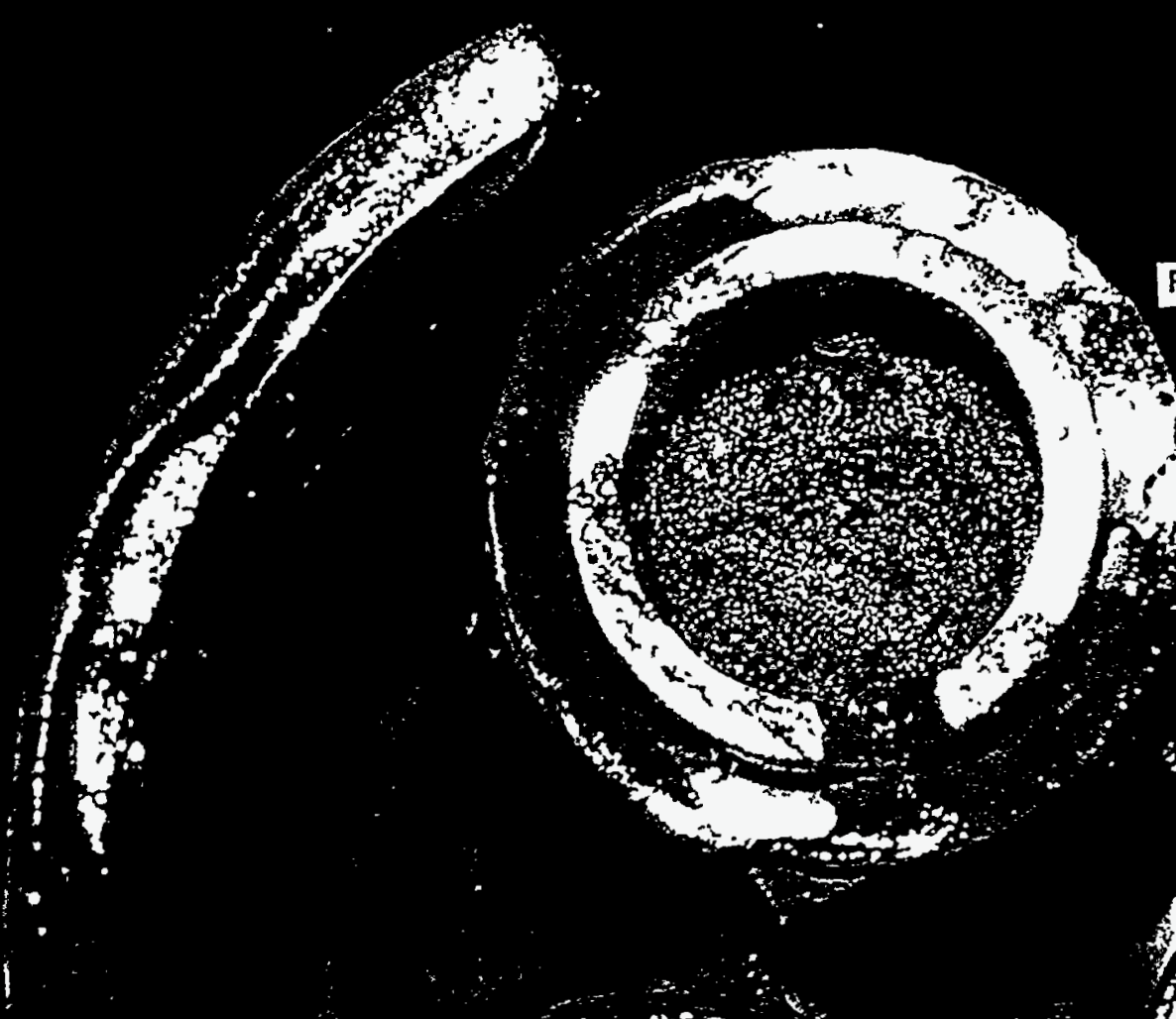

Prob
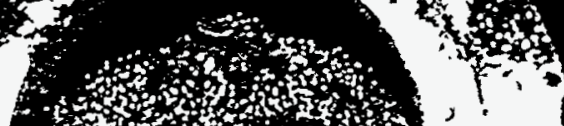

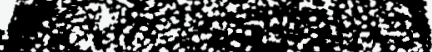

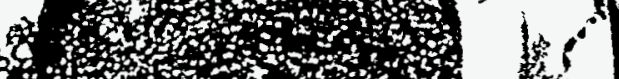

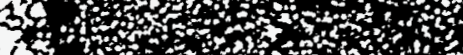

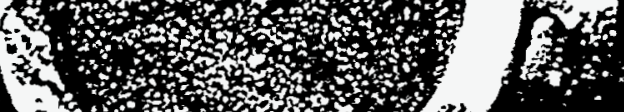
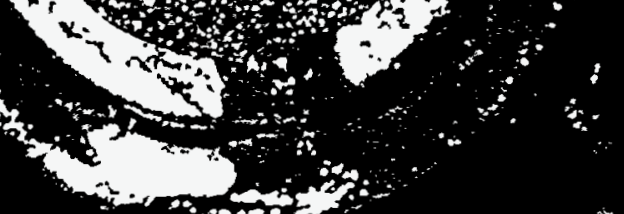

40

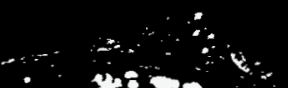

3

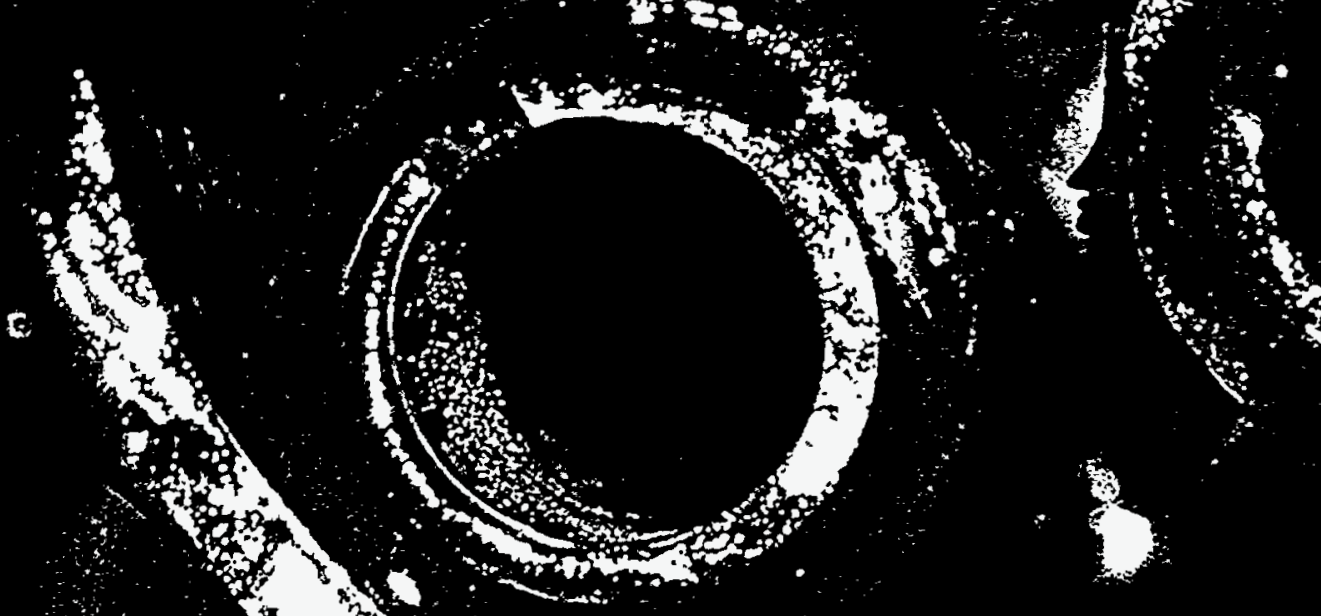

Probe 7
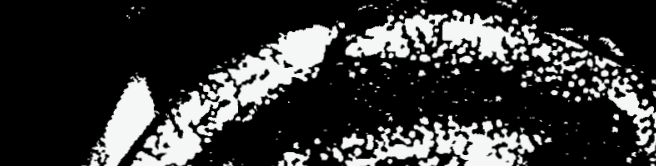

Probe 9

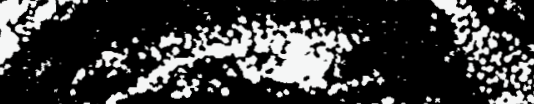

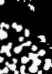


Final Report: Full-scale Test of DWPF Advanced Liquid-level and

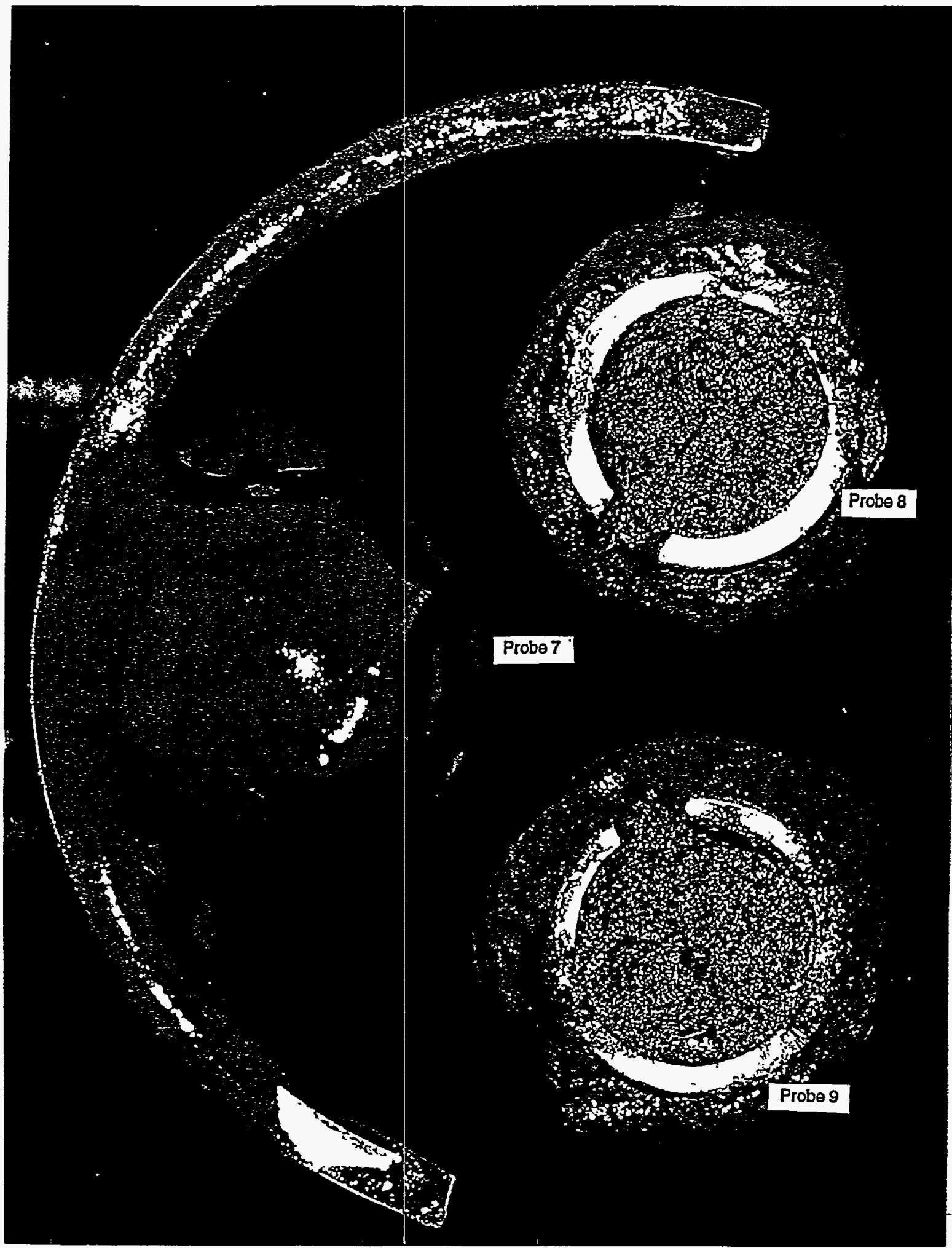

WSRC Photograph No. 97-1039-2

Figure B9: Probes 7,8, 9 One Week of Operation From a Blowdown 1/23/97 
Final Report: Full-scale Test of DWPF Advanced Liquid-level and

Density Measurement Bubblers (U)- WSRC-TR-97-0103, Rev. 0

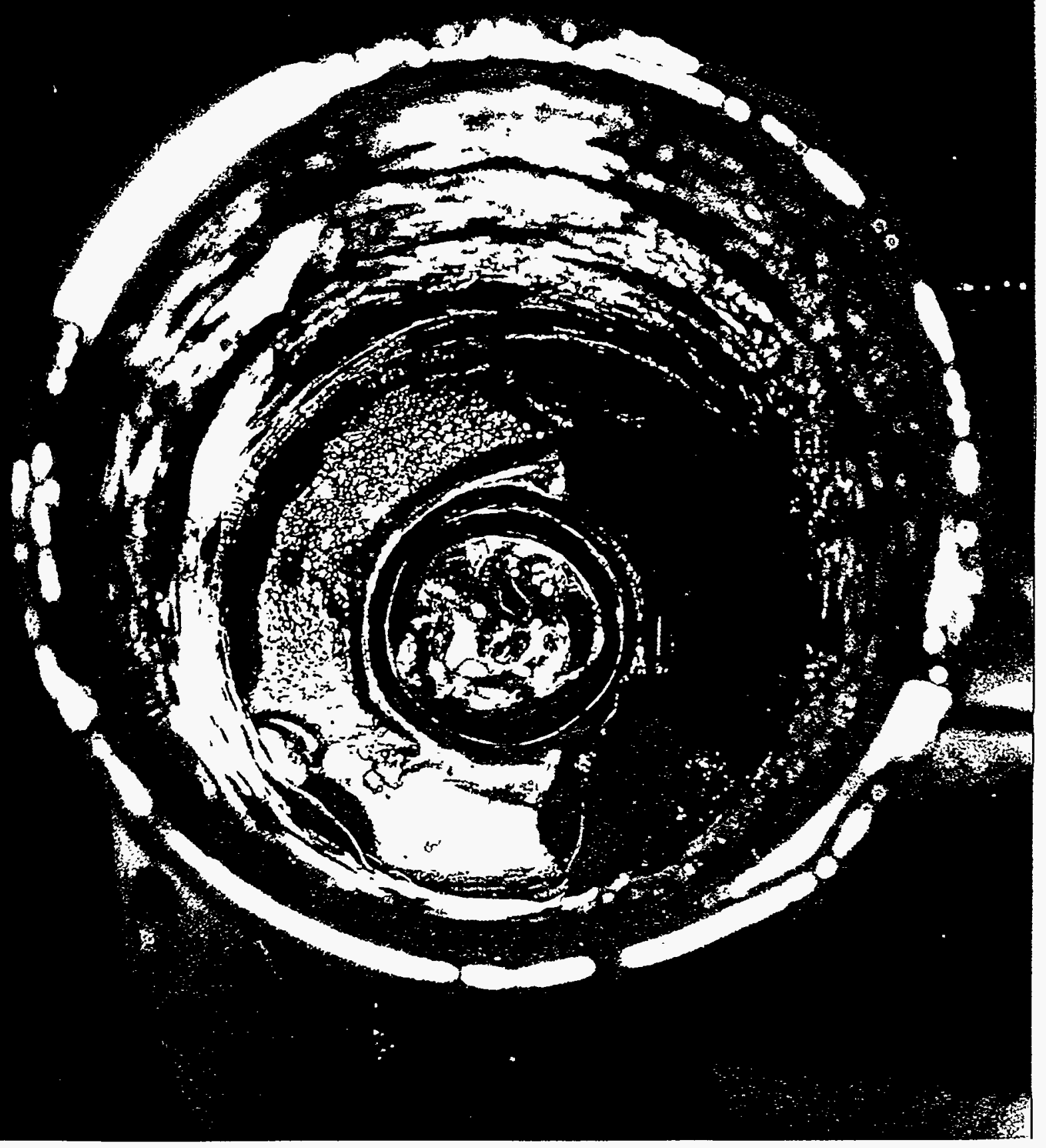

Figure B10: Probe 12 After Blowdown Done on 1/7/97 


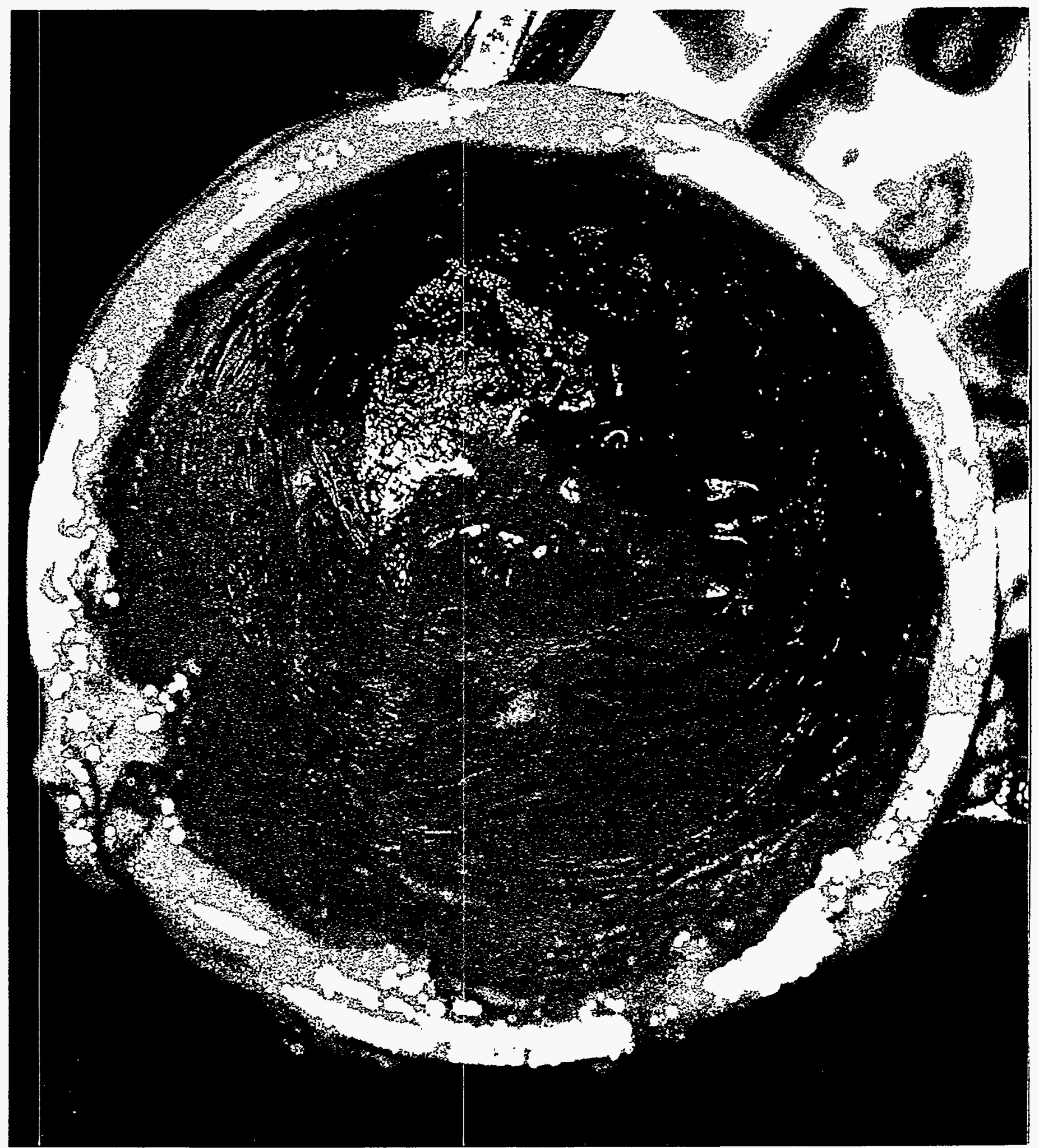


Final Report: Full-scale Test of DWPF Advanced Liquid-level and

Density Measurement Bubblers (U)- WSRC-TR-97-0103, Rev. 0

WSRC Photograph No. 1002-1

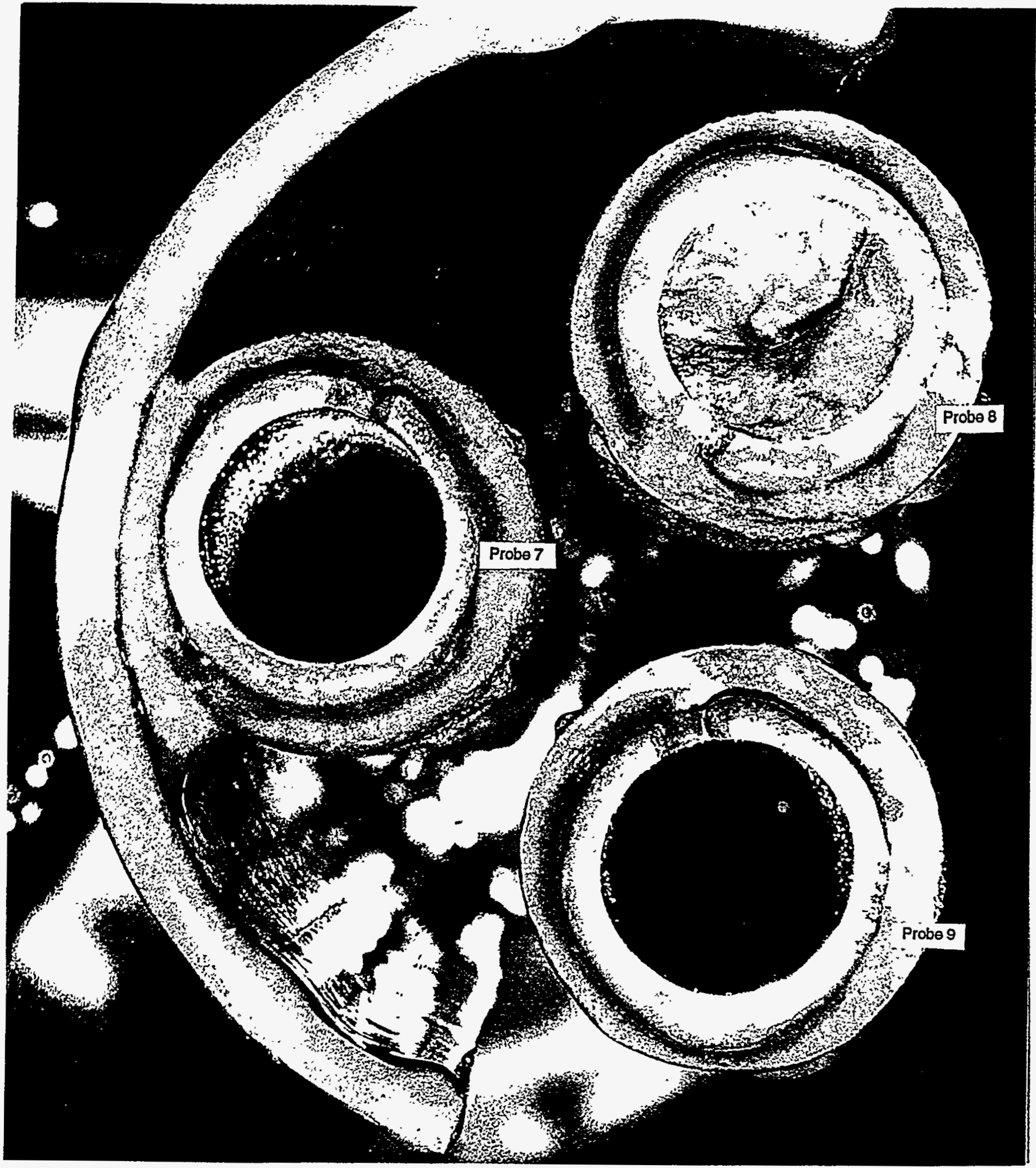

Figure B12: Probes 7, 8, and 9 After Blowdown Done on 1/7/97 (Only Two Probes Were Blown Down) 
Final Report: Full-scale Test of DWPF Advanced Liquid-level and

Page 40 of 84

Density Measurement Bubblers (U)- WSRC-TR-97-0103, Rev. 0

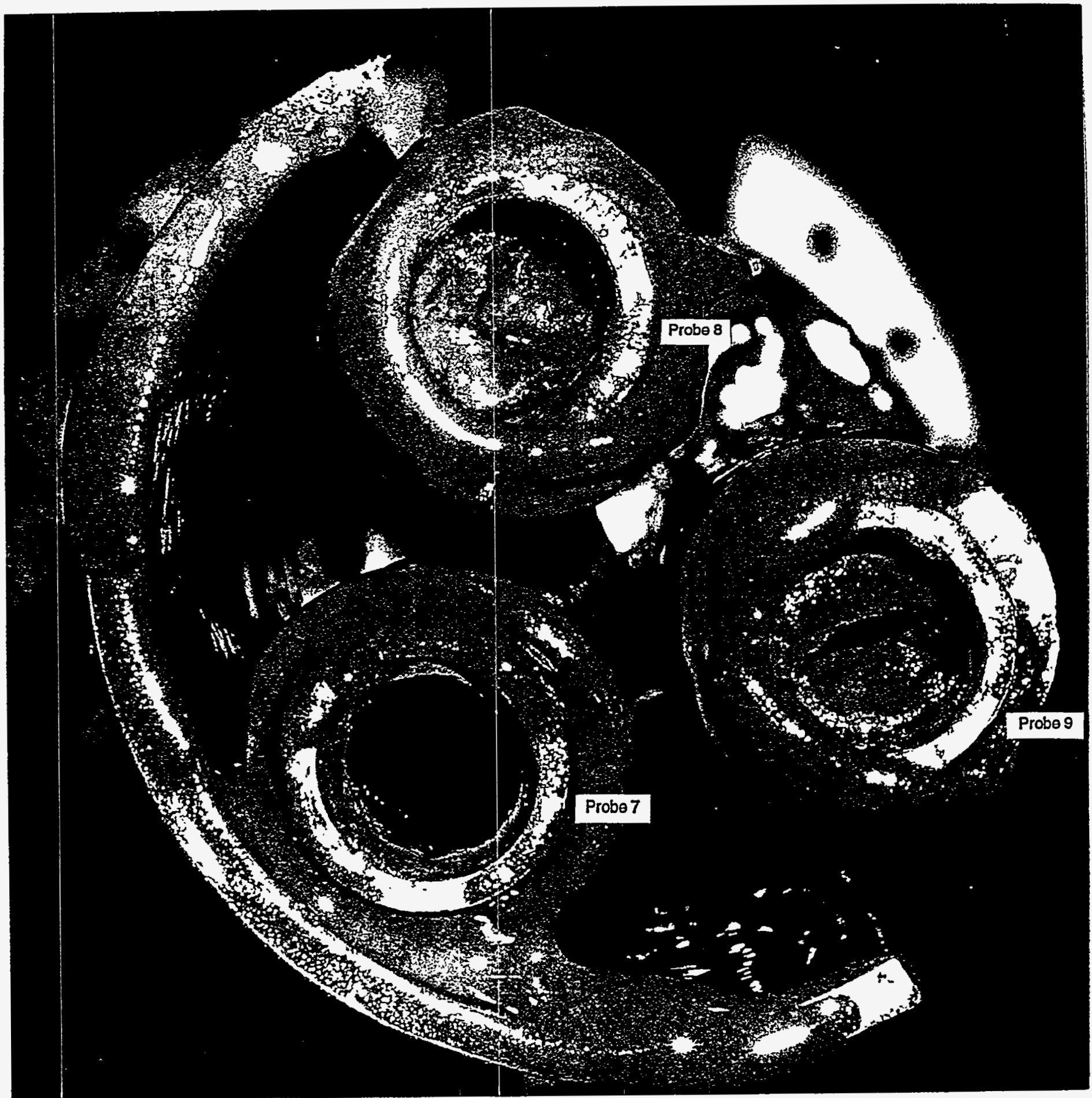

WSRC Photograph No. 97-1023-1

Figure B13: Probes 7, 8, and 9 After Blowdown Done on 1/16/97 
Final Report: Full-scale Test of DWPF Advanced Liquid-level and

Density Measurement Bubblers (U)- WSRC-TR-97-0103, Rev. 0

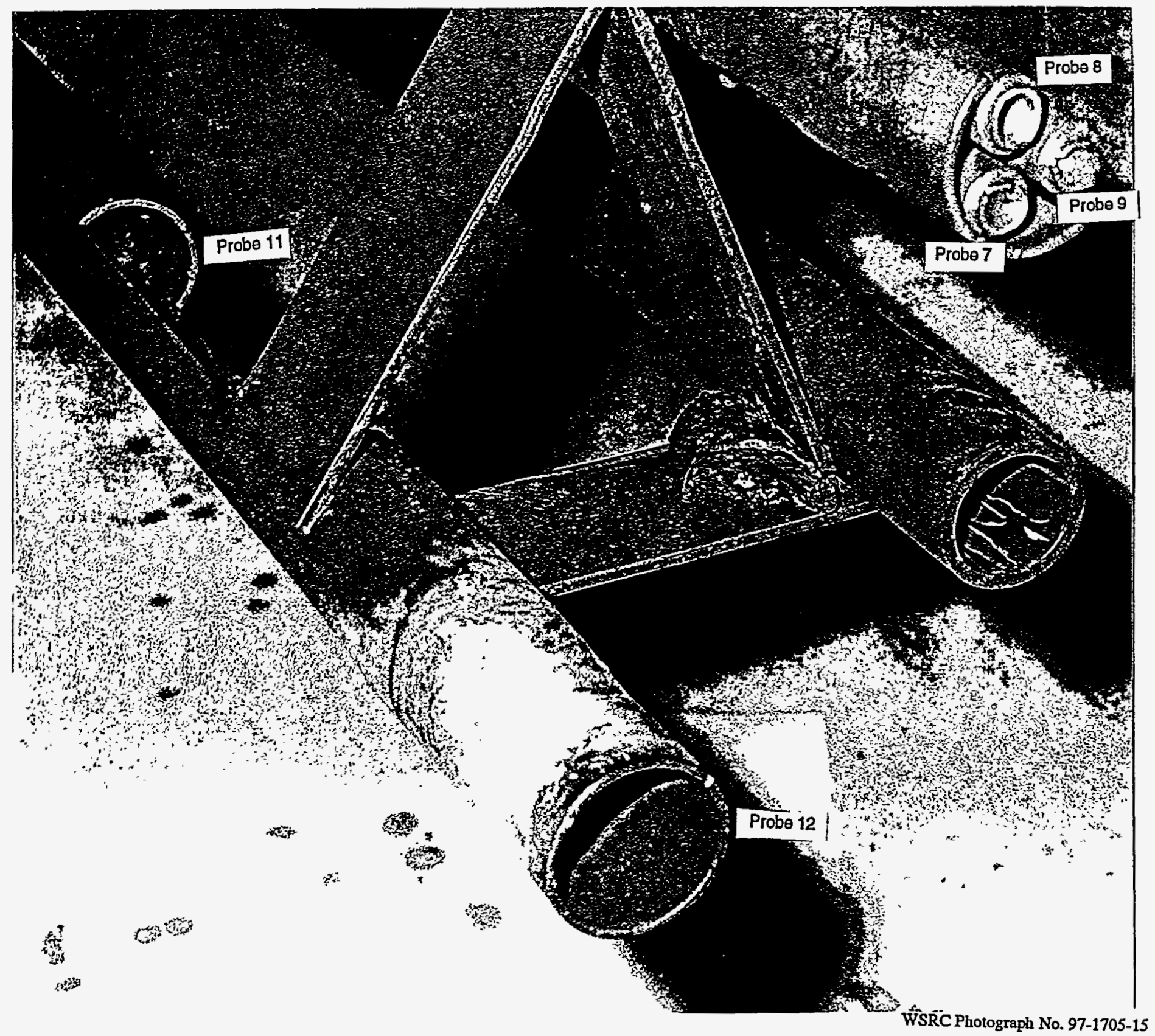

Figure B14: Typical Large-diameter Tube Plug, 12/12/96 
Final Report: Full-scale Test of DWPF Advanced Liquid-level and Density Measurement Bubblers (U)- WSRC-TR-97-0103, Rev. 0

\section{APPENDIX C}

\section{Explanation of Experimental Measurement Data}

While the data are discussed within the body of this report, there are several general features of the graphical presentation that are highlighted here for convenience.

1. Hourly data have been reduced to a datum point every four hours because the extra volume of data do not give any more information, but only serve to make the graphs harder to read.

2. Each time the probe tree was taken out of the tank for documentation a test period ended. Those periods are indicated at the top of each graph.

3. The test tank was "rodded" on 12/5/96 to obtain an absolute measurement of the slurry height. That information is depicted on the figures with a circle and error bars. The rod indicated 93 inches of slurry. That slurry height was then converted to the height (in inches of $\mathrm{H}_{2} \mathrm{O}$ ) that corresponded to a specific probe location so a comparison could be made to the reading given by each probe. For example, for bubbler probe \#1, located 56.4 inches from the bottom of the tank, the reading should be:

$\left(93^{\prime \prime}\right.$ Slurry -56.4 inches $) * 1.3$ inches $\mathrm{H} 2 \mathrm{O} /$ inches Slurry -7 inches $\mathrm{H} 2 \mathrm{O}=41$ inches $\mathrm{H} 2 \mathrm{O}$

Note: The 1.3 is the approximate SpG of the slurry, the 7 inches $\mathrm{H} 2 \mathrm{O}$ is the approximate vacuum over the slurry pool, and the uncertainty bars shown in the figures are determined from the uncertainty in the SpG $( \pm 0.05)$ and in the applied vacuum $\left( \pm 2\right.$ inches $\left.\mathrm{H}_{2} \mathrm{O}\right)$.

4. Near the end of the tèsting periods, on $1 / 21 / 97,500$ gallons of water were added the tank to make up for the evaporative losses that occurred. The water addition amounts to approximately a 7-inch increase in slurry height which translates to slightly over a 9-inch increase in water pressure. This fact is indicated by a vertical line near the bottom of the graphs at the appropriate time.

5. On about 14 days, of the 2-month test, boiling temperatures were obtained. The specific boiling temperature times are indicated by horizontal lines near the bottom of the graphs. For days which show no indication, the slurry was maintained at $50^{\circ} \mathrm{C}$. 
Final Report: Full-scale Test of DWPF Advanced Liquid-level and

Density Measurement Bubblers (U)- WSRC-TR-97-0103, Rev. 0

6. All twelve probes had air flow measurements. Those measurements are located to the right of each graph along with the appropriate measurement uncertainty.

7. The nine porous tube probes also had water flow measurements. Those measurements are located to the right of each graph, below the air flow measurements, along with the appropriate measurement uncertainty.

8. For all the probes which were maintained out of the slurry between periods 2 and 4 , i.e., probes $1,2,3$, and 10 [Figs. C1, C2, C3, and C10], their data between the next periods, 4 and 5 , cannot be used on an absolute basis, because the pressure gauges were not rezeroed. However, the data between periods 4 and 5 are useful in a relative sense because indication of pluggage would still be present if it had occurred. At the beginning of period 5 the gauges were reset and the data show that the probes were reading accurately once again. 
Final Report: Full-scale Test of DWPF Advanced Liquid-level and Density Measurement Bubblers (U)- WSRC-TR-97-0103, Rev. 0

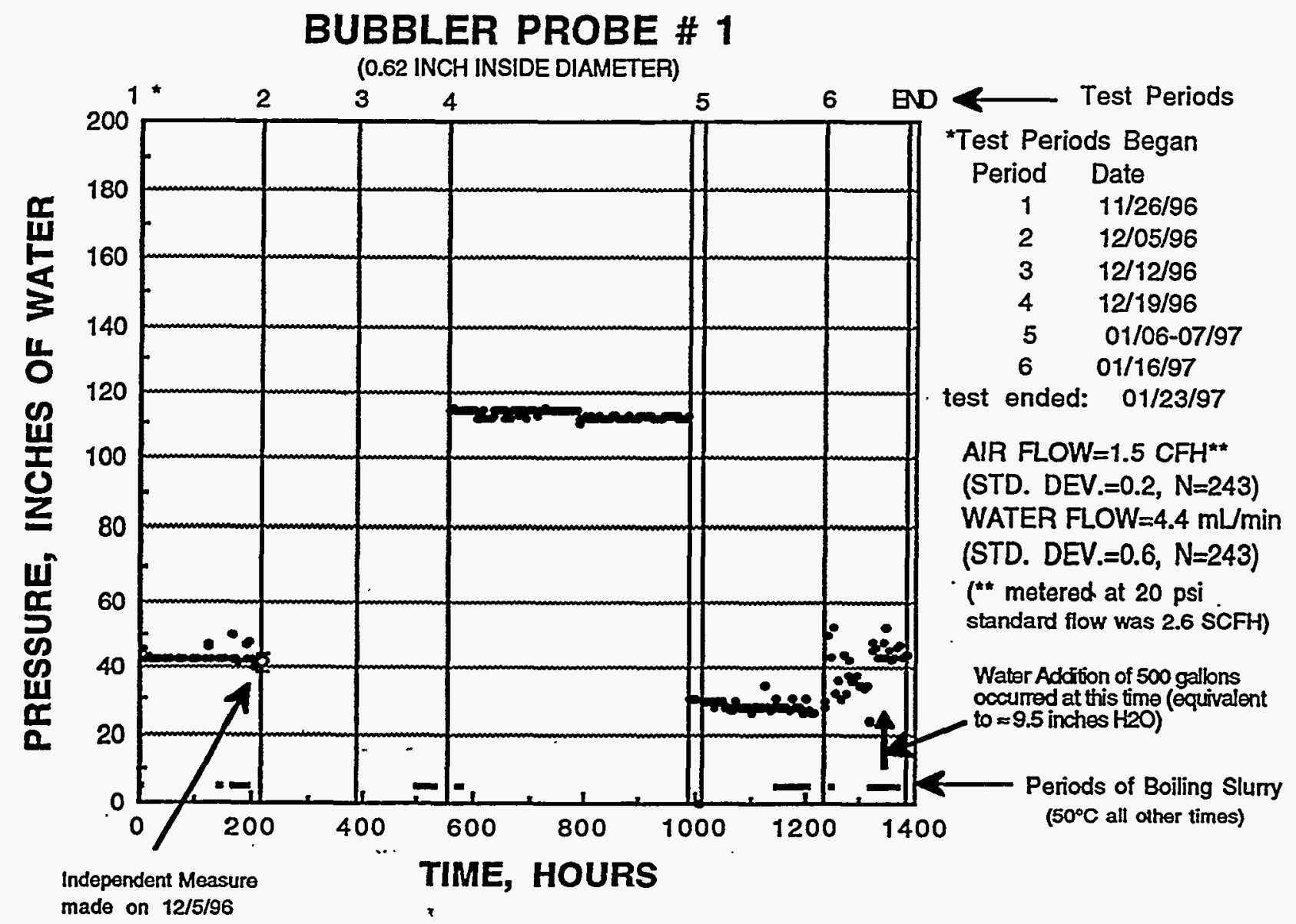

Figure C1: Experimentāl Data - Bubbler Probe \#1 (56.4" from tank bottom) [see pages 42 and 43 for an explanation of graph and data] 
Final Report: Full-scale Test of DWPF Advanced Liquid-level and Density Measurement Bubblers (U)- WSRC-TR-97-0103, Rev. 0

BUBBLER PROBE \# 2

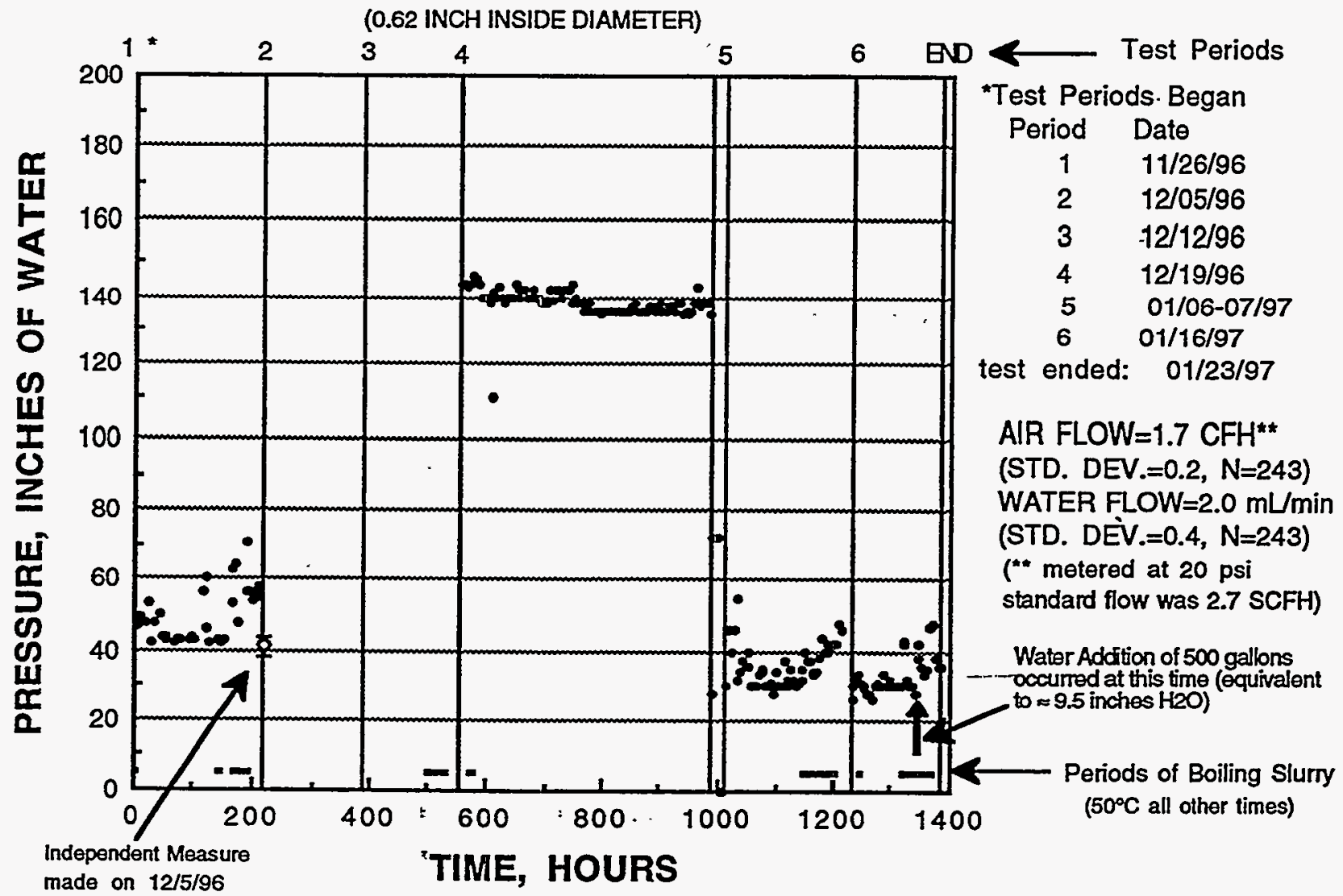

Figure C2: Experimental Data - Bubbler Probe \#2 (56.4" from tank bottom) [see pages 42 and 43 for an explanation of graph and data] 
Final Report: Full-scale Test of DWPF Advanced Liquid-level and

BUBBLER PROBE \# 3

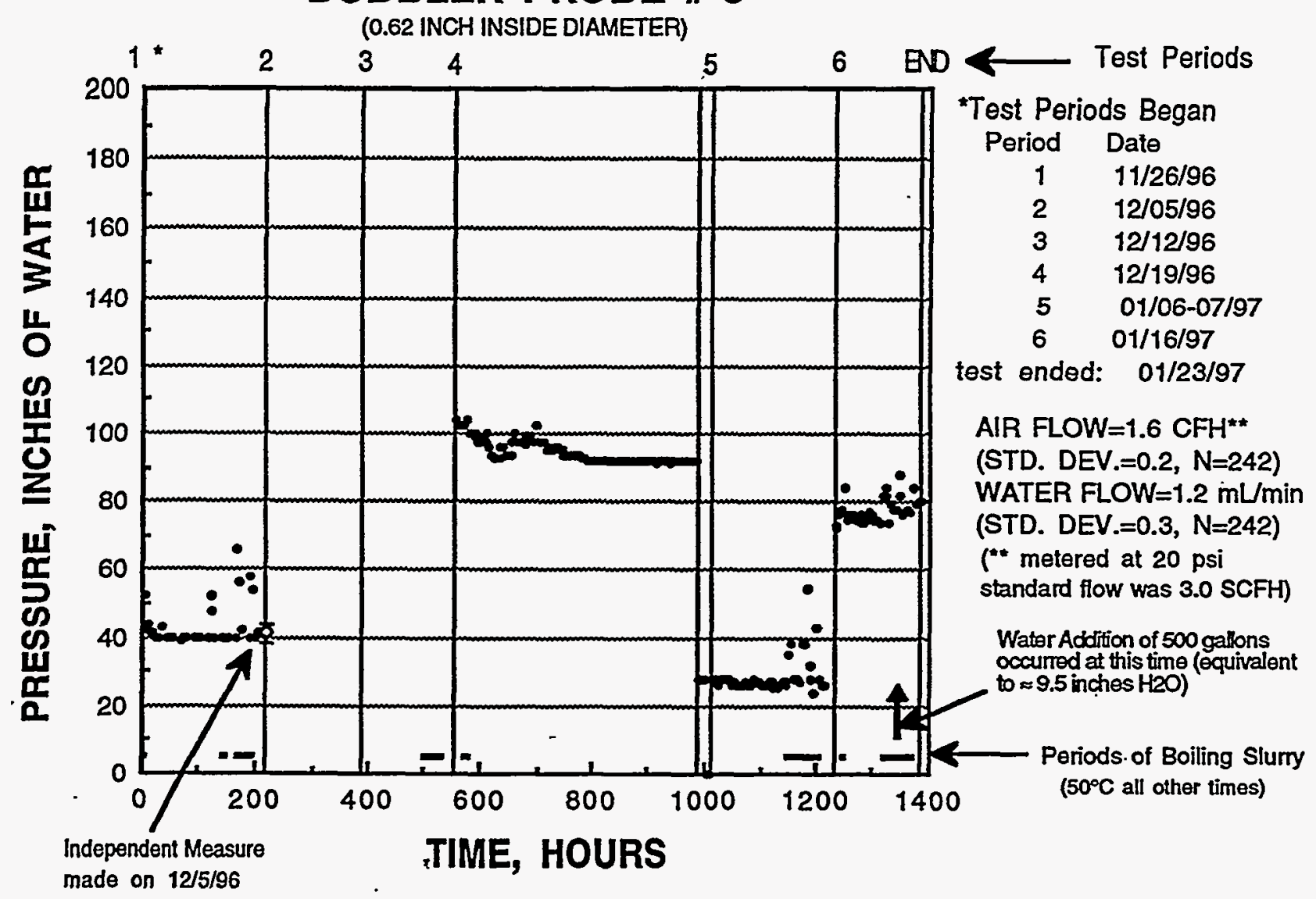

Figure C3: Experimental Data - Bubbler Probe \#3 (56.4" from tank bottom) [see pages 42 and 43 for an explanation of graph and data] 
Final Report: Full-scale Test of DWPF Advanced Liquid-level and Density Measurement Bubblers (U)- WSRC-TR-97-0103, Rev. 0

\section{BUBBLER PROBE \# 4}

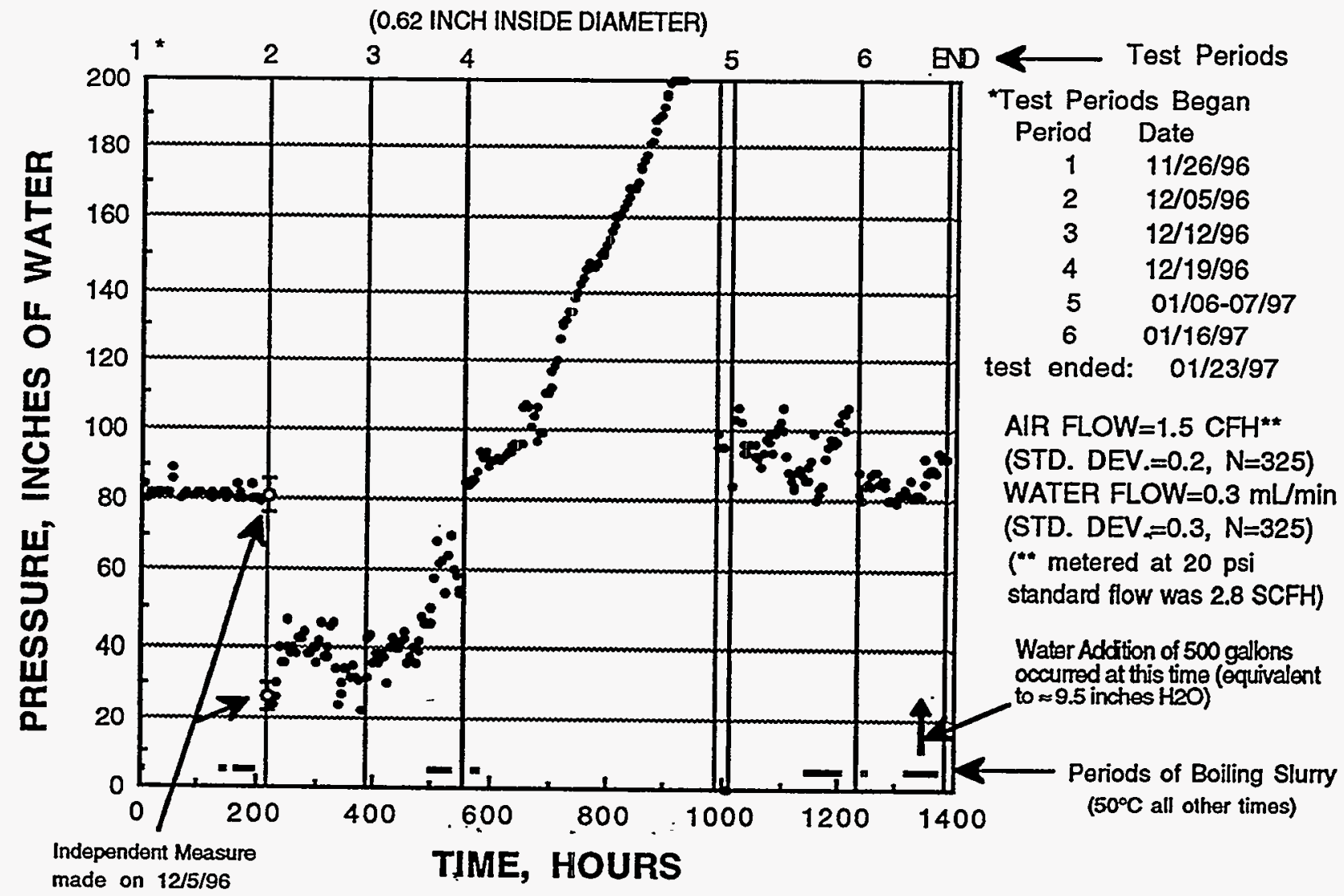

Figure C4: Experimental Data - Bubbler Probe \#4 (25.4" from tank bottom) [see pages 42 and 43 for an explanation of graph and data] 
Final Report: Full-scale Test of DWPF Advanced Liquid-level and

BUBBLER PROBE \# 5

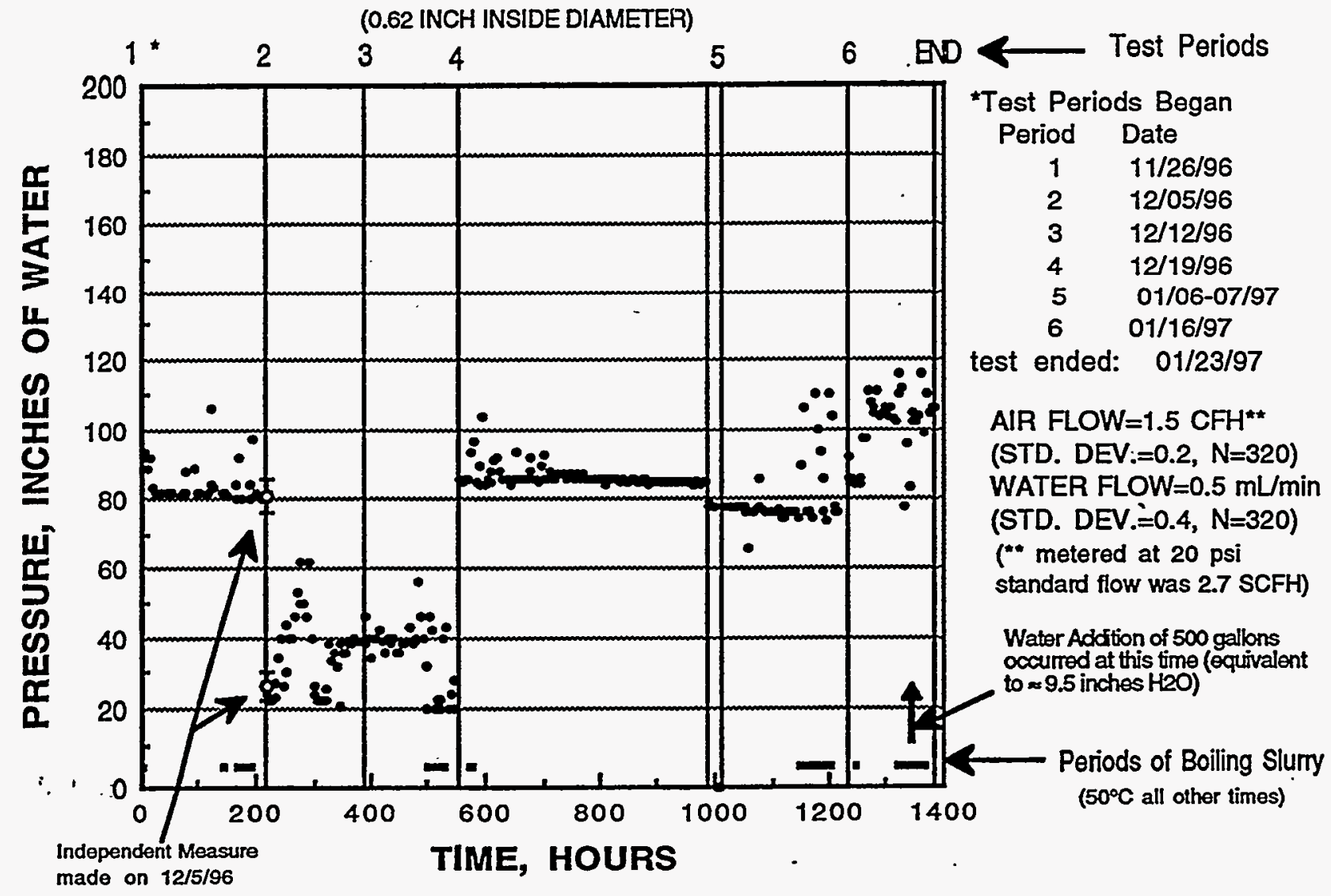

Figure C5: Experimental Data - Bubbler Probe \#5 (25.4" from tank bottom) [see pages 42 and 43 for an explanation of graph and data] 
Final Report: Full-scale Test of DWPF Advanced Liquid-level and Density Measurement Bubblers (U)- WSRC-TR-97-0103, Rev. 0

\section{BUBBLER PROBE \# 6}

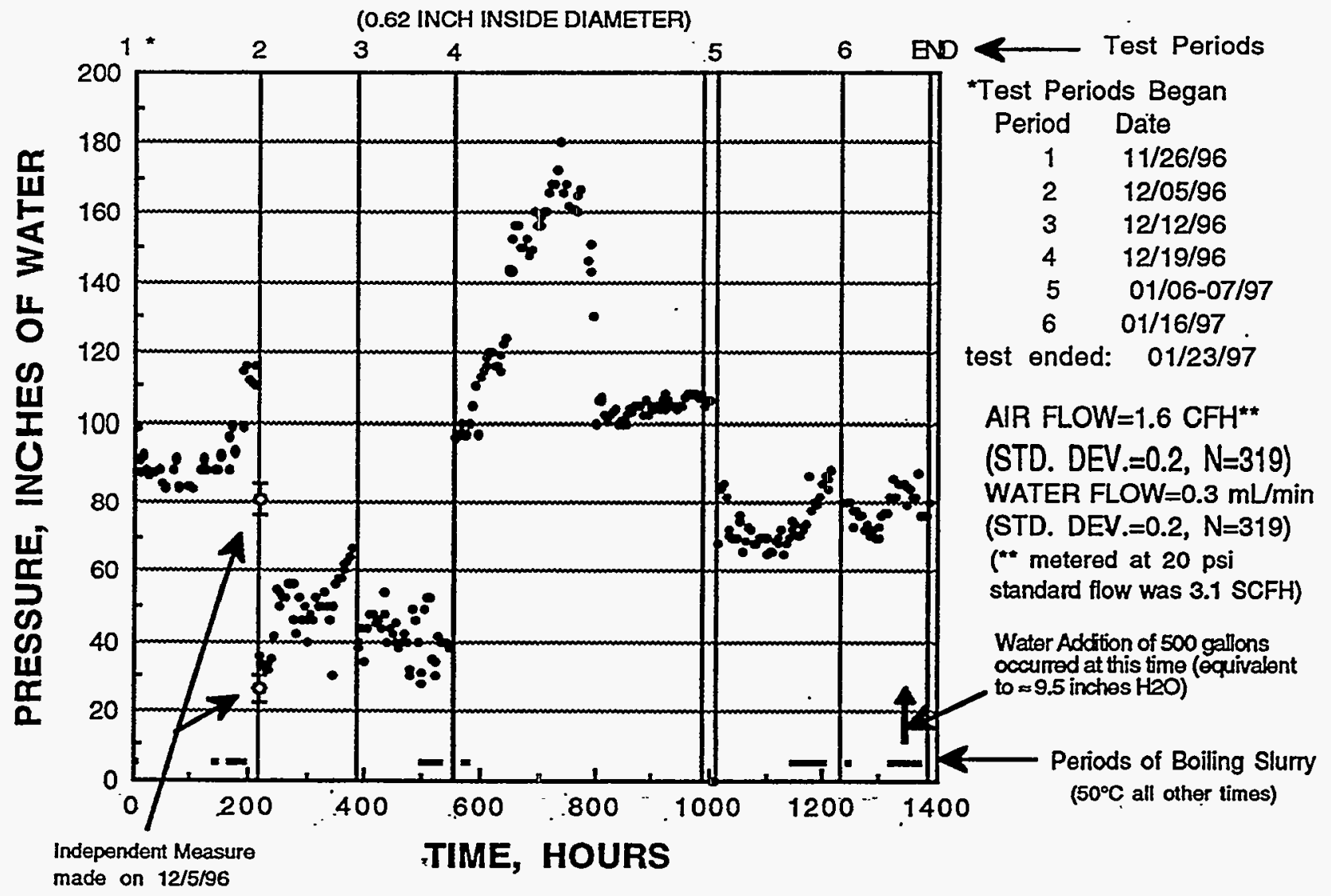

Figure C6: Experimental Data - Bubbler Probe \#6 (25.4” from tank bottom) [see pages 42 and 43 for an explanation of graph and data] 
Final Report: Full-scale Test of DWPF Advanced Liquid-level and Page 50 of 84 Density Measurement Bubblers (U)- WSRC-TR-97-0103, Rev. 0

\section{BUBBLER PROBE \# 7}

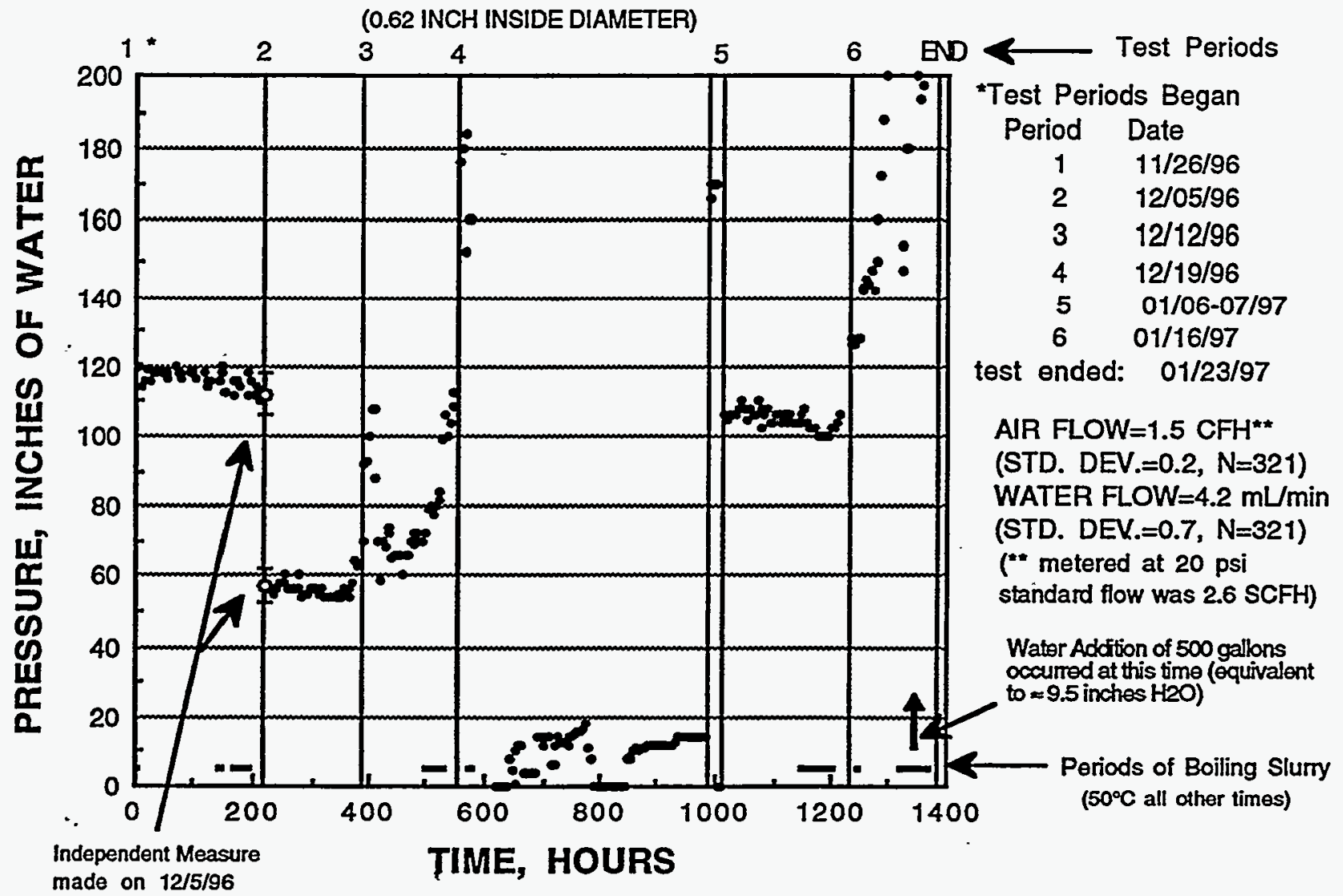

Figure C7: Experimental Data - Bubbler Probe \#7 (1.4" from tank bottom) [see pages 42 and 43 for an explanation of graph and data] 
Final Report: Full-scale Test of DWPF Advanced Liquid-level and Density Measurement Bubblers (U)- WSRC-TR-97-0103, Rev. 0

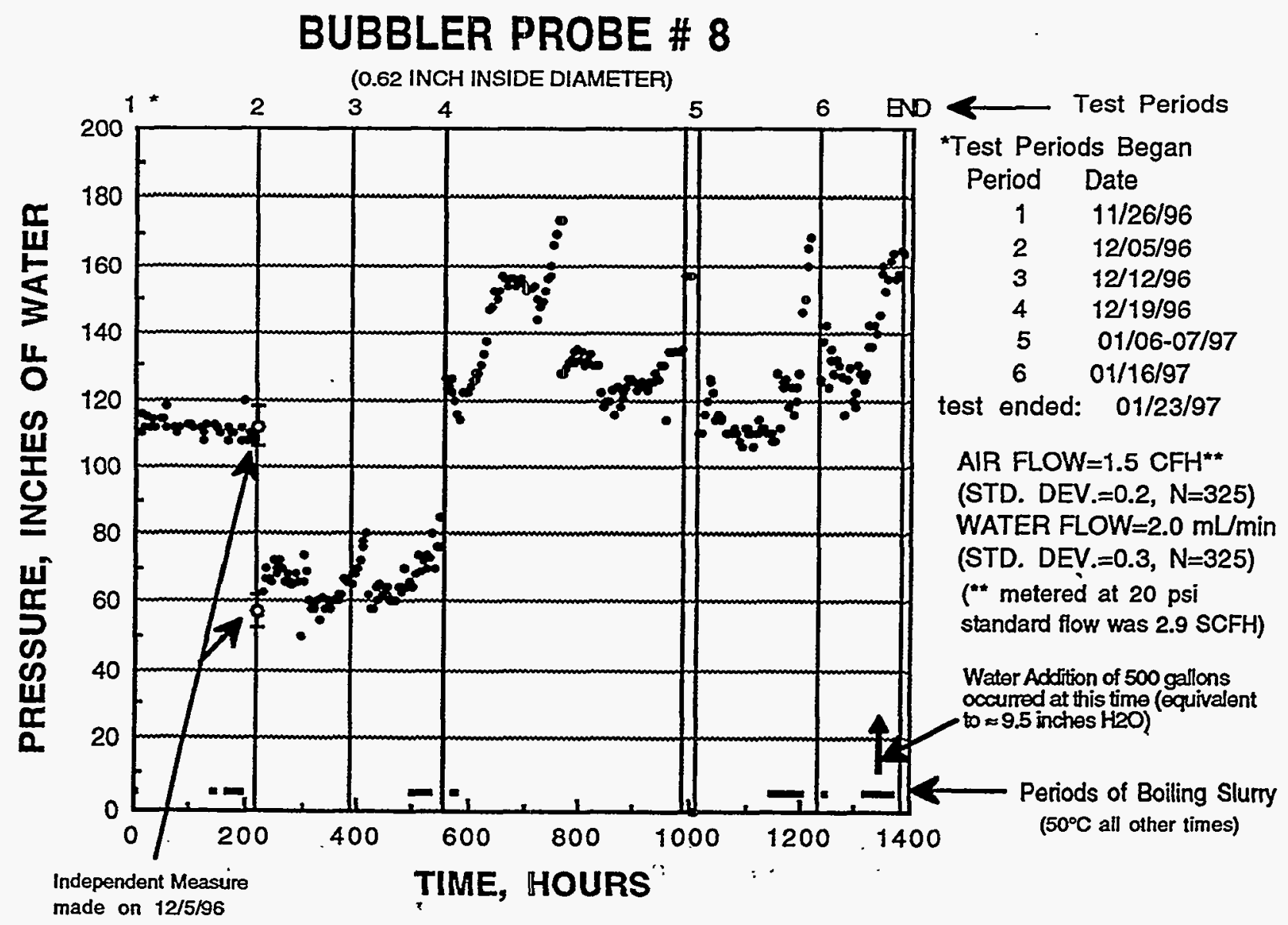

Figure C8: Experimental Data - Bubbler Probe \#8 (1.4" from tank bottom) [see pages 42 and 43 for an explanation of graph and data] 
Final Report: Full-scale Test of DWPF Advanced Liquid-level and

\section{BUBBLER PROBE \# 9}

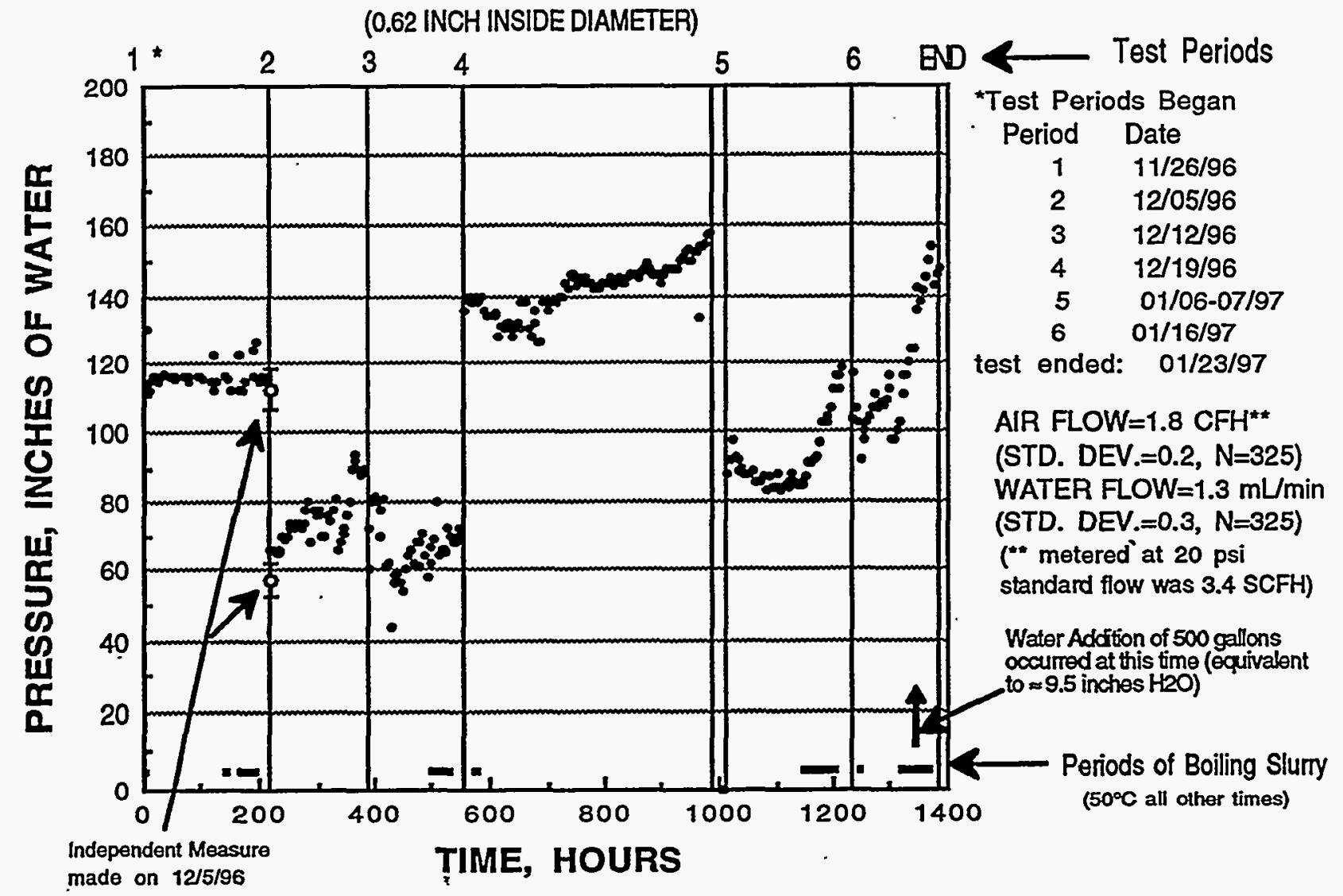

Figure C9: Experimental Data - Bubbler Probe \#9 (1.4” from tank bottom) [see pages 42 and 43 for an explanation of graph and data] 
Final Report: Full-scale Test of DWPF Advanced Liquid-level and

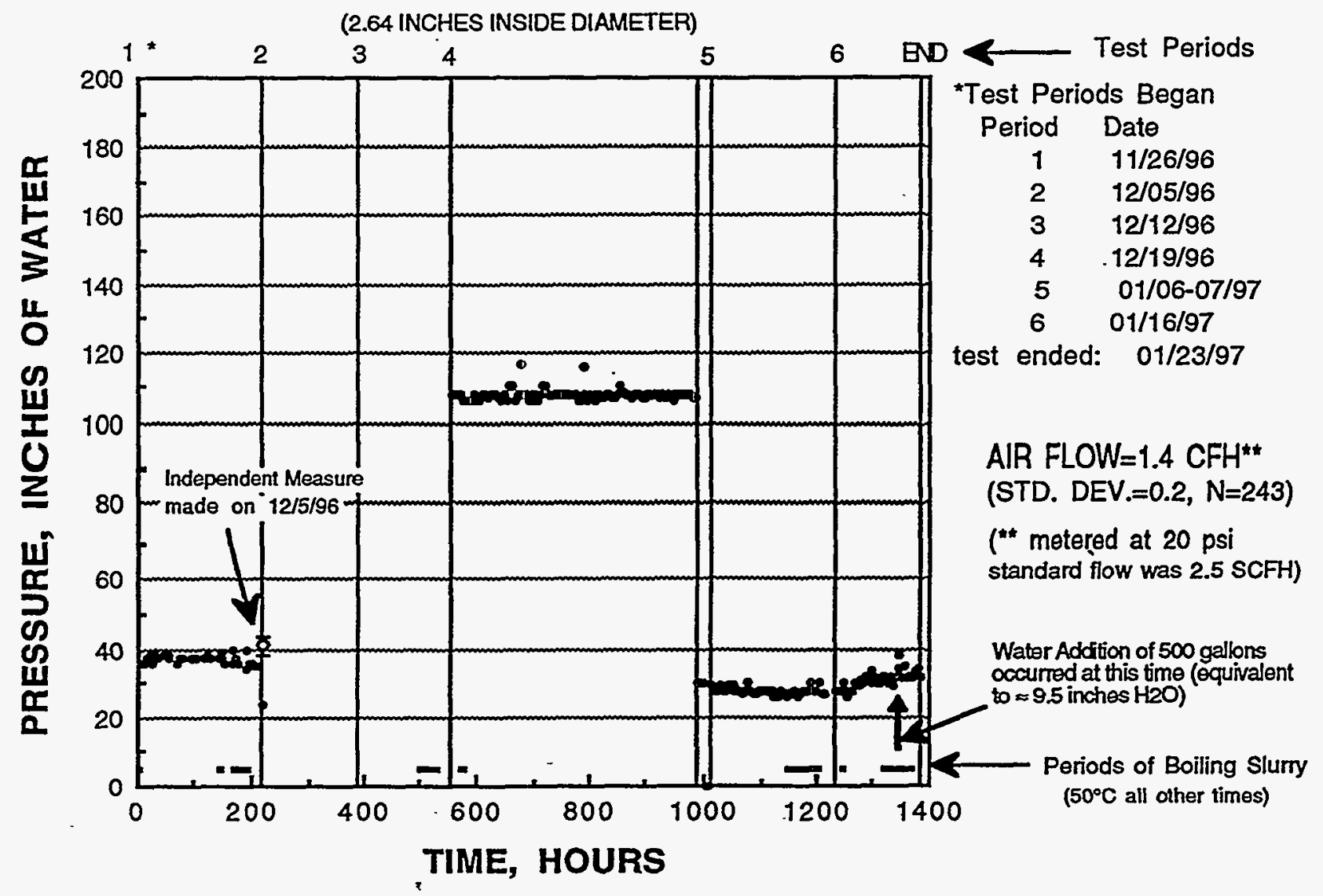

Figure C10: Experimental Data - Bubbler Probe \#10 (56.4" from tank bottom) [see pages 42 and 43 for an explanation of graph and data] 
Final Report: Full-scale Test of DWPF Advanced Liquid-level and

Density Measurement Bubblers (U)- WSRC-TR-97-0103, Rev. 0

\section{BUBBLER PROBE \# 11}

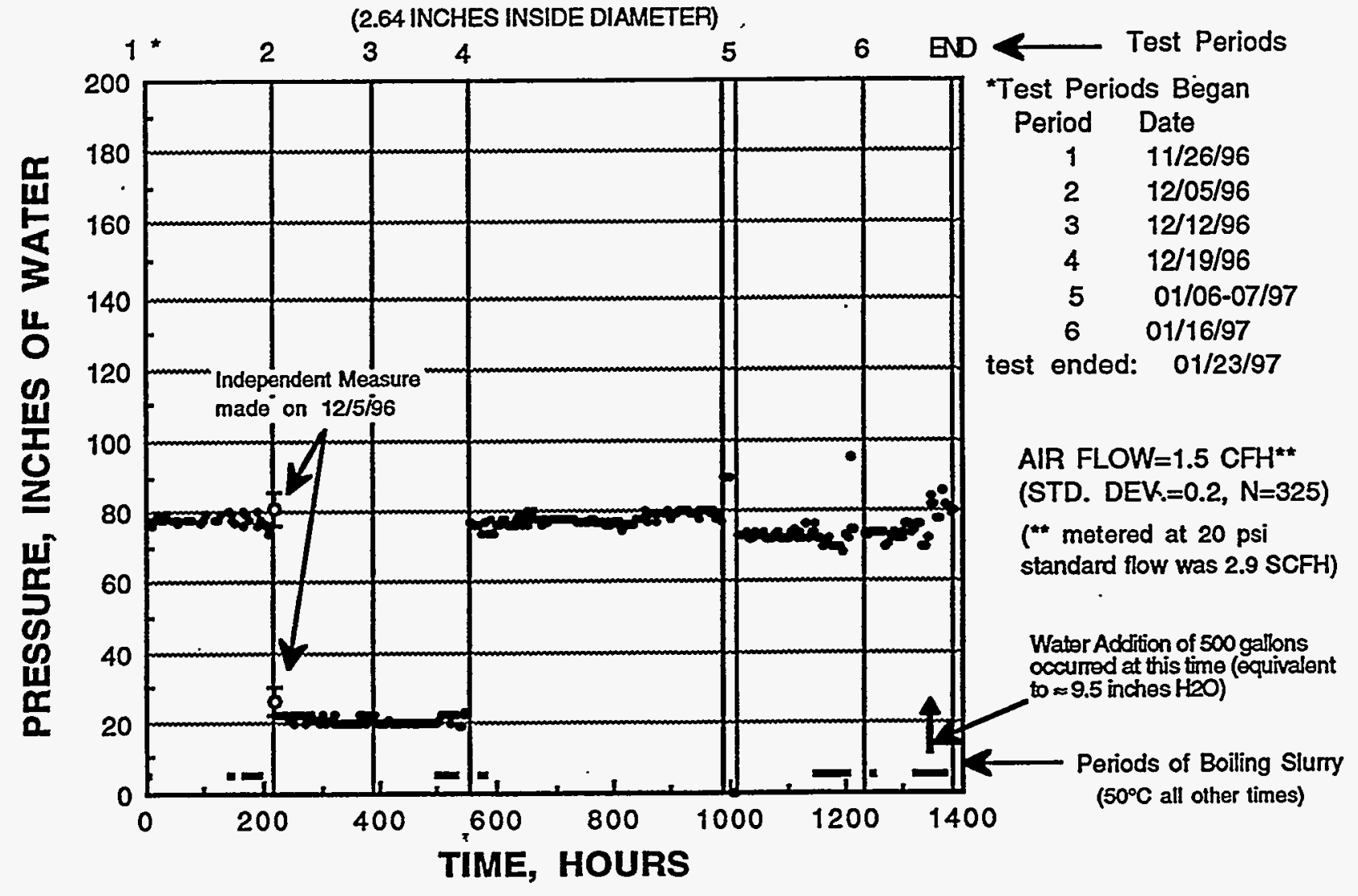

Figure C11: Experimental Data - Bubbler Probe \#11 (25.4” from tank bottom)

[see pages 42 and 43 for an explanation of graph and data] 
Final Report: Full-scale Test of DWPF Advanced Liquid-level and

\section{BUBBLER PROBE \# 12}

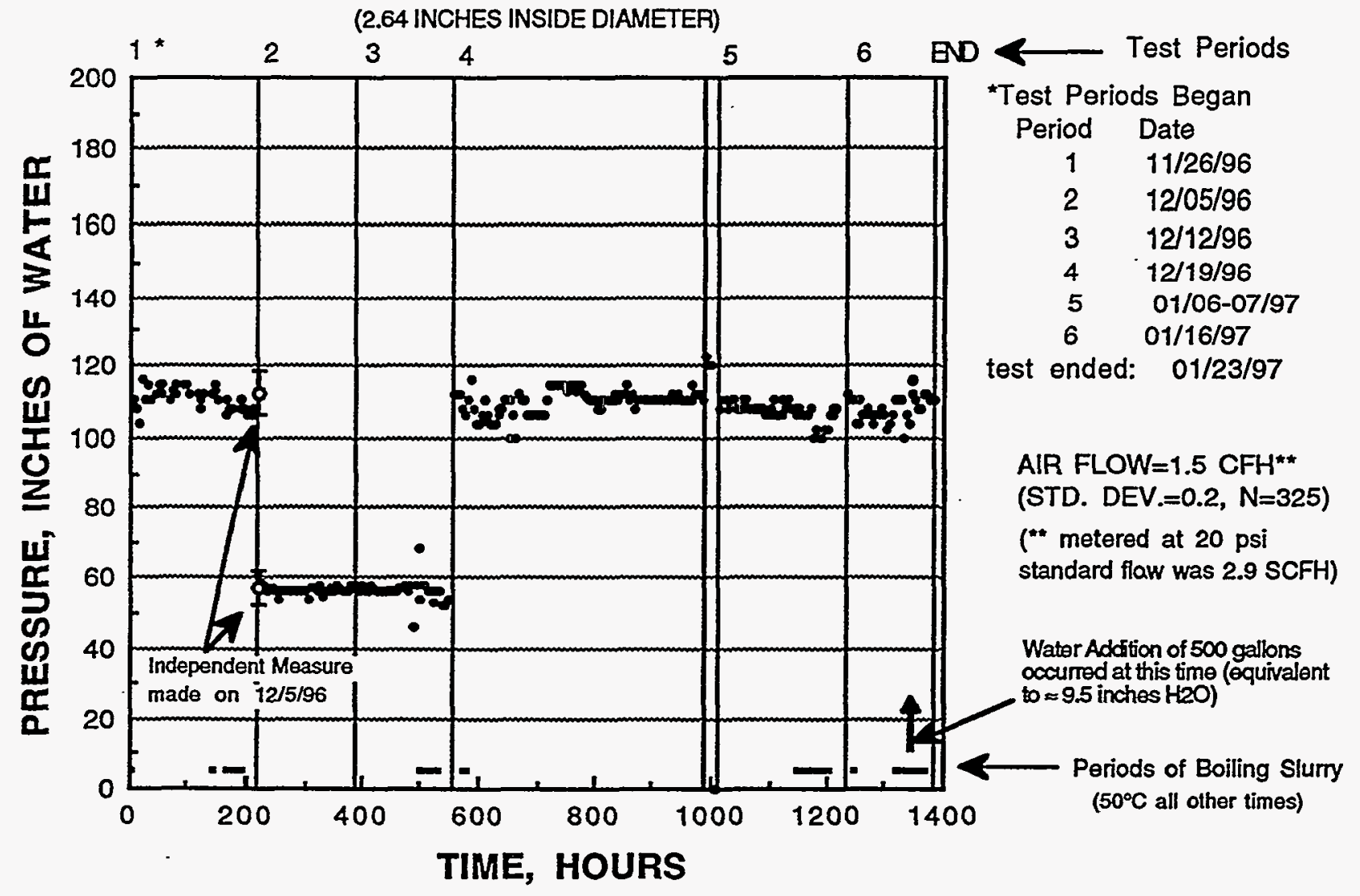

Figure C12: Experimental Data - Bubbler Probe \#12 (1.4" from tank bottom)

[see pages 42 and 43 for an explanation of graph and data] 
Final Report: Full-scale Test of DWPF Advanced Liquid-level and

Density Measurement Bubblers (U)- WSRC-TR-97-0103, Rev.. 0

BUBBLER PROBES \# 10, 11, \& 12

(2.64 INCHES INSIDE DIAMETER)

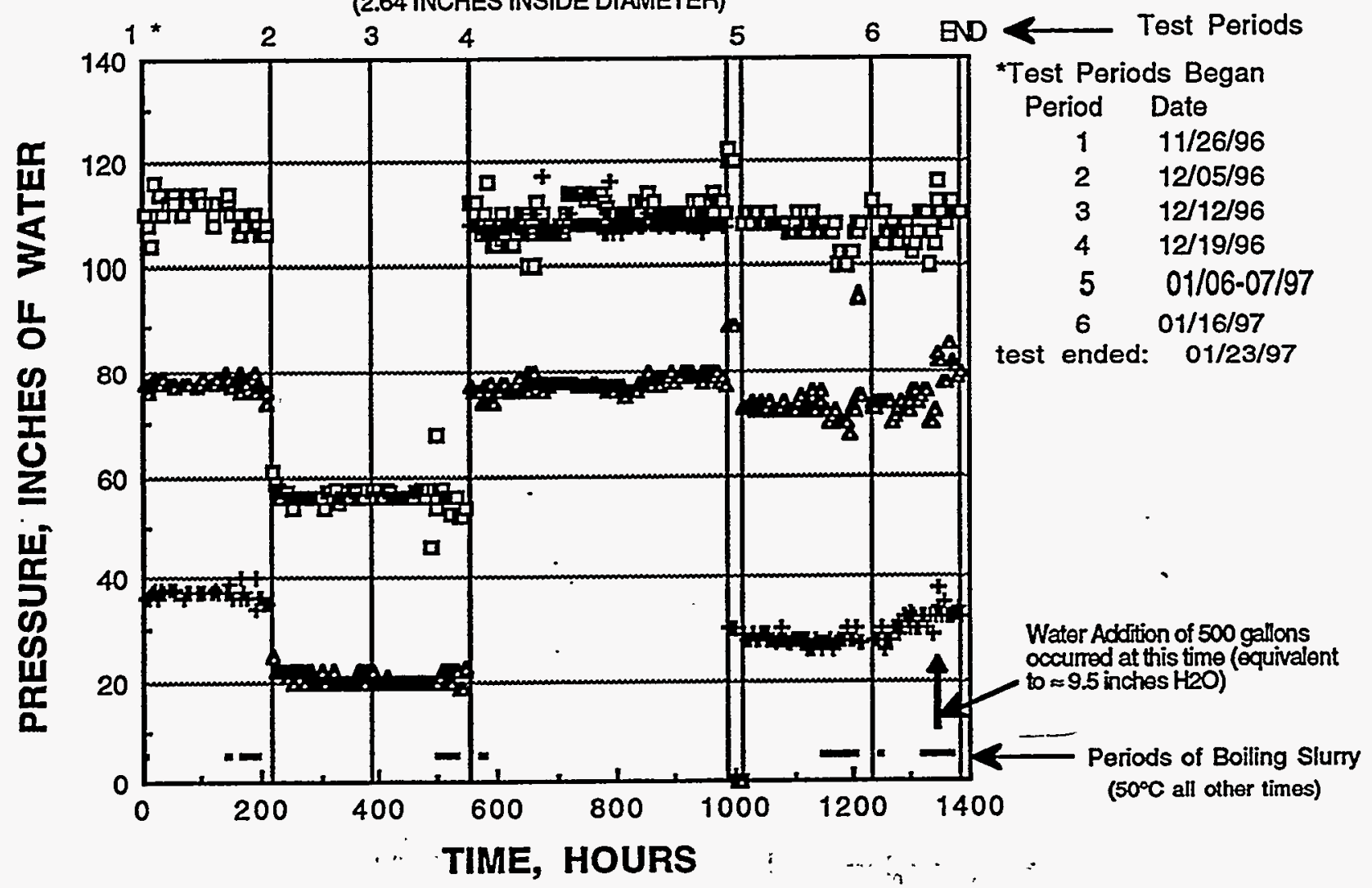

Figure C13: Experimental Data - Bubbler Probes \#10, \#11, and \#12 [see pages 42 and 43 for an explanation of graph and data] 
Final Report: Full-scale Test of DWPF Advanced Liquid-level and Density Measurement Bubblers (U)- WSRC-TR-97-0103, Rev. 0

\section{APPENDIX D}

\section{Instrument Uncertainty Analysis}

High accuracy for the instruments used in this test was not needed since the main purpose of this test was to determine if a type of an advanced bubbler probe would plug or not under prototypic mixing tank conditions. A total pluggage would prevent air flow to continue in a probe and the air pressure to build up to line pressure; basically a go no-go situation. Even the exact water flow rate was not crucial, it only had to be in increments of the value used in the benchtop test, $2.2 \mathrm{~cm}^{3} / \mathrm{min}$, for an 8 -inch tall porous tube (2); A $10 \%$ uncertainty would suffice for the test. As such, instruments were chosen either for their prototypicality (same air flow meters used in the plant) or for being inexpensive (air pressure and water flow rate).

Each of the twelve bubbler tubes had a pressure gauge and an air flow meter. Each of the nine porous bubbler tubes had a water flow meter. All of the instruments were mounted on a single panel, Fig. D1 [WSRC Photograph No. 96-1569-16], and the make and range are given below:

\begin{tabular}{lcclll} 
Measurement & Quantity & & I.D. Numbers & Instrument Make & \multicolumn{2}{l}{ Range } \\
\cline { 2 - 5 } Water Flow & 9 & WF-1 to -9 & Gilmont & $0-5 \mathrm{ml} / \mathrm{min}$ \\
Air Flow & 12 & AF-1 to -12 & Wallace \& Tieman $0-2.5 \mathrm{scfh}$ \\
Air Pressure & 12 & AP-1 to -12 & Noshok & $0-200$ inches H2O
\end{tabular}

The individual instrument measurement uncertainly can be found on the appropriate analysis sheet in this Appendix.

Highlights of the Uncertainty Analyses:

Water Flow Meters [Figure D2]- There is only a single calibration sheet which contains all the uncertainty analyses for the 9 meters. A rough pre-test and post-test check was done to determine the level of accuracy. All nine probes were calibrated together. This was done to save time and because high accuracy was not required. A tolerance of $10 \%$ was thought to be acceptable. As shown in the calibration sheet the meters performed as expected. One note of caution: the meter readings were confounded from time-to-time by the presence of air bubbles. Either trapped air or air coming out of solution would raise the float and affect the reading. However, the actual flow rate would not be affected. In this case, a reading could only be made after the bubble left the meter, returning the 
ball to its original setting. This was done during calibration, but there may be field data affected by air movement in a meter.

Air Flow Meters [Figures D3-D14] - These instrument are not built for accuracy but for their robustness; they can withstand considerable overpressurization and high temperatures. However, two of the instruments ( $A F-1$ and $A F-7$ ) had unusually high uncertainties $\approx 35 \%$. These large variances were believed to the result of manufacture defects. Excluding these two devices the average uncertainty was approximately 0.5 scfh or $14 \%$ of the pressurized ( 20 psig) maximum flow rate of 4 scfh. This uncertainty is still high, but is acceptable for in-plant use, because the meter is more to indicate that a flow exists, as opposed measuring the actual flow rate. Setting the flow rate anywhere between 0.5 and $1.5 \mathrm{scfh}$ is common practice.

Air Pressure Gauges [Figures D15-D26] - During the pre-test calibration these inexpensive gauges were found to be exceptionally accurate (2 in. $\mathrm{H}_{2} \mathrm{O}$ ) and repetitive. However, during the testing they were overpressurized which not only changed their calibration, but also affected their precision. The post-test calibration indicates a precision uncertainly of 15 inches $\mathrm{H}_{2} \mathrm{O}$. The overpressurization had the strongest impact on the accuracies. At the highest meter reading $\left(200 \mathrm{in} . \mathrm{H}_{2} \mathrm{O}\right)$ the instrument readings deviated from the true pressure by as little as 6 in. $\mathrm{H}_{2} \mathrm{O}$ (AP.-12) to as much as 70 in. $\mathrm{H}_{2} \mathrm{O}$ (AP-2). The instruments which have uncertainties close to the latter value can only be used to determine a plugging situation and not for making liquid-level measurements. Fortunately, for two of the three large-diameter probes (AP-11 and AP12) the pressure gauges still showed sufficient accuracy to make statements about liquid level measurement. 
Final Report: Full-scale Test of DWPF Advanced Liquid-level and

Density Measurement Bubblers (U)- WSRC-TR-97-00103, Rev. 0

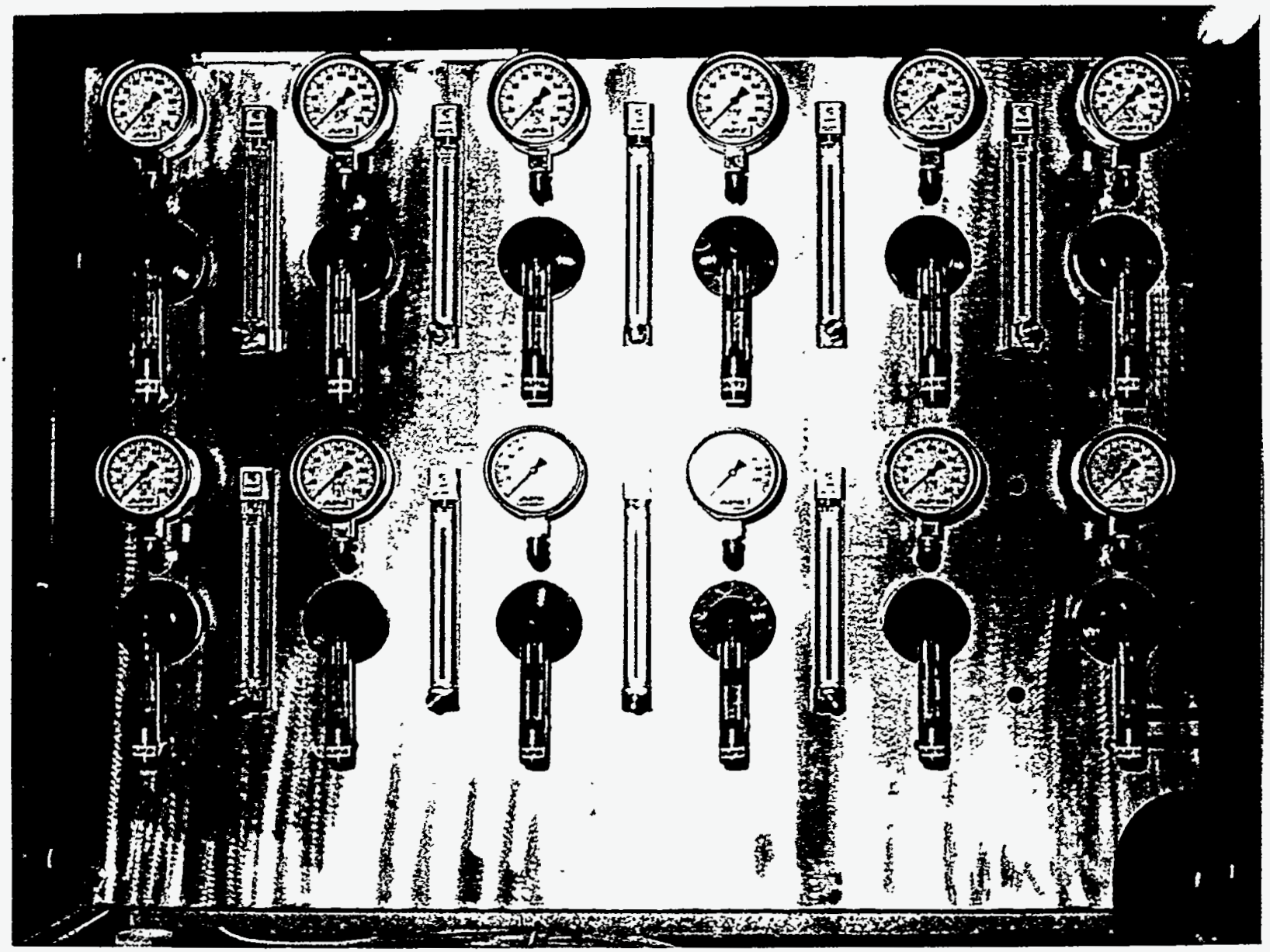

WSRC Photograph No. 1569-16

Figure D1 (No. 96-1569-16, taken 11/96): Instrument Panel 


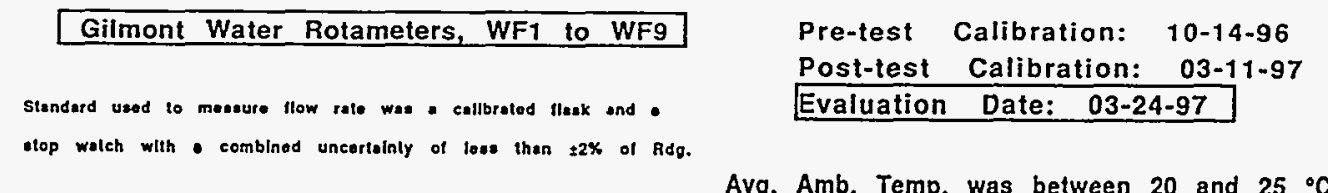

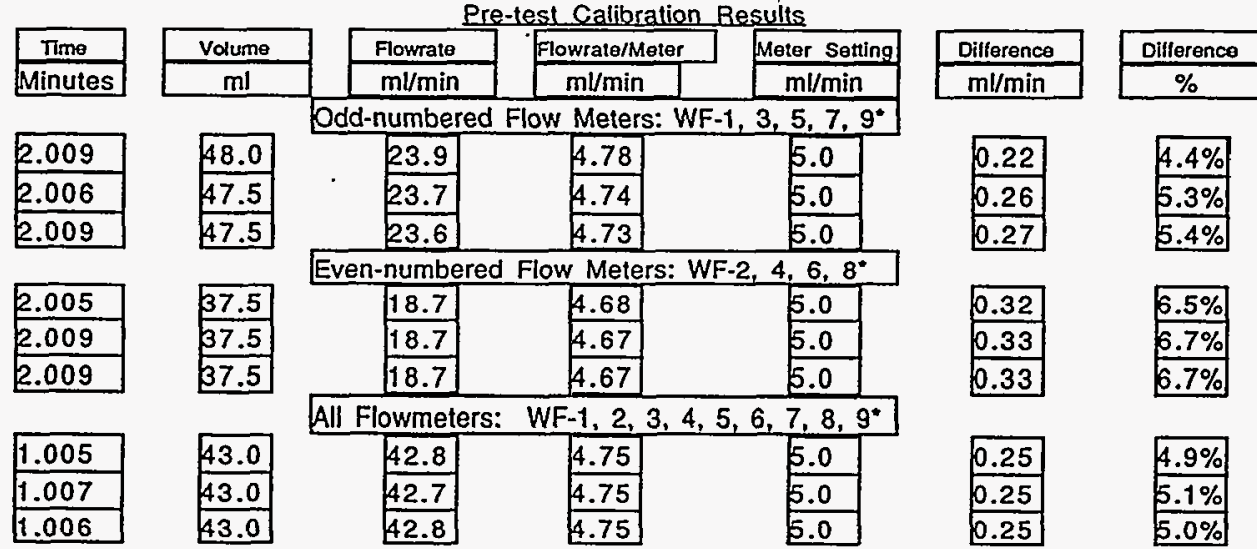

\begin{tabular}{|l|l|l|}
\hline Pre-test Overall Percent Deviation From Maximum Meter Setting & $5.6 \%$ \\
\hline
\end{tabular}

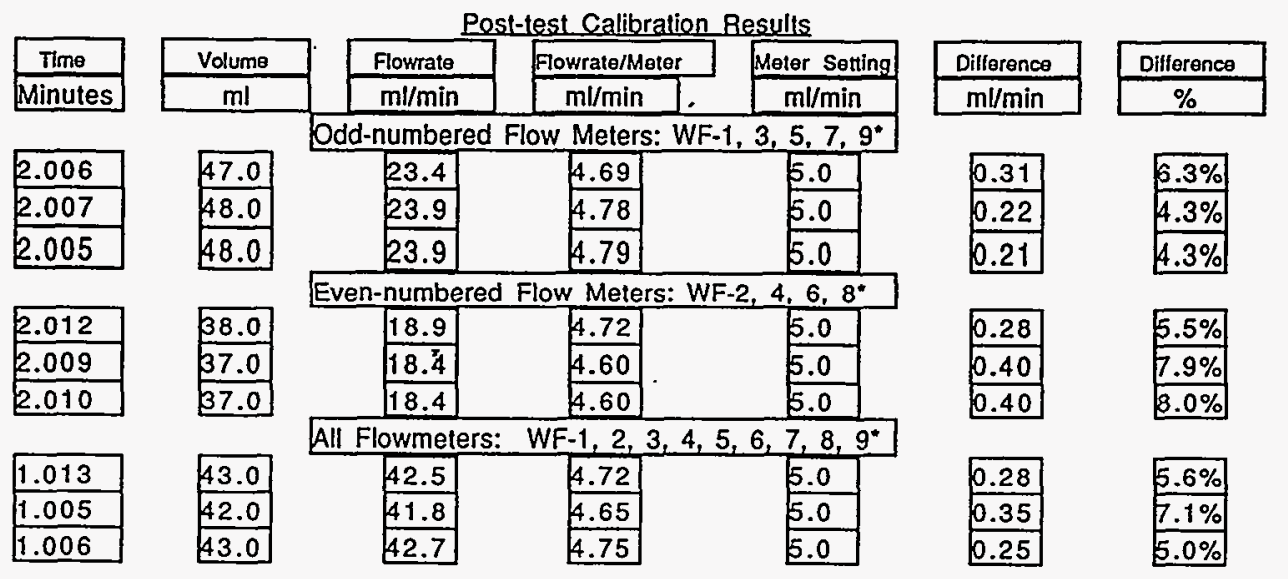

\begin{tabular}{|l|l|}
\hline Post-test Overall Percent Deviation From Maximum Meter Setting & $6.0 \%$ \\
\hline
\end{tabular}

With the Standard Uncertainy, the Overall Uncertainty based on the Post-Calibration is: $6.3 \%$ FS

The Overall Standard Deviation of the Uncertainty is: $1,2 \%$

(These meters were measured together to obtain a higher accuracy in the standard source - more volume per time - because of the small quantities of liquid. However. the listed meter uncertainty is an average therelore an actual meter uncertainty may be higher

or lower. The overall standard deviation indicates the level of variance from the mean.) 
Final Report: Full-scale Test of DWPF Advanced Liquid-level and Density Measurement Bubblers (U)- WSRC-TR-97-0103, Rev. 0

\begin{tabular}{|c|c|c|c|c|}
\hline \multicolumn{5}{|c|}{ Wallace \& Tiernan Air Flow Meter, AF1 } \\
\hline \multicolumn{5}{|c|}{ 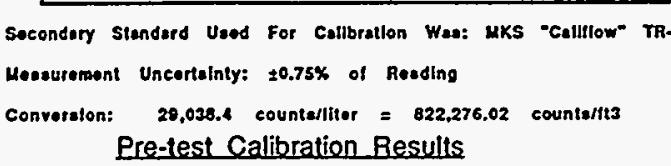 } \\
\hline \multicolumn{5}{|c|}{$\frac{\text { Pre-test Calibration Results }}{\text { Califlow }}$ W\&T } \\
\hline \multicolumn{5}{|c|}{ counts time sec. } \\
\hline \multicolumn{5}{|c|}{$8969 \quad 60.3342$} \\
\hline \multicolumn{5}{|c|}{$12668 \quad 18.6919$} \\
\hline \multicolumn{5}{|c|}{$12899 \quad 15.4505$} \\
\hline \multicolumn{5}{|c|}{$12656 \quad 15.2839$} \\
\hline \multicolumn{5}{|c|}{1268518.4068} \\
\hline \multicolumn{5}{|c|}{60.3321} \\
\hline \multirow{2}{*}{$\begin{array}{l}\text { Average } \\
\text { Average }\end{array}$} & \multirow{2}{*}{$\begin{array}{l}\text { Ambient } \\
\text { Ambient }\end{array}$} & \\
\hline & & \multicolumn{3}{|c|}{$\begin{array}{l}\text { Temperature }=21^{\circ} \mathrm{C} \\
\text { Pressure }=762 \mathrm{mmHg}\end{array}$} \\
\hline \multicolumn{5}{|c|}{ Pre+Post Pre+Post } \\
\hline Califlow, scth & WT. scth & Best Fit & KBest & Fit)-(WT) \\
\hline 0.65 & 0.70 & 0.61 & & -0.09 \\
\hline 2.97 & 1.50 & 1.83 & & 0.33 \\
\hline 3.66 & 2.50 & 2.19 & & -0.31 \\
\hline 3.63 & 2.50 & 2.18 & & -0.32 \\
\hline 3.02 & 1.50 & 1.86 & & 0.36 \\
\hline 0.66 & 0.70 & 0.62 & & -0.08 \\
\hline 0.67 & 0.70 & 0.63 & & -0.07 \\
\hline 3.05 & 1.50 & 1.87 & & 0.37 \\
\hline 3.82 & 2.50 & 2.28 & & -0.22 \\
\hline 3.82 & 2.50 & 2.28 & & -0.22 \\
\hline 2.96 & 1.50 & 1.83 & & 0.33 \\
\hline 0.65 & 0.70 & 0.61 & & .0 .09 \\
\hline
\end{tabular}

RESPONSE (Wallace \& Tieman, sc(q)

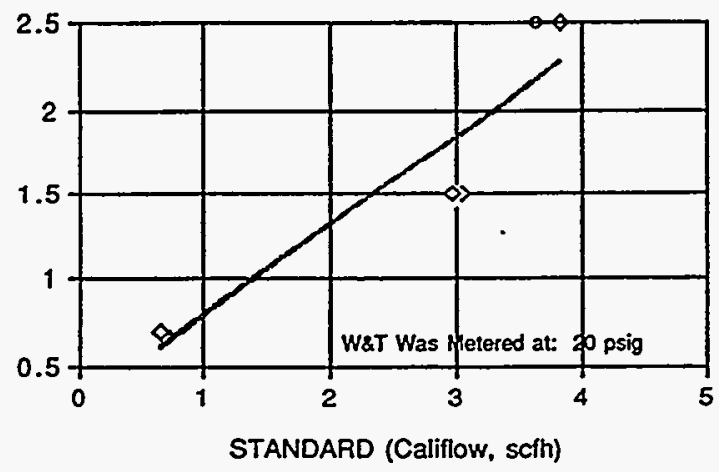

fit: Actual,scth $=b 0+b 1 \times(W \& T, s c f h)$

\begin{tabular}{|l|l|}
\multicolumn{2}{|c}{ for $D A S$} \\
\hline 00 & $0.150399 \ldots$ \\
\hline 01 & $1.6683401 \ldots$ \\
\hline corr.coef. & $0.9359010 \ldots$ \\
\hline
\end{tabular}

fit: $W \& T, s c f h=a 0+\operatorname{atx}$ (Actual, scth)

\begin{tabular}{|l|l|}
\multicolumn{2}{|c}{ for statistics } \\
\hline a0 & $0.2733692 \ldots$ \\
\hline a1 & 0.5250192 \\
\hline corr.coef. & $0.9359010 \ldots$ \\
\hline
\end{tabular}

\begin{tabular}{|c|c|c|c|}
\hline \multicolumn{3}{|c|}{ STATISTICALDATA } & \\
\hline 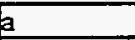 & \multicolumn{3}{|c|}{$0.2733692 \ldots$} \\
\hline 5 & \multicolumn{3}{|c|}{$0.5250192 \ldots$} \\
\hline SEI & \multicolumn{3}{|c|}{$0.8074075 \ldots$} \\
\hline MSE & \multicolumn{3}{|c|}{$0.0807407 \ldots$} \\
\hline$S x x$ & \multicolumn{3}{|c|}{$20.676066 \ldots$} \\
\hline $\operatorname{sum}\left(X j^{\wedge} 2\right)$ & \multicolumn{2}{|l|}{93.4922} & \\
\hline $\operatorname{avg}(X)$ & \multicolumn{3}{|c|}{$2.4633333 \ldots$} \\
\hline \multicolumn{2}{|c|}{ Degrees Freedom } & 10 & \\
\hline \multicolumn{2}{|c|}{ (95\% confidence) } & 2.228 & \\
\hline \multicolumn{2}{|c|}{ Iest Statistic, $T$} & 8.402 & \\
\hline \multicolumn{2}{|c|}{ W\&T: Uncert.,Wy low } & 0.706 & sefl \\
\hline \multicolumn{2}{|c|}{ W\&T: Uncert.,Wy high } & 0.685 & sef \\
\hline \multicolumn{2}{|c|}{ Cune Fit: Uncert.,We } & 1.306 & scth \\
\hline \multirow{2}{*}{\multicolumn{2}{|c|}{$\begin{array}{l}\text { Cal. Equip. Uncert..Wc } \\
\text { Total Uncertainty, Wt }\end{array}$}} & 0.015 & scfl \\
\hline & & 1.31 & \\
\hline
\end{tabular}

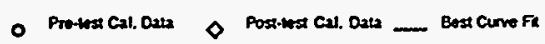

Le. Uncentainty When Using Cunve Fil: $1.4 \mathrm{sch}$ 


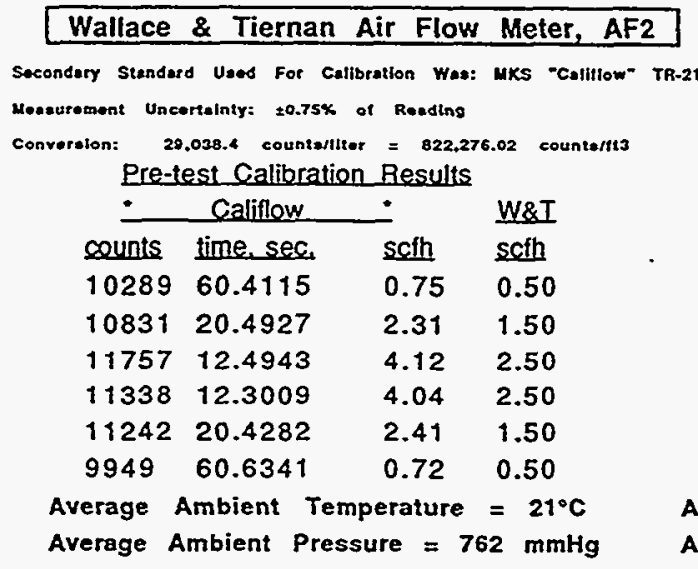

\begin{tabular}{|c|c|c|c|c|}
\hline Pre+Post & Pre+Post & & & \\
\hline Califiow, sefh & WT, scfh & Best Fit & Kest & Fit) $-(W T)$ \\
\hline 0.75 & 0.50 & 0.49 & & -0.01 \\
\hline 2.31 & 1.50 & 1.38 & & -0.12 \\
\hline 4.12 & 2.50 & 2.41 & & -0.09 \\
\hline 4.04 & 2.50 & 2.37 & & -0.13 \\
\hline 2.41 & 1.50 & 1.44 & & -0.06 \\
\hline 0.72 & 0.50 & 0.47 & & -0.03 \\
\hline 0.87 & 0.50 & 0.56 & & 0.06 \\
\hline 2.63 & 1.50 & 1.56 & & 0.06 \\
\hline 4.46 & 2.50 & 2.61 & & 0.11 \\
\hline 4.47 & 2.50 & 2.61 & & 0.11 \\
\hline 2.61 & 1.50 & 1.55 & & 0.05 \\
\hline \multirow[t]{2}{*}{0.87} & 0.50 & 0.56 & & 0.06 \\
\hline & & $\mathrm{ms} \mathrm{o}$ & & $0.08^{\mathrm{scfh}}$ \\
\hline
\end{tabular}

RESPONSE (Wallace \& Tieman, scfh),

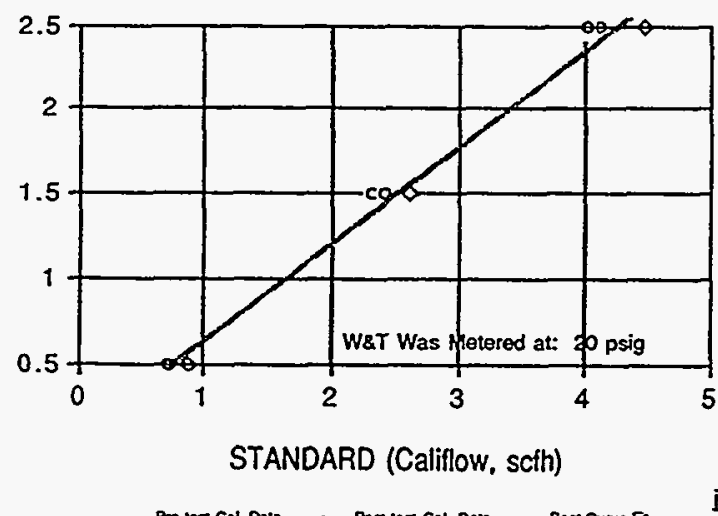

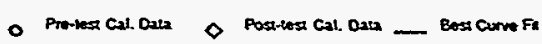

\author{
Pre-test Calibration: 10-01-96 \\ Post-test Calibration: 03-10-97 \\ Evaluation Date: 03-13-97
}

Post-test Calibration Results

\begin{tabular}{|c|c|c|c|}
\hline & Ca & & N\&T \\
\hline ounts & time, sec & scfh & scth \\
\hline 1908 & 60.2427 & 0.87 & 0.50 \\
\hline 12480 & 20. & 2.63 & 1.50 \\
\hline 12353 & 12. & 4.46 & 2.50 \\
\hline 12565 & 72.3 & 4.47 & 2.50 \\
\hline 2015 & 20. & 2.61 & 1.50 \\
\hline 2001 & 60.4459 & 0.87 & .50 \\
\hline
\end{tabular}

Average Ambient Temperature $=23^{\circ} \mathrm{C}$

Average Ambient Pressure $=756 \mathrm{mmHg}$

fit: Actual,scth $=60+$ bix(W\&T,scth)

\begin{tabular}{|l|l|}
\hline \multicolumn{2}{|c}{ for DAS } \\
\hline po & $0.080833 \ldots$ \\
\hline b1 & 1.735 \\
\hline corr.coef. & $0.9948705 \ldots$ \\
\hline
\end{tabular}

fit: $W \& T, s c f h=a 0+a 1 \times$ (Actual, scfh) \begin{tabular}{|l|l|}
\multicolumn{2}{c}{ for statistics } \\
\hline a0 & $0.0614619 \ldots$ \\
\hline a1 & $0.5704711 \ldots$ \\
\hline corr.coef. & $0.9948705 \ldots$ \\
\hline
\end{tabular}

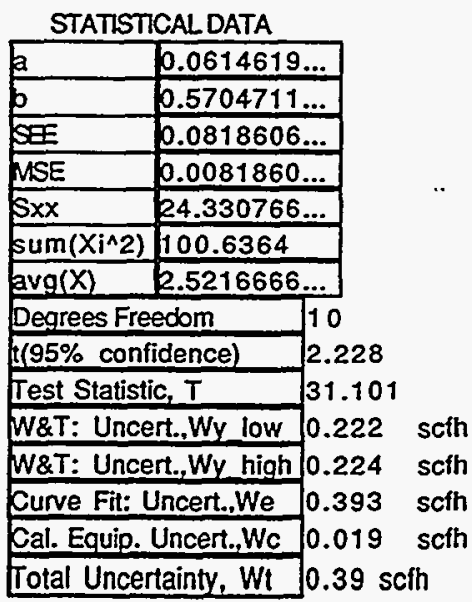
i.e. Uncertainty When Using Curve Fit: 0.4 scth

Figure D4: Uncertainty Analysis, Air-flow Meters AF2 


\begin{tabular}{|c|c|c|c|c|}
\hline \multicolumn{5}{|c|}{ Wallace \& Tiernan Air Flow Meter, AF3 } \\
\hline \multicolumn{5}{|c|}{ 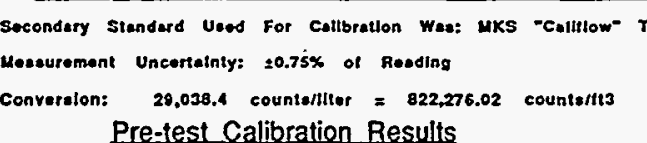 } \\
\hline \multicolumn{5}{|c|}{ - Califlow } \\
\hline \multicolumn{5}{|c|}{ counts time.sec. } \\
\hline \multicolumn{5}{|c|}{$\overline { 1 2 9 8 5 } \longdiv { 3 8 . 3 3 1 6 }$} \\
\hline \multicolumn{5}{|c|}{$12702 \quad 19.1057$} \\
\hline \multicolumn{5}{|c|}{$12529 \quad 13.2216$} \\
\hline \multicolumn{5}{|c|}{$12768 \quad 13.4554$} \\
\hline \multicolumn{5}{|c|}{$13022 \quad 18.7595$} \\
\hline \multicolumn{5}{|c|}{$13120 \quad 37.1204$} \\
\hline \multirow{2}{*}{\multicolumn{2}{|c|}{$\begin{array}{l}\text { Average Ambient } \\
\text { Average Ambient }\end{array}$}} & \multirow{2}{*}{\multicolumn{3}{|c|}{$\begin{array}{l}\text { Temperature }=21^{\circ} \mathrm{C} . \\
\text { Pressure }=762 \mathrm{mmHg}\end{array}$}} \\
\hline & & & & \\
\hline \multicolumn{5}{|l|}{ Pre+Post } \\
\hline Califiow, seth & WT, scth & Best Fit & ¿Best & $t$ Fit $)-(W$ \\
\hline 1.48 & 0.50 & 0.47 & & -0.03 \\
\hline 2.91 & 1.50 & 1.49 & & -0.01 \\
\hline 4.15 & 2.50 & 2.37 & & -0.13 \\
\hline 4.15 & 2.50 & 2.37 & & -0.13 \\
\hline 3.04 & 1.50 & 1.58 & & 0.08 \\
\hline 1.55 & 0.50 & 0.52 & & 0.02 \\
\hline 1.47 & 0.50 & 0.46 & & -0.04 \\
\hline 3.07 & 1.50 & 1.60 & & 0.10 \\
\hline 4.32 & 2.50 & 2.49 & & -0.01 \\
\hline 4.47 & 2.50 & 2.60 & & 0.10 \\
\hline 3.05 & 4.50 & 1.59 & & 0.09 \\
\hline 1.48 & 0.50 & 0.47 & & -0.03 \\
\hline & & & & \\
\hline
\end{tabular}

RESPONSE (Wallace \& Tieman, sch),

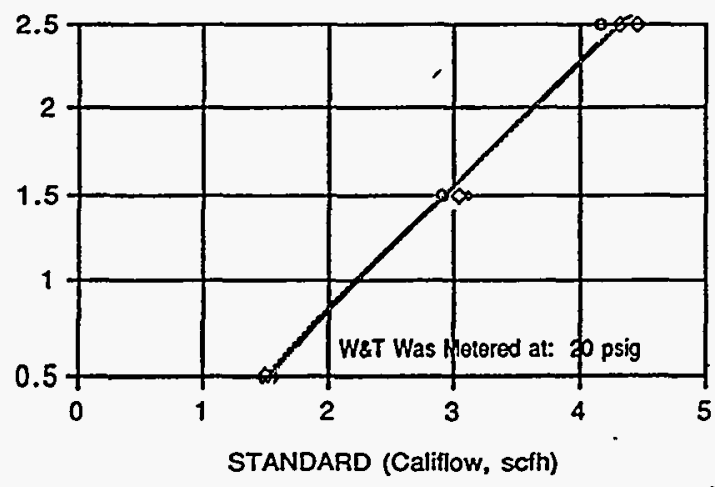

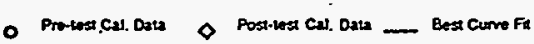

Pre-test Calibration: 10-01-96

Post-test Calibration: 03-10-97

Evaluation Date: 03-13-97

Post-test Calibration Results

\begin{tabular}{|c|c|c|c|}
\hline • & Califilow & $\bullet$ & W\&T \\
\hline counts & time, sec & $5 \mathrm{sch}$ & $\mathrm{scfh}$ \\
\hline 13020 & 38.9077 & 1.47 & 0.50 \\
\hline 12828 & 18.2766 & 3.07 & 1.50 \\
\hline 12798 & 12.9731 & 4.32 & 2.50 \\
\hline 12587 & 12.3416 & 4.47 & 2.50 \\
\hline 12782 & 18.3580 & 3.05 & 1.50 \\
\hline 12953 & 38.3547 & 1.48 & 0.50 \\
\hline
\end{tabular}

Average Ambient Temperature $=23^{\circ} \mathrm{C}$

Average Ambient Pressure $=756 \mathrm{mmHg}$

fit: Actual,sch $=b 0+b 1 \times(W \& T, s c f h)$

for DAS

\begin{tabular}{|l|l|}
\hline 00 & $0.8452083 \ldots$ \\
\hline b1 & 1.38875 \\
\hline corr.coef. & $0.9955271 \ldots$ \\
\hline
\end{tabular}

fit: $W \& T, s c f h=a 0+\operatorname{atx}$ (Actual, scfh)

\begin{tabular}{|l|l|}
\hline \multicolumn{2}{c}{ for statistics } \\
\hline $\mathrm{a} 0$ & $0.589790 \ldots$ \\
\hline $\mathrm{a} 1$ & $0.7136448 \ldots$ \\
\hline corr.coef. & $0.9955271 \ldots$ \\
\hline
\end{tabular}

\begin{tabular}{|c|c|c|}
\hline \multicolumn{3}{|c|}{ STATISTICALDATA } \\
\hline & \multicolumn{2}{|c|}{$0.589790 \ldots$} \\
\hline b & \multicolumn{2}{|c|}{$0.7136448 \ldots$} \\
\hline sex & \multicolumn{2}{|c|}{$0.0714051 \ldots$} \\
\hline MSE & \multicolumn{2}{|c|}{$0.0071405 \ldots$} \\
\hline $5 x x$ & \multicolumn{2}{|c|}{$15.567966 \ldots$} \\
\hline $\operatorname{sum}\left(X i^{\wedge} 2\right)$ & \multicolumn{2}{|c|}{118.4696} \\
\hline $\operatorname{avg}(X)$ & \multicolumn{2}{|c|}{$2.9283333 \ldots$} \\
\hline \multicolumn{2}{|c|}{ Degrees Freedom } & 10 \\
\hline \multicolumn{2}{|c|}{ (95\% confidence) } & 2.228 \\
\hline \multicolumn{2}{|c|}{ Iest Statistic, $T$} & 33.322 \\
\hline \multicolumn{2}{|c|}{ W\&T: Uncert.,Wy low } & 0.208 \\
\hline \multicolumn{2}{|c|}{ W\&T: Uncert.,Wy high } & 0.209 \\
\hline \multicolumn{2}{|c|}{ Curve Fit: Uncert.,We } & 0.293 \\
\hline \multirow{2}{*}{\multicolumn{2}{|c|}{ Cal. Equip. Uncert..Wc }} & 0.019 \\
\hline & & $0.29 \mathrm{sct}$ \\
\hline
\end{tabular}

i.e. Uncertainty when Using Curve Fit:0.3 sch

Figure D5: Uncertainty Analysis, Air-flow Meters AF3 
Final Report: Full-scale Test of DWPF Advanced Liquid-level and

Density Measurement Bubblers (U)- WSRC-TR-97-0103, Rev. 0

Wallace \& Tiernan Air Flow Meter, AF4

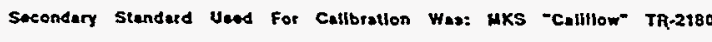

Moasuroment Uncertalnty: 20.75\% of Reading

Converslon: 29.038.4 counte/lltor $=822.276 .02$ countants

Pre-test_calibration Results

$\therefore$ Califlow W\&T

counts time, ses scth scih

$\begin{array}{llll}12934 & 50.5512 & 1.12 & 0.50\end{array}$

$\begin{array}{llll}12669 & 20.3354 & 2.73 & 1.50\end{array}$

$\begin{array}{llll}12498 & 12.3633 & 4.43 & 2.50\end{array}$

$\begin{array}{lll}12364 & 12.2472\end{array}$

$\begin{array}{llll}13216 & 20.1563 & 2.87 & 1.50\end{array}$

$\begin{array}{llll}13322 & 50.0851 & 1.16 & 0.50\end{array}$

Average Ambient Temperature $=21^{\circ} \mathrm{C}$

Average Ambient Pressure $=762 \mathrm{mmHg}$

Pre+Post Pre+Post

\begin{tabular}{|l|l|l|}
\hline Califlow, seth & WT. sch & Best Fit \\
\hline
\end{tabular}

\begin{tabular}{|c|c|c|c|}
\hline 1.12 & 0.50 & 0.49 & -0.01 \\
\hline 2.73 & 1.50 & 1.46 & -0.04 \\
\hline 4.43 & 2.50 & 2.47 & -0.03 \\
\hline 4.42 & 2.50 & 2.47 & -0.03 \\
\hline 2.87 & 1.50 & 1.54 & 0.04 \\
\hline 1.16 & 0.50 & 0.52 & 0.02 \\
\hline 1.10 & 0.50 & 0.48 & -0.02 \\
\hline 2.92 & 1.50 & 1.57 & 0.07 \\
\hline 4.48 & 2.50 & 2.50 & 0.00 \\
\hline 4.49 & 2.50 & 2.51 & 0.01 \\
\hline 2.84 & 1.50 & 1.52 & 0.02 \\
\hline 0.07 & 0.50 & 0.47 & -0.03 \\
\hline
\end{tabular}

RESPONSE (Wallace \& Tieman, scth)

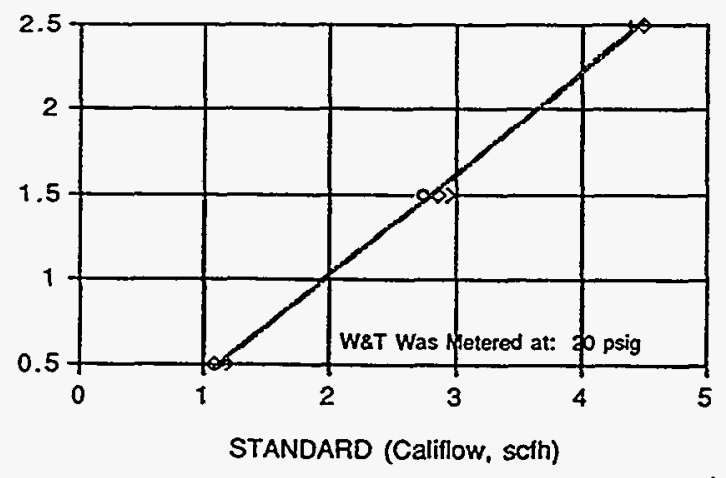

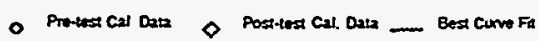

Pre-test Calibration: 10-01-96

Post-test Calibration: 03-10-97

Evaluation Date: 03-13-97

Post-test Calibration Results

\begin{tabular}{|c|c|c|c|}
\hline & Ealifilo & & $W \& T$ \\
\hline counts & hime, sec & scíh & $\operatorname{seth}$ \\
\hline 12699 & 50.5493 & 1.10 & 0.50 \\
\hline 12911 & 19.3548 & 2.92 & 1.50 \\
\hline 12629 & 12.3286 & 4.48 & 2.50 \\
\hline 12539 & 12.2266 & 4.49 & 2.50 \\
\hline 12517 & 19.3039 & 2.84 & 1.50 \\
\hline 12323 & 50.4281 & 1.07 & 0.50 \\
\hline
\end{tabular}

Average Ambient Temperature $=23^{\circ} \mathrm{C}$

Average Ambient Pressure $=756 \mathrm{mmHg}$ fit: Actual,scfh $=b 0+b 1 \times(W \& T, s c f h)$

for DAS

\begin{tabular}{|l|l|}
\hline bo & $0.2956249 \ldots$ \\
\hline b1 & 1.67125 \\
\hline corr.coef. & $0.9991995 \ldots$ \\
\hline
\end{tabular}

fit: $W \& T, \operatorname{scfh}=a 0+a 1 \times$ (Actual, scfh)

\begin{tabular}{|l|l|}
\multicolumn{2}{c}{ for statistics } \\
\hline 00 & $0.174205 \ldots$ \\
\hline 21 & $0.5973970 \ldots$ \\
\hline corr.coef. & $0.9991995 \ldots$ \\
\hline
\end{tabular}

STATISTICAL DATA

\begin{tabular}{|c|c|c|c|}
\hline \\
\hline a & \multicolumn{3}{|l|}{$0.174205 \ldots$} \\
\hline 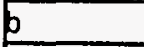 & \multicolumn{3}{|c|}{$0.5973970 \ldots$} \\
\hline SeI & \multicolumn{3}{|c|}{$0.0128013 \ldots$} \\
\hline MSE & \multicolumn{3}{|c|}{$0.0012801 \ldots$} \\
\hline$S x x$ & \multicolumn{3}{|l|}{22.380425} \\
\hline $\operatorname{sum}\left(X i^{\wedge} 2\right)$ & \multicolumn{3}{|l|}{116.6285} \\
\hline $\operatorname{avg}(X)$ & \multicolumn{3}{|l|}{2.8025} \\
\hline \multicolumn{2}{|c|}{ Degrees Freedom } & 10 & \\
\hline \multicolumn{2}{|c|}{ (95\% confidence) } & 2.228 & \\
\hline \multicolumn{2}{|c|}{ Test Statistic, T } & 78.989 & \\
\hline \multicolumn{2}{|c|}{ W\&T: Uncert.,Wy low } & 0.088 & scth \\
\hline \multicolumn{2}{|c|}{ W\&T: Uncert.,Wy high } & 0.088 & scfh \\
\hline \multicolumn{2}{|c|}{ Curve Fit: Uncert.,We } & 0.147 & $\operatorname{scfh}$ \\
\hline \multicolumn{2}{|c|}{ Cal. Equip. Uncert.,Wc } & 0.019 & $\operatorname{scth}$ \\
\hline \multicolumn{2}{|c|}{ Total Uncertainty, Wt } & $0.15 \mathrm{scft}$ & \\
\hline
\end{tabular}


Final Report: Full-scale Test of DWPF Advanced Liquid-level and Density Measurement Bubblers (U)- WSRC-TR-97-0103, Rev. 0

Wallace \& Tiernan Air Flow Meter, Af5 Socondary Stenderd Used for calibration Was: UKS "Catillow- TR-2180 Monouroment Uncertelinty: $: 0.75 \%$ of Reeding

Cenverslon: $29,038.4$ counta/liter $=822,276.02$ counto/113 Pre-test Calibration Results Califlow $\quad$ W\&T counts time.sec scfh scfh $\begin{array}{llll}11589 & 50.5030 & 1.00 & 0.50\end{array}$ $\begin{array}{llll}12599 & 20.4315 & 2.70 & 1.50\end{array}$ $\begin{array}{llll}12665 & 13.3201 & 4.16 & 2.50\end{array}$ $\begin{array}{llll}12832 & 13.2143 \quad 4.25 & 2.50\end{array}$ $\begin{array}{llll}12938 & 19.4799 & 2.91 & 1.50\end{array}$ $\begin{array}{llll}11652 & 50.3214 & 1.01 & 0.50\end{array}$ Average Ambient Temperature $=22^{\circ} \mathrm{C}$ Average Ambient Pressure $=762 \mathrm{mmHg}$

Pre+Post Pre+Post

\begin{tabular}{|l|l|l|l|l}
\hline Califow, seth WT, scth & Best Fit Kest Fit)-(WT) \\
\hline
\end{tabular}

\begin{tabular}{|c|c|c|c|}
\hline 1.00 & 0.50 & 0.44 & -0.06 \\
\hline 2.70 & 1.50 & 1.46 & -0.04 \\
\hline 4.16 & 2.50 & 2.34 & -0.16 \\
\hline 4.25 & 2.50 & 2.40 & -0.10 \\
\hline 2.91 & 1.50 & 1.59 & 0.09 \\
\hline 1.01 & 0.50 & 0.44 & -0.06 \\
\hline 1.14 & 0.50 & 0.52 & 0.02 \\
\hline 2.96 & 1.50 & 1.62 & 0.12 \\
\hline 4.49 & 2.50 & 2.54 & 0.04 \\
\hline 4.50 & 2.50 & 2.55 & 0.05 \\
\hline 2.89 & 1.50 & 1.58 & 0.08 \\
\hline 1.11 & 0.50 & 0.51 & 0.01 \\
\hline
\end{tabular}

RESPONSE (Wallace \& Tiernan, scfh)

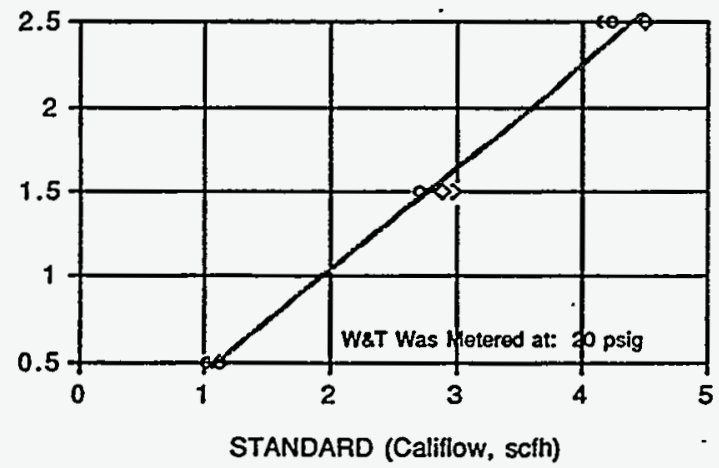

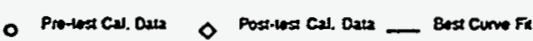

Pre-test Calibration: 10-01-96

Post-test Calibration: 03-10-97 Evaluation Date: 03-13-97

Post-test Calibration Results

\begin{tabular}{|c|c|c|c|}
\hline \pm & Califlow & & W\&T \\
\hline ounts & time, & $\mathrm{scfh}$ & \\
\hline 3080 & 50.3 & 1.14 & 50 \\
\hline 12929 & 19. & 2.96 & 1.50 \\
\hline 2536 & 12. & 4.49 & 2.50 \\
\hline 2707 & 12. & 4.50 & 2.50 \\
\hline 2789 & 19.3 & 2.89 & .50 \\
\hline 2804 & 50.2879 & 11 & \\
\hline
\end{tabular}

Average Ambient Temperature $=23^{\circ} \mathrm{C}$

Average Ambient Pressure $=756 \mathrm{mmHg}$ fit: Actual,scfh $=$ bo + bix(W\&T,scfh $)$

\begin{tabular}{|l|l|}
\multicolumn{2}{|c}{ for DAS } \\
\hline $\mathrm{b0}$ & $0.2962500 \ldots$ \\
\hline $\mathrm{p} 1$ & 1.6425 \\
\hline corr.coef. & $0.9952123 \ldots$ \\
\hline
\end{tabular}

fit: W\&T, scfh $=a 0+a 1 \times($ Actual, scth)

\begin{tabular}{|l|l|}
\multicolumn{2}{c}{ for statistics } \\
\hline $\mathrm{a} 0$ & $0.164313 \ldots$ \\
\hline 11 & $0.6030123 \ldots$ \\
\hline corr.coef. & $0.9952123 \ldots$ \\
\hline
\end{tabular}

STATISTICAL DATA

\begin{tabular}{|c|c|c|c|}
\hline $\mathbf{a}$ & \multicolumn{3}{|c|}{$0.164313 \ldots$} \\
\hline 5 & \multicolumn{3}{|c|}{$0.6030123 \ldots$} \\
\hline sex & \multicolumn{3}{|c|}{$0.0764182 \ldots$} \\
\hline MSE & \multicolumn{3}{|c|}{$0.0076418 \ldots$} \\
\hline Sxx & \multicolumn{3}{|l|}{21.7906} \\
\hline $\operatorname{sum}\left(X i^{\wedge} 2\right)$ & \multicolumn{3}{|l|}{113.2018} \\
\hline $\operatorname{avg}(X)$ & \multicolumn{3}{|l|}{2.76} \\
\hline \multicolumn{2}{|c|}{ Degrees Freedom } & \multirow{2}{*}{\multicolumn{2}{|c|}{10}} \\
\hline \multicolumn{2}{|c|}{ (95\% confidence) } & & \\
\hline \multicolumn{2}{|c|}{ Test Statistic. $T$} & 32.200 & \\
\hline \multicolumn{2}{|c|}{ W\&T: Uncert.,Wy low } & 0.216 & \\
\hline \multicolumn{2}{|c|}{ W\&T: Uncert.,WY high } & 0.215 & \\
\hline \multicolumn{2}{|c|}{ Curve Fit: Uncert.,We } & 0.357 & \\
\hline \multicolumn{2}{|c|}{ Cal. Equip. Uncert.Wc } & 0.019 & \\
\hline \multicolumn{2}{|c|}{ Total Uncertainty, Wt } & $0.36 \mathrm{scf}$ & \\
\hline
\end{tabular}


Final Report: Full-scale Test of DWPF Advanced Liquid-level and

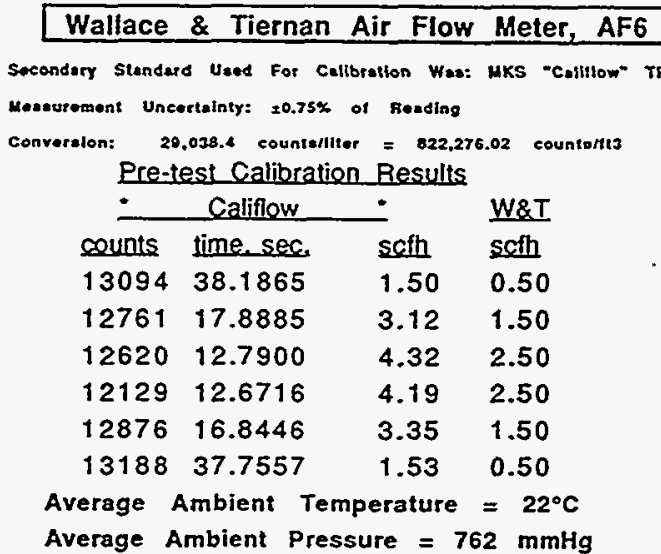

\begin{tabular}{|c|c|c|c|c|}
\hline Pre+Post & Pre+Post & & & \\
\hline Califow, scti & WT, scth & Best Fit & (Best & $F(t)-(W T)$ \\
\hline 1.50 & 0.50 & 0.44 & & -0.06 \\
\hline 3.12 & 1.50 & 1.50 & & -0.00 \\
\hline 4.32 & 2.50 & 2.28 & & -0.22 \\
\hline 4.19 & 2.50 & 2.20 & & -0.30 \\
\hline 3.35 & 1.50 & 1.65 & & 0.15 \\
\hline 1.53 & 0.50 & 0.46 & & -0.04 \\
\hline 1.54 & 0.50 & 0.46 & & -0.04 \\
\hline 3.54 & 1.50 & 1.77 & & 0.27 \\
\hline 4.64 & 2.50 & 2.49 & & -0.01 \\
\hline 4.72 & 2.50 & 2.54 & & 0.04 \\
\hline 3.51 & 1.50 & 1.75 & & 0.25 \\
\hline 1.55 & 0.50 & 0.47 & & -0.03 \\
\hline & & $\mathrm{kms} d$ & & $.16 \mathrm{scfh}$ \\
\hline
\end{tabular}

RESPONSE (Wallace \& Tiernan, scfh)

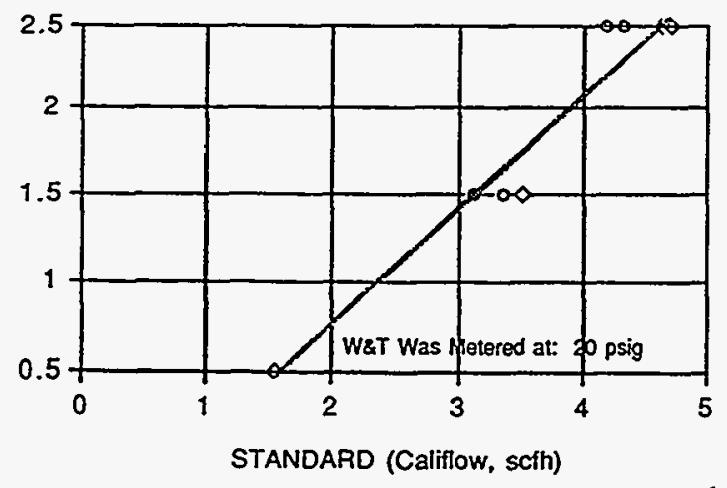

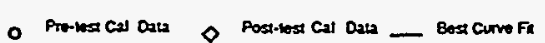

Pre-test Calibration: 10-01-96

Post-test Calibration: 03-11-97 Evaluation Date: 03-13-97

Post-test Calibration Results

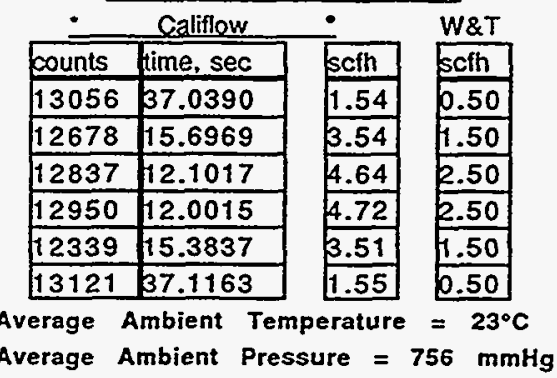

fit: Actual,scth $=$ bo + bix(W\&T,scfh)

\begin{tabular}{|l|l|}
\hline \multicolumn{2}{|c|}{ for DAS } \\
\hline 00 & $0.9227083 \ldots$ \\
\hline 01 & 1.46875 \\
\hline corr.coef. & $0.9805269 \ldots$ \\
\hline
\end{tabular}

fit: W\&T, $s c f h=a 0+a i x($ Actual, scfh)

\begin{tabular}{|l|l|}
\multicolumn{2}{|c}{ for statistics } \\
\hline 20 & $0.546147 \ldots$ \\
\hline 21 & $0.6545927 \ldots$ \\
\hline corr.coef. & $0.9805269 \ldots$ \\
\hline
\end{tabular}

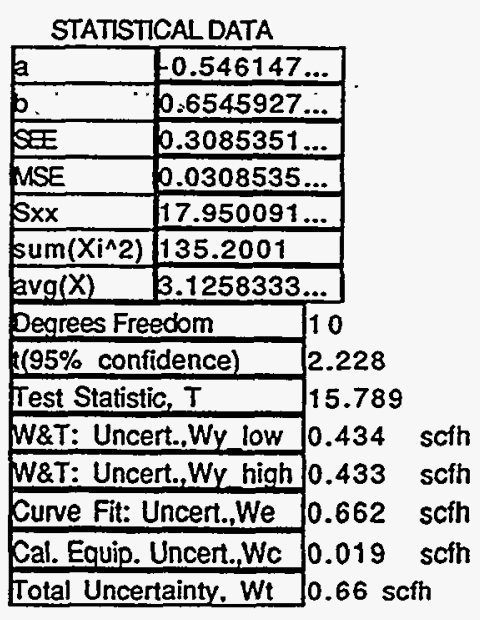


Final Report: Full-scale Test of DWPF Advanced Liquid-level and Density Measurement Bubblers (U)- WSRC-TR-97-0103, Rev. 0

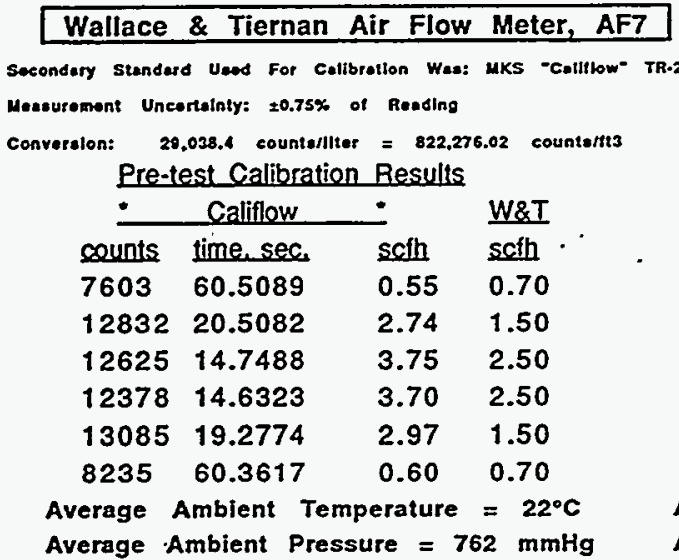

\begin{tabular}{|c|c|c|c|c|}
\hline Pre+Post & Pre+Post & & & \\
\hline Calfiow, sech & WT, scth & Best Fit & Kest & Fit)-(WT) \\
\hline 0.55 & 0.70 & 0.58 & & -0.12 \\
\hline 2.74 & 1.50 & 1.71 & & 0.21 \\
\hline 3.75 & 2.50 & 2.23 & & -0.27 \\
\hline 3.70 & 2.50 & 2.21 & & -0.29 \\
\hline 2.97 & 1.50 & 1.83 & & 0.33 \\
\hline 0.60 & 0.70 & 0.60 & & -0.10 \\
\hline 0.68 & 0.70 & 0.65 & & -0.05 \\
\hline 3.06 & 1.50 & 1.88 & & 0.38 \\
\hline 3.87 & 2.50 & 2.30 & & -0.20 \\
\hline 3.87 & 2.50 & 2.30 & & -0.20 \\
\hline 3.06 & 7.50 & 1.88 & & 0.38 \\
\hline \multirow[t]{2}{*}{0.68} & 0.70 & 0.65 & & -0.05 \\
\hline & & $\mathrm{ms}$ de & ion & $0.24^{\circ}$ scth \\
\hline
\end{tabular}

RESPONSE (Wallace \& Tieman, scfh)

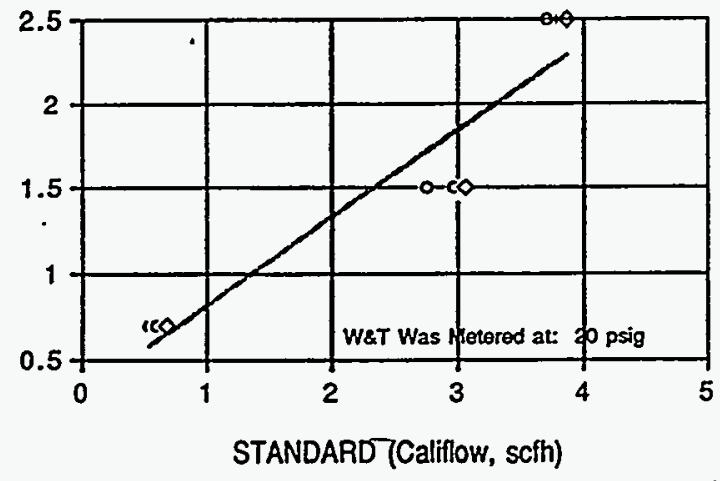

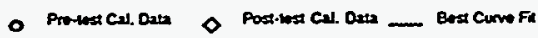

Pre-test Calibration: 10-01-96 Post-test Calibration: 03-10-97 Evaluation Date: 03-13-97

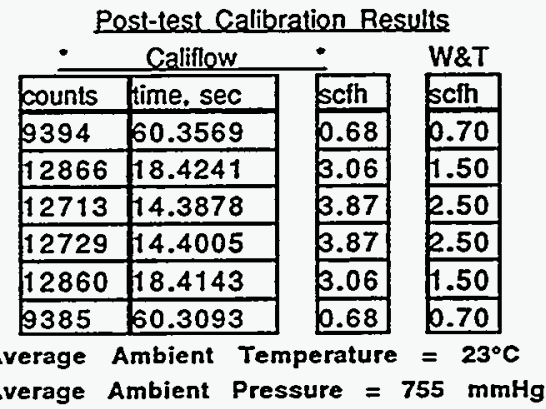

fit: Actual,scfh $=b 0+b 1 x(W \& T, s c f h)$

\begin{tabular}{|l|l|}
\hline \multicolumn{2}{|c|}{ for DAS } \\
\hline 00 & $0.239098 \ldots$ \\
\hline corr.coef. & $0.9440975 \ldots$ \\
\hline
\end{tabular}

fit: $W \& T, \operatorname{scfh}=a 0+a 1 \times($ Actual, scfh)

\begin{tabular}{|l|l|}
\multicolumn{2}{c}{ for statistics } \\
\hline 30 & $0.2939263 \ldots$ \\
\hline 31 & $0.5171989 \ldots$ \\
\hline corr.coef. & $0.9440975 \ldots$ \\
\hline
\end{tabular}

\begin{tabular}{|c|c|c|}
\hline \multicolumn{3}{|c|}{ STATISTICAL DATA } \\
\hline $\mathrm{a}$ & \multicolumn{2}{|c|}{$0.2939263 \ldots$} \\
\hline$b$ & \multicolumn{2}{|c|}{$0.5171989^{\circ} \ldots$} \\
\hline SE & \multicolumn{2}{|c|}{$0.7071429 \ldots$} \\
\hline MSE & \multicolumn{2}{|c|}{$0.0707142 \ldots$} \\
\hline$S \times x$ & \multicolumn{2}{|c|}{$21.680891 \ldots$} \\
\hline $\operatorname{sum}\left(\mathrm{Xi}^{\wedge} 2\right)$ & \multicolumn{2}{|l|}{94.3493} \\
\hline $\operatorname{avg}(X)$ & \multicolumn{2}{|c|}{$2.4608333 \ldots$} \\
\hline \multicolumn{2}{|c|}{ Degrees Freedom } & 10 \\
\hline \multicolumn{2}{|c|}{ (95\% confidence) } & 2.228 \\
\hline \multicolumn{2}{|c|}{ Test Statistic, T } & 9.056 \\
\hline \multicolumn{2}{|c|}{ W\&T: Uncert.,Wy low } & 0.663 \\
\hline \multicolumn{2}{|c|}{ W\&T: Uncert.,Wy high } & 0.642 \\
\hline \multicolumn{2}{|c|}{ Curve Fit: Uncert..We } & 1.242 \\
\hline \multicolumn{2}{|c|}{ Cal. Equip. Uncert.,Wc } & 0.019 \\
\hline \multicolumn{2}{|c|}{ Total Uncertainty, Wt } & 1.24 \\
\hline
\end{tabular}

i.e. Uncertainty When Using Cune Fil: $1.3 \mathrm{sc}$ h

Figure D9: Uncertainty Analysis, Air-flow Meters AF7 
Final Report: Full-scale Test of DWPF Advanced Liquid-level and Density Measurement Bubblers (U)- WSRC-TR-97-0103, Rev. 0

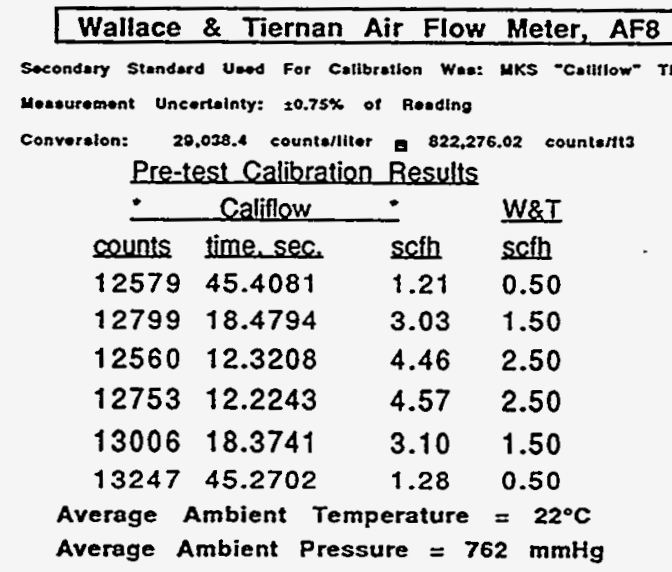

\section{\begin{tabular}{|l|l|}
\hline Pre+Post & Pre+Post \\
\hline
\end{tabular}}

\begin{tabular}{|l|l|l|}
\hline Califiow. sch & $W T$. sch & Best Fit (Best Fit)-(WT) \\
\hline
\end{tabular}

\begin{tabular}{|l|l|}
\hline 1.21 & 0.50 \\
\hline 3.03 & 1.50 \\
\hline 4.46 & 2.50 \\
\hline 4.57 & 2.50 \\
\hline 3.10 & 1.50 \\
\hline 1.28 & 0.50 \\
\hline 1.20 & 0.50 \\
\hline 3.30 & 1.50 \\
\hline 4.72 & 2.50 \\
\hline 4.72 & 2.50 \\
\hline 3.26 & 1.50 \\
\hline 1.21 & 0.50 \\
\hline
\end{tabular}

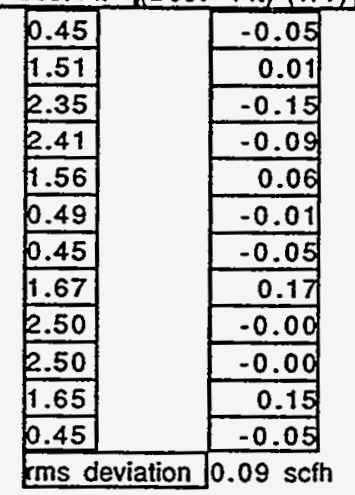

RESPONSE (Wallace \& Tieman, scth)

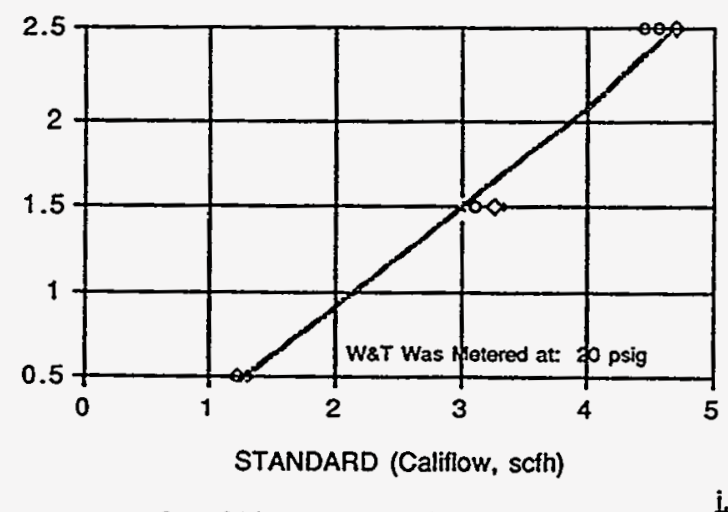

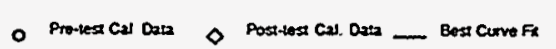

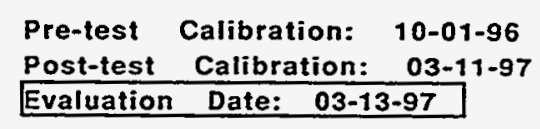

Post-test Calibration Results

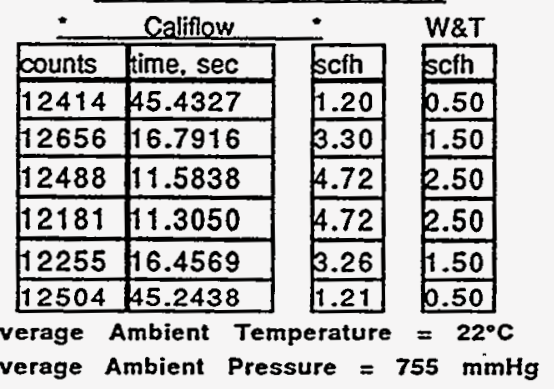

fit: Aciual,scfh $=$ bo + b1x(W\&T,scth $)$

\begin{tabular}{|l|l|}
\multicolumn{2}{c}{ for DAS } \\
\hline bo . & $0.4606249 \ldots$ \\
\hline b1 & 1.69625 \\
\hline corr.coef. & $0.9941864 \ldots$ \\
\hline
\end{tabular}

fit: W\&T, scfh $=a 0+a i x($ Actual, scfh)

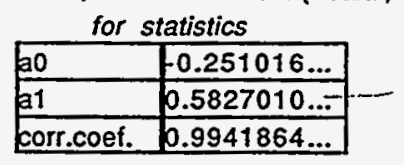

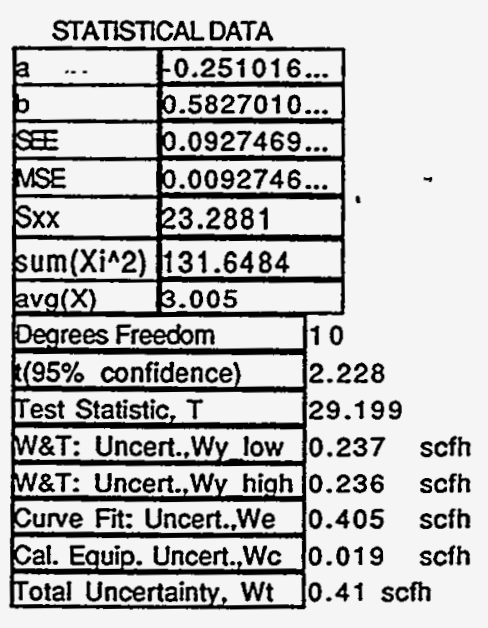

i.e. Uncertainty When Usine Curve Fit: $0.5 \mathrm{scth}$

Figure D10: Uncertainty Analysis, Air-flow Meters AF8 
Final Report: Full-scale Test of DWPF Advanced Liquid-level and

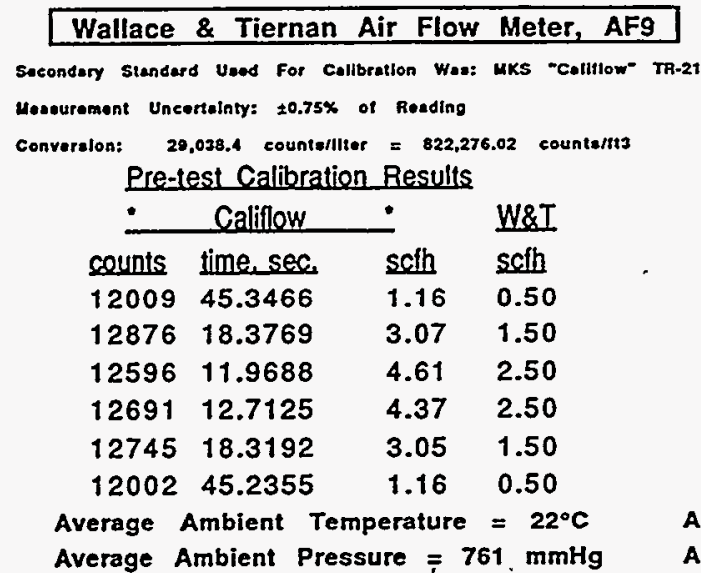

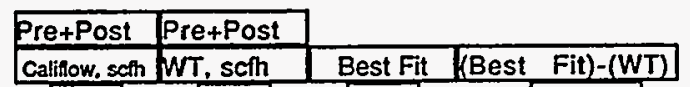

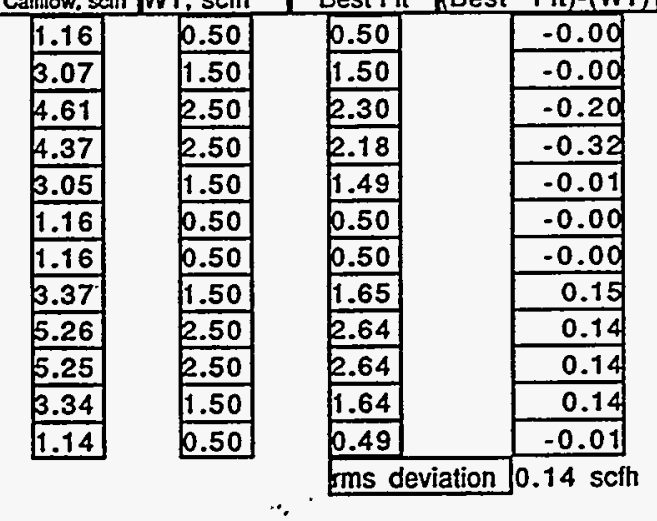

RESPONSE (Wallace \& Tieman, sc(ְ̨)

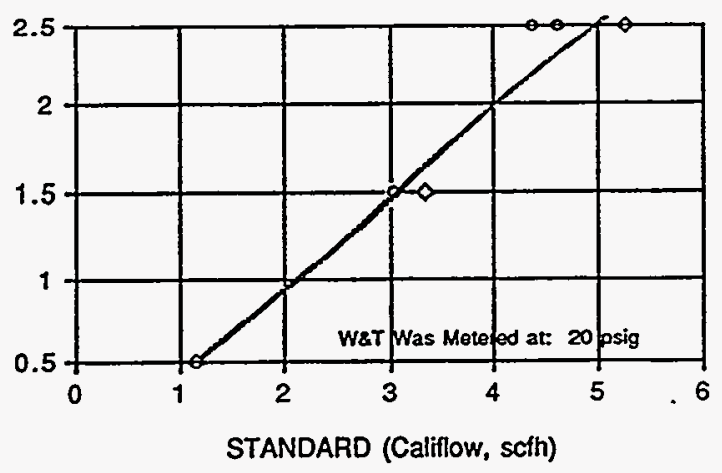

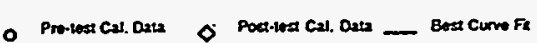

Pre-test Calibration: 10-01-96

Post-test Calibration: 03-11-97 Evaluation Date: 03-13-97

Pest-test Calibration Results

\begin{tabular}{|c|c|c|c|}
\hline - & Califlow & 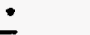 & W\&T \\
\hline counts & time, sec & scfh & scth \\
\hline 12086 & 45.6488 & 1.16 & 0.50 \\
\hline 12937 & 16.7904 & 3.37 & 1.50 \\
\hline 12397 & 10.3187 & 5.26 & 2.50 \\
\hline 12275 & 10.2316 & 5.25 & 2.50 \\
\hline 12482 & 16.3781 & 3.34 & 1.50 \\
\hline 11819 & 45.5378 & 1.14 & 0.50 \\
\hline
\end{tabular}

fit: Actual,scth $=$ bo + b1x $(W \& T, s c f h)$

\begin{tabular}{|l|l|}
\hline \multicolumn{2}{l}{ for $D A S$} \\
\hline 00 & $0.2902083 \ldots$ \\
\hline b1 & 1.85875 \\
\hline corr.coef. & $0.9857974 \ldots$ \\
\hline
\end{tabular}

fit: $W \& T, \operatorname{scth}=a 0+a 1 x($ Actual, $s c f h)$

\begin{tabular}{|l|l|}
\multicolumn{2}{l}{ for statistics } \\
\hline 20 & $0.109422 \ldots$ \\
\hline 21 & $0.5228226 \ldots$ \\
\hline Eorr.coef. & $0.9857974 \ldots$ \\
\hline
\end{tabular}

\begin{tabular}{|c|c|c|c|}
\hline \multicolumn{2}{|c|}{ STATISTICALDATA } & & \\
\hline a & \multicolumn{3}{|l|}{$-0.109422 \ldots$} \\
\hline$b$ & \multicolumn{3}{|c|}{$0.5228226 \ldots$} \\
\hline SeE & \multicolumn{3}{|c|}{$0.2256271 \ldots$} \\
\hline MSE & \multicolumn{3}{|c|}{$0.0225627 \ldots$} \\
\hline $5 \times x$ & \multicolumn{3}{|c|}{$28.441766 \ldots$} \\
\hline $\operatorname{sum}\left(X i^{\wedge} 2\right)$ & \multicolumn{3}{|l|}{142.1554} \\
\hline $\operatorname{avg}(X)$ & \multicolumn{3}{|c|}{$3.0783333 \ldots$} \\
\hline \multicolumn{2}{|c|}{ Degrees Freedom } & 10 & \\
\hline \multicolumn{2}{|c|}{ (95\% confidence) } & 2.228 & \\
\hline \multicolumn{2}{|c|}{ Test Statistic, $T$} & 18.563 & \\
\hline \multicolumn{2}{|c|}{ W\&T: Uncert..Wy low } & $0.369^{\circ}$ & scfh \\
\hline \multicolumn{2}{|c|}{ W\&T: Uncert.,Wy high } & 0.374 & $\operatorname{scfh}$ \\
\hline \multicolumn{2}{|c|}{ Curve Fit: Uncert..We } & 0.716 & $\operatorname{scfh}$ \\
\hline \multicolumn{2}{|c|}{ Cal. Equip. Uncert.Wc } & 0.019 & \\
\hline \multicolumn{2}{|c|}{ Total Uncertainty, Wt } & $0.72 \mathrm{~s}$ & \\
\hline
\end{tabular}

i.e. Uncertainty When Using Curve Fit: $0.8 \mathrm{scth}$

Figure D11: Uncertainty Analysis, Air-flow Meters AF9 
Final Report: Full-scale Test of DWPF Advanced Liquid-level and

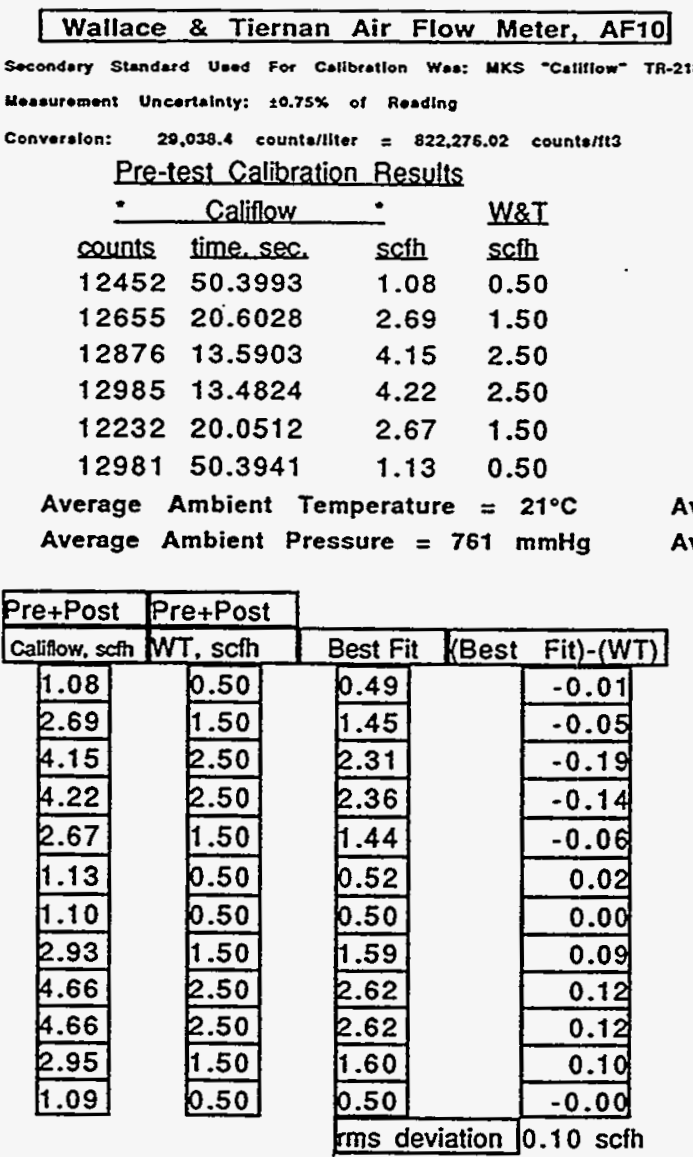

RESPONSE (Wallace \& Tieman, scfh)

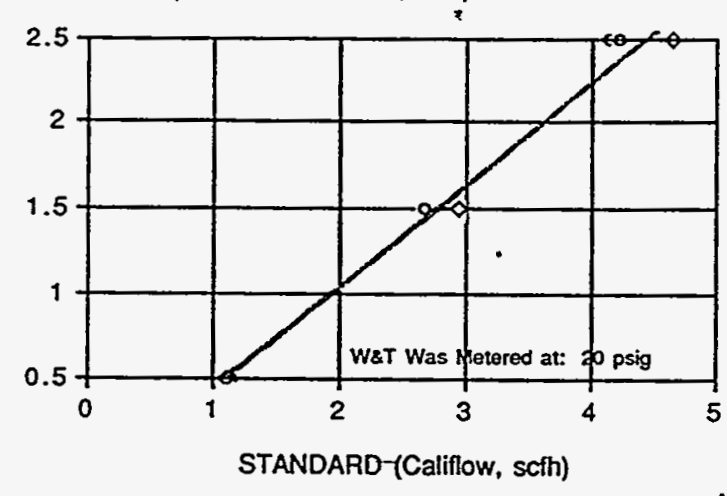

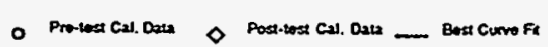

Pre-test Calibration: 10-01-96

Post-test Calibration: 03-11-97

Evaluation Date: 03-13-97

Post-test Calibration Results

\begin{tabular}{|c|c|c|c|}
\hline 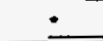 & Califiow & • & W\&T \\
\hline ounts & time, sec & scth & scfh \\
\hline 26 & 50. & 1.10 & 0.50 \\
\hline 28 & 119. & 2.93 & 1.50 \\
\hline 126 & 11. & 4.66 & 2.50 \\
\hline 12285 & 11.5 & 4.66 & 2.50 \\
\hline 29 & 19.2 & 2.95 & 1.50 \\
\hline 2505 & 50.1777 & 1.09 & 0.50 \\
\hline
\end{tabular}

Average Ambient Temperature $=22^{\circ} \mathrm{C}$

Average Ambient Pressure $=755 \mathrm{mmHg}$

fit: Actual,scfh $=b 0+b 1 \times(W \& T, s c h)$

\begin{tabular}{|l|l|}
\multicolumn{2}{c}{ for DAS } \\
\hline bo & $0.2856249 \ldots$ \\
\hline b1 & 1.66125 \\
\hline corr.coef. & $0.9931897 \ldots$ \\
\hline
\end{tabular}

fit: $W \& T, s c f h=a 0+a 1 \times($ Actual, scfh)

\begin{tabular}{|l|l|}
\multicolumn{2}{|c}{ for statistics } \\
\hline $\mathrm{a} 0$ & $0.149238 \ldots$ \\
\hline $\mathrm{a} 1$ & $0.5937853 \ldots$ \\
\hline corr.coef. & $0.9931897 \ldots$ \\
\hline
\end{tabular}

\begin{tabular}{|c|c|c|c|}
\hline \multicolumn{2}{|c|}{ STATISTICAL DATA } & & \\
\hline $\mathrm{a}$ & \multicolumn{3}{|c|}{$0.149238 \ldots$} \\
\hline b & \multicolumn{3}{|c|}{$0.5937853 \ldots$} \\
\hline sif & \multicolumn{3}{|c|}{$0.1085925 \ldots$} \\
\hline MSE & \multicolumn{3}{|l|}{$0.0108592 \ldots$} \\
\hline $5 \times x$ & \multicolumn{3}{|l|}{22.381825} \\
\hline $\operatorname{sum}\left(X_{i \wedge} 2\right)$ & \multicolumn{3}{|l|}{114.9559} \\
\hline $\operatorname{avg}(X)$ & \multicolumn{3}{|l|}{2.7775} \\
\hline \multicolumn{2}{|c|}{ Degrees Freedom } & 10 & \\
\hline \multicolumn{2}{|c|}{ (95\% confidence) } & 2.228 & \\
\hline \multicolumn{2}{|c|}{ Test Statistic, $T$} & 26.957 & \\
\hline \multicolumn{2}{|c|}{ W\&T: Uncert.,Wy low } & 0.256 & scth \\
\hline \multicolumn{2}{|c|}{ W\&T: Uncert.,Wy high } & 0.259 & safh \\
\hline \multicolumn{2}{|c|}{ Curve Fit: Uncert.,We } & 0.436 & $\operatorname{sefh}$ \\
\hline \multirow{2}{*}{\multicolumn{2}{|c|}{$\begin{array}{l}\text { Cal. Equip. Uncert.,Wc } \\
\text { Total Uncertainty, Wt }\end{array}$}} & 0.019 & sct \\
\hline & & $0.44 \mathrm{sc}$ & \\
\hline
\end{tabular}


Final Report: Full-scale Test of DWPF Advanced Liquid-level and

Wallace \& Tiernan Air Flow Meter, AF11

Socondary Stenderd Usod for Callbretion Hes: MKS "Cellliow" TR-2180

Messurement Uncertalnty: $\pm 0.75 \times$ of Resding

Converelon: 29,038.4 counts/liter $=822,276.02$ counts/tis Pre-test Calibration Results

- Califlow $\quad$ W\&T

counts "time sec sch

$\begin{array}{llll}11841 \quad 45.4076 & 1.14 & 0.50\end{array}$

$\begin{array}{llll}12987 & 18.6225 & 3.05 & 1.50\end{array}$

$\begin{array}{llll}12873 & 13.3611 & 4.22 & 2.50\end{array}$

$\begin{array}{llll}12895 & 13.1815 & 4.28 & 2.50\end{array}$

$\begin{array}{llll}13109 & 17.6427 & 3.25 & 1.50\end{array}$

$\begin{array}{llll}12721 & 45.3108 & 1.23 & 0.50\end{array}$

Average Ambient Temperature $=22^{\circ} \mathrm{C}$

Average Ambient Pressure $=760 \mathrm{mmHg}$

\section{Pre+Post Pre+Post}

\begin{tabular}{|l|l|l|}
\hline Califlow, scth WT, scfh & Best Fit Kest Fit)-(WT) \\
\hline
\end{tabular}

3.05

4.22

4.28

3.25

1.23

1.21

3.45

4.79

4.80

3.45

1.20

0.50

1.50

2.50

2.50

1.50

0.50

0.50

1.50

2.50

2.50

1.50

0.50

0.42

1.53

2.23

1.64

0.48

0.46

1.76

2.53

2.53

1.76

0.46

Ims deviation $0.16^{\circ} \mathrm{scfh}$

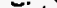

RESPONSE (Wallace \& Tieman, scth)

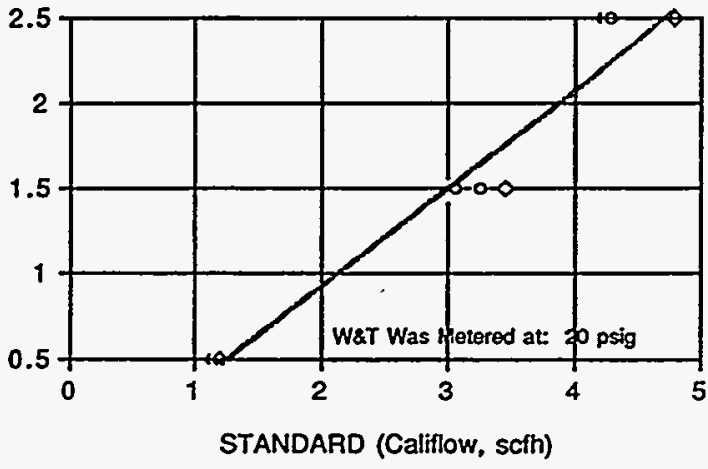

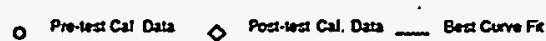

Pre-test Calibration: $\quad$ 0-01-96

Post-test Calibration: 03-11-97 Evaluation Date: 03-13-97

Post-test Calibration Results

\begin{tabular}{|c|c|c|c|}
\hline - & Califlow & $\dot{\square}$ & W\&T \\
\hline counts & fime. sec & scfh & scth \\
\hline 12486 & 45.3623 & 1.21 & b.50 \\
\hline 12858 & 16.3037 & 3.45 & 1.50 \\
\hline 12652 & 11.5659 & 4.79 & 2.50 \\
\hline 12286 & 11.2144 & 4.80 & 2.50 \\
\hline 12816 & 16.2635 & 3.45 & 1.50 \\
\hline 12401 & 45.2797 & 1.20 & 0.50 \\
\hline
\end{tabular}

Average Ambient Temperature $=22^{\circ} \mathrm{C}$

Average Ambient Pressure $=755 \mathrm{mmHg}$ fit: Actual,scfh $=b 0+b 1 \times(W \& T, s c f h)$

for DAS

\begin{tabular}{|l|l|}
\hline 60 & $0.5102083 \ldots$ \\
\hline 01 & 1.66375 \\
\hline corr.coef. & $0.9795858 \ldots$ \\
\hline
\end{tabular}

fit: $W \& T, s c t h=a 0+a t x(A c t u a l, s c f h)$

\begin{tabular}{|l|l|}
\multicolumn{2}{c}{ for statistics } \\
\hline ao & $0.233651 \ldots$ \\
\hline at & $0.5767624 \ldots$ \\
\hline corr.coef. & $0.9795858 \ldots$ \\
\hline
\end{tabular}

STÄTISTICAL DATA

\begin{tabular}{|l|l|}
\hline 2 & $0.233651 \ldots$ \\
\hline L... & $0.5767624 \ldots$ \\
\hline MSE & $0.3232917 \ldots$ \\
\hline SXX & $0.0323291 \ldots$ \\
\hline sum(Xi^2) & 131.4975 \\
\hline $\operatorname{avg}(X)$ & $3.0058333 \ldots$ \\
\hline
\end{tabular}

Degrees Freedom 10

(95\% confidence) 2.228

Test Statistic, $T$

W\&T: Uncert.,Wy low 0.445 scth

W\&T: Uncert.,Wy high 0.443 scfh

Curve Fit: Uncert..We 0.768 scth

Cal. Equip. Uncert.Wc 0.019 scth

Total Uncertainty, Wt $0.77 \mathrm{scfh}$

Figure D13: Uncertainty Analysis, Air-flow Meters AF11 
Final Report: Full-scale Test of DWPF Advanced Liquid-level and Density Measurement Bubblers (U)- WSRC-TR-97-0103, Rev. 0

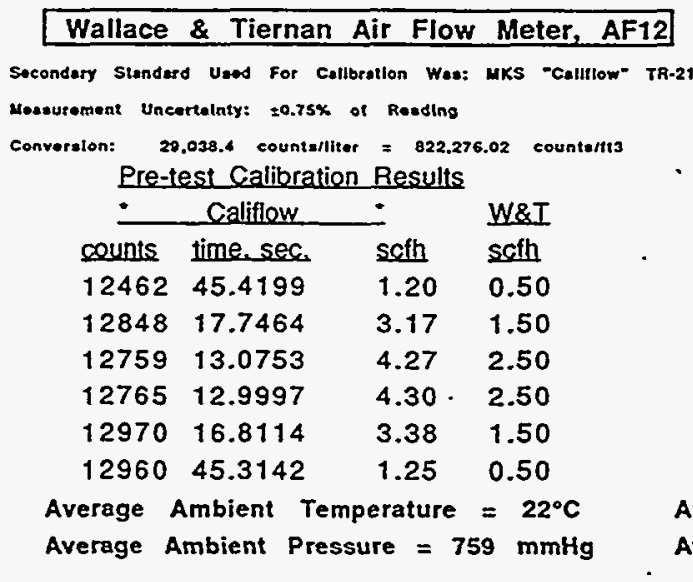

Pre+Post Pre+Post \begin{tabular}{|c|c|c|c|}
\hline Calfiow, sefh WT, scth & Best Fit (Best Fit)-(WT) \\
\hline
\end{tabular}

\begin{tabular}{|c|c|c|c|}
\hline 1.20 & 0.50 & 0.44 & -0.06 \\
\hline 3.17 & 1.50 & 1.58 & 0.08 \\
\hline 4.27 & 2.50 & 2.22 & -0.28 \\
\hline 4.30 & 2.50 & 2.23 & -0.27 \\
\hline 3.38 & 1.50 & 1.70 & 0.20 \\
\hline 7.25 & 0.50 & 0.47 & -0.03 \\
\hline 1.20 & 0.50 & 0.44 & -0.06 \\
\hline 3.40 & 1.50 & 1.71 & 0.21 \\
\hline 4.82 & 2.50 & 2.53 & 0.03 \\
\hline 4.82 & 2.50 & 2.53 & 0.03 \\
\hline 3.34 & 1.50 & 1.68 & 0.18 \\
\hline 1.20 & 0.50 & 0.44 & -0.06 \\
\hline
\end{tabular}

RESPONSE (Wallace \& Tieman, scfh),

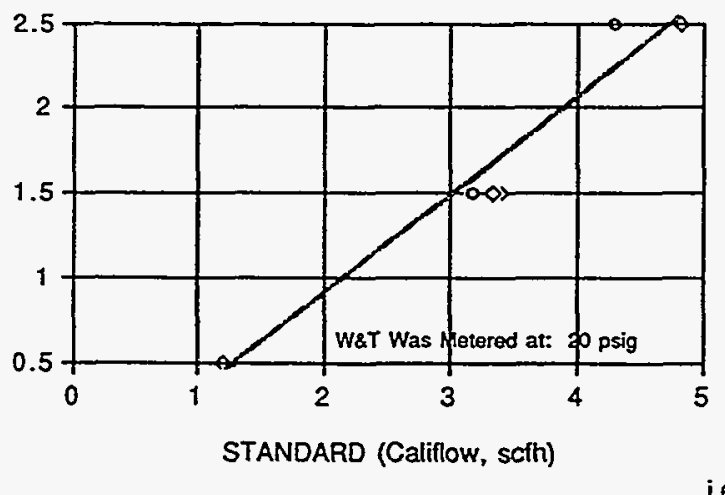

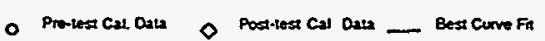

Pre-test Calibration: 10-01-96

Post-test Calibration: 03-11-97 Evaluation Date: 03-13-97

\begin{tabular}{|c|c|c|c|}
\hline \multicolumn{4}{|c|}{ Post-test Calibration Results } \\
\hline • & Califiow & 送 & W\&T \\
\hline counts & time, sec & $\operatorname{sefh}$ & $\operatorname{scth}$ \\
\hline 12457 & 45.3848 & 1.20 & 0.50 \\
\hline 12853 & 16.5595 & 3.40 & 1.50 \\
\hline 12719 & 11.5436 & 4.82 & 2.50 \\
\hline 12368 . & 11.2238 & 4.82 & 2.50 \\
\hline 12426 & 16.2658 & 3.34 & 1.50 \\
\hline 12511 & 45.7692 & 1.20 & 0.50 \\
\hline & & iture & $=22$ \\
\hline & & & \\
\hline
\end{tabular}

fit: Actual,sch $=b 0+b 1 x(W \& T, s c f h)$ for DAS

\begin{tabular}{|l|l|}
\hline $\mathrm{b0}$ & $0.5241666 \ldots$ \\
\hline 01 & 1.67 \\
\hline corr.coef. & $0.9817397 \ldots$ \\
\hline
\end{tabular}

fit: W\&T, scfh $=a 0+a \nmid x$ (Actual, scih)

\begin{tabular}{|l|l|}
\hline for statistics \\
\hline a0 & $0.248233 \ldots$ \\
\hline a1 & $0.5771334 \ldots$ \\
\hline corr.coef. & $0.9817397 \ldots$ \\
\hline
\end{tabular}

STATISTICAL DATA

\begin{tabular}{|c|c|c|c|}
\hline \multicolumn{4}{|c|}{ STATISTICALDATA } \\
\hline $\mathrm{a}$ & \multicolumn{3}{|c|}{$0.248233 \ldots$} \\
\hline b & \multicolumn{3}{|c|}{$0: 5771334 \ldots$} \\
\hline SEE & \multicolumn{3}{|c|}{$0.2894969 \ldots$} \\
\hline MSE & \multicolumn{3}{|c|}{$0.0289496 \ldots$} \\
\hline$S x x$ & \multicolumn{3}{|c|}{$23.148891 \ldots$} \\
\hline $\operatorname{sum}\left(x i^{\wedge} 2\right)$ & \multicolumn{3}{|l|}{133.2591} \\
\hline $\operatorname{avg}(X)$ & \multicolumn{3}{|c|}{$3.0291666 \ldots$} \\
\hline \multicolumn{2}{|c|}{ Degrees Freedom } & \multirow{2}{*}{\multicolumn{2}{|c|}{$\begin{array}{l}10 \\
2.228\end{array}$}} \\
\hline \multicolumn{2}{|c|}{ (195\% confidence) } & & \\
\hline \multicolumn{2}{|c|}{ Test Statistic, $T$} & 16.320 & \\
\hline \multicolumn{2}{|c|}{ W\&T: Uncert..Wy low } & 0.420 & $\operatorname{scfh}$ \\
\hline \multicolumn{2}{|c|}{ W\&T: Uncert.,Wy high } & 0.419 & scth \\
\hline \multicolumn{2}{|c|}{ Curve Fit: Uncert..We } & 0.726 & scfh \\
\hline \multicolumn{2}{|c|}{ Cal. Equip. Uncert.,Wc } & 0.019 & scth \\
\hline \multicolumn{2}{|c|}{ Total Uncertainty, Wt } & $0.73 \mathrm{scf}$ & \\
\hline
\end{tabular}

ie. Uncertainty When Using Curve Fil: 0.8 safh

Figure D14: Uncertainty Analysis, Air-flow Meters AF12 
Final Report: Full-scale Test of DWPF Advanced Liquid-level and

\begin{tabular}{|c|c|}
\hline \multicolumn{2}{|c|}{ Noshok Air } \\
\hline \multirow{2}{*}{\multicolumn{2}{|c|}{$\begin{array}{l}\text { Socondary Standerd UEC } \\
\text { Mousuremont Uncortahoty }\end{array}$}} \\
\hline & \\
\hline & Post-test \\
\hline \multirow{2}{*}{\multicolumn{2}{|c|}{$\begin{array}{r}\text { Average A } \\
(29.80+29.78+29\end{array}$}} \\
\hline & \\
\hline \multicolumn{2}{|c|}{ - Standard - } \\
\hline In.Hga & In. $\mathrm{H} 2 \mathrm{Og}$ \\
\hline 29.8 & 0.1 \\
\hline 33.5 & 50.5 \\
\hline 37.2 & 100.8 \\
\hline 40.8 & 149.8 \\
\hline 44.5 & 200.2 \\
\hline 44.5 & 200.2 \\
\hline 40.8 & 149.8 \\
\hline 37.2 & 100.8 \\
\hline 33.5 & 50.5 \\
\hline 29.8 & -0.1 \\
\hline 29.8 & 0.1 \\
\hline 33.5 & 50.5 \\
\hline 37.2 & 100.8 \\
\hline 40.8 & 149.8 \\
\hline 44.5 & 200.2 \\
\hline 44.5 & 200.2 \\
\hline 40.8 & 149.8 \\
\hline 37.2 & 100.8 \\
\hline 33.5 & 50.5 \\
\hline 29.8 & 0.0 \\
\hline
\end{tabular}

Pre-test Calibration: 10-15-96 Post-test Calibration: 03-12-97 Evaluation. Date: 03-21-97

Pre-test Calibration Results

A cursory check before testing showed that all gauges indicated within \pm 2 in. $\mathrm{H} 2 \mathrm{O}$ of a standard.

Therefore the Pre-Cal. Data Relation is:

Noshoh $=1 \times$ (Standard), $\pm 2 \ln . \mathrm{H} 2 \mathrm{O}$

fit: Standard,In. $\mathrm{H} 2 \mathrm{Og}=\mathrm{bO}+\mathrm{b} 1 \times($ Noshok, In. $\mathrm{H} 2 \mathrm{Og})$

\begin{tabular}{|l|l|}
\hline \multicolumn{2}{|c|}{ for DAS } \\
\hline bo & 1.723377 \\
\hline corr.coef. & 0.988266 \\
\hline
\end{tabular}

fit: Noshok, In. $\mathrm{H} 2 \mathrm{Og}=\mathrm{a} 0+\mathrm{a} \times(\mathrm{Standard}$, In. $\mathrm{H} 2 \mathrm{Og})$ for statistics

\begin{tabular}{|l|l|}
\hline a0 & 2.9695672 \\
\hline 21 & 0.7139174 \\
\hline corr.coef. & 0.9882664 \\
\hline
\end{tabular}

POST CALBRATIONSTATISTICAL DATA

\begin{tabular}{|l|l|}
\hline $\mathrm{Q}$ & 2.96956717 \\
\hline SEx & 0.71391739 \\
\hline MSE. & 1216.47177 \\
\hline SXX.. & 67.581 .7648 \\
\hline
\end{tabular}

99918.9177

$\operatorname{sum}\left(X i^{\wedge} 2\right) 300977.545$

\begin{tabular}{l|l}
\hline $\operatorname{avg}(X)$ & 100.2643075 \\
\hline
\end{tabular}

Degrees Freedom 18

(95\% confidence) 2.101

Test Statistic, $T$

W\&T: Uncert.Wy low 18.529 in.H2O

W\&T: Uncert.Wy high 18.522 In.H2O

Curve Fit: Uncert.We 25.943 in.H2O

Cal. Equip. Uncert.,Wc 4.000 in.H2O

Total Uncertainty, Wt 26.25 In.H2O

STANDARD (Sensotec, In. H2Og)

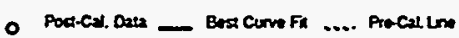


Final Report: Full-scale Test of DWPF Advanced Liquid-level and

Page 74 of 84

Density Measurement Bubblers (U)- WSRC-TR-97-0103, Rev. 0

\footnotetext{
Noshok Air Pressure Gauge, AP2

socondery standard uned For Callbestion Was: SEHSOTEC TR-1503

Mesuurement Uncertalnty: $=2 \times$ of Roeding
}

Post-test Calibration Resulls

Average Ambient Pressure $=$ $(29.79+29.78+29.77) / 3=29.78$ In. Hga.

In.Hga In. $\mathrm{H} 2 \mathrm{Og}$

$29.8 \quad 0.1$

$33.5 \quad 50.6$

$37.2 \quad 101.0$

$40.8 \quad 150.0$

$44.5 \quad 200.3$

$44.5 \quad 200.3$

$40.8 \quad 150.0$

$37.2 \quad 101.0$

$33.5 \quad 50.6$

$29.8 \quad 0.0$

$29.8 \quad 0.0$

$33.5 \quad 50.6$

$37.2 \quad 101.0$

$40.8 \quad 150.0$

$44.5 \quad 200.3$

$44.5 \quad 200.3$

$40.8 \quad 150.0$

$37.2 \quad 101.0$

33.5

29.8

50.6

$-0.1$
In.H2Og Best Fit (Best Fit)-(Noshok)

\begin{tabular}{|l|l|l|l|}
\hline 0 & 4 & & 4 \\
\hline
\end{tabular} $37 \quad 37$

7470

$108 \quad 102$

134

132

104

76

42

0

38

74

105

129

128

102

74

40

$\frac{40}{6}$

135

135

102

70

37

4

4

37

70

102

135

135

102

70

37

4 ms deviation

RESPONSE (Noshok, In. $\mathrm{H} 2 \mathrm{Og}$ )

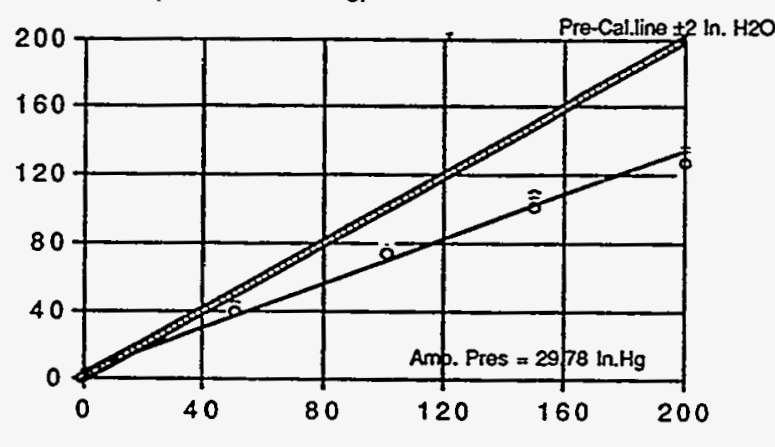

Pre-test Calibration: 10-15-96

Post-test Calibration: 03-12-97 Evaluation Date: 03-21-97

Pre-test_Calibration Results

A cursory check before lesting showed that all gauges indicated within \pm 2 in. $\mathrm{H} 2 \mathrm{O}$ of a standard.

Therefore the Pre-Cal. Data Relation is:

. Noshoh $=1 \times$ (Standard), $\pm 2 \ln . \mathrm{H} 2 \mathrm{O}$

Standard, In. $\mathrm{H} 2 \mathrm{Og}=\mathrm{b} 0+\mathrm{b} 1 \times($ Noshok,In. $\mathrm{H} 2 \mathrm{Og})$

\begin{tabular}{|l|l|}
\multicolumn{2}{|c|}{ for DAS } \\
\hline 00 & 5.601736 \\
\hline 61 & 1.517276 \\
\hline corr.coef. & 0.996265 \\
\hline
\end{tabular}

fit: Noshok, In. $\mathrm{H} 2 \mathrm{Og}=\mathrm{a0}+\mathrm{a} 1 \times($ Standard, In.H2Og) for statistics

\begin{tabular}{|l|l|}
\hline ao & 4.1853086 \\
\hline a1 & 0.6541612 \\
\hline corr.coef. & 0.9962645 \\
\hline
\end{tabular}

POST CALBRATION STATISTICALDATA

\begin{tabular}{|l|l|}
\hline & 4.18530862 \\
\hline & 0.65416121 \\
\hline MSE & 321.50449 \\
\hline SXX & 17.8613604 \\
\hline
\end{tabular}

\begin{tabular}{l|l}
\hline $\operatorname{sum}\left(X j^{\wedge} 2\right)$ & 301523.658
\end{tabular}

\begin{tabular}{l|l}
$\operatorname{avg}(X)$ & 100.379984 \\
\hline
\end{tabular}

Degrees Freedom 18

(95\% confidence)

2.101

Test Statistic, $T$ 48.947

W\&T: Uncert. Wy low 9.526 In.H2O

W\&T: Uncert.,Wy high 9.522 In.H2O

Curve Fit: Uncert.We 14.555 in.H2O

Cal. Equip. Uncert.,Wc 4.000 in. $\mathrm{H} 2 \mathrm{O}$

Total Uncertainty. Wt 15.10 in.H2O

STANDARD (Sensotec, in. H2Og)

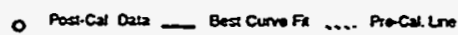

Figure D16: Uncertainty Analysis, Air Pressure Gauge AP2 
Final Report: Full-scale Test of DWPF Advanced Liquid-level and

Noshok Air Pressure Gauge, AP3

socondery stenderd Uaod for Celltrotlon was: 'SENSOTEC YR-1503

Hoseuremont Uncertolnty: $\pm 2 x$ of Rosding

Post-test Calibration Results

Average Ambient Pressure $=$

$(29.80+29.78+29.79) / 3=29.79$ In. Hga

- Standard - Noshok

In. Hga $\ln . \mathrm{H} 2 \mathrm{Og}$

$29.8 \quad 0.1$

$33.5 \quad 50.5$

$37.2 \quad 100.8$

$40.8 \quad 149.8$

44.5

44.5

40.8

37.2

33.5

29.8

29.8

33.5

37.2

40.8

44.5

44.5

40.8

37.2

33.5

29.8

200.2

200.2 .

149.8

100.8

50.5

$-0.1$

0.1

50.5

100.8

149.8

200.2

200.2

149.8

100.8

50.5

0.0
In.H2Og Best Fit (Best Fit)-(Noshok)

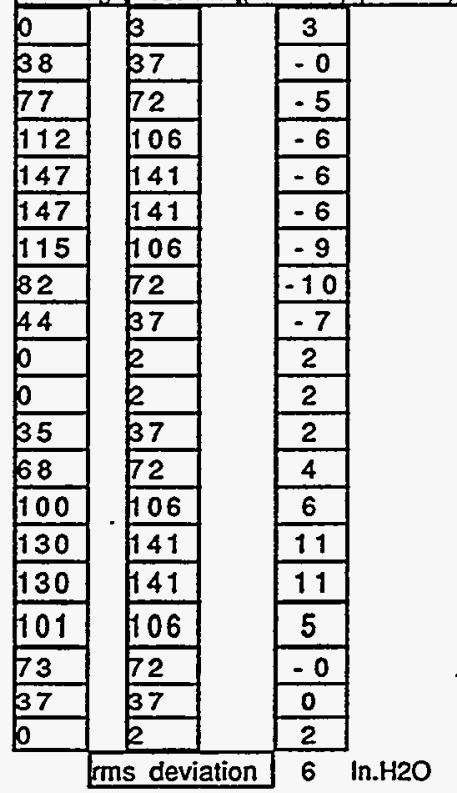

' RESPONSE (Noshok, In. H2Og)

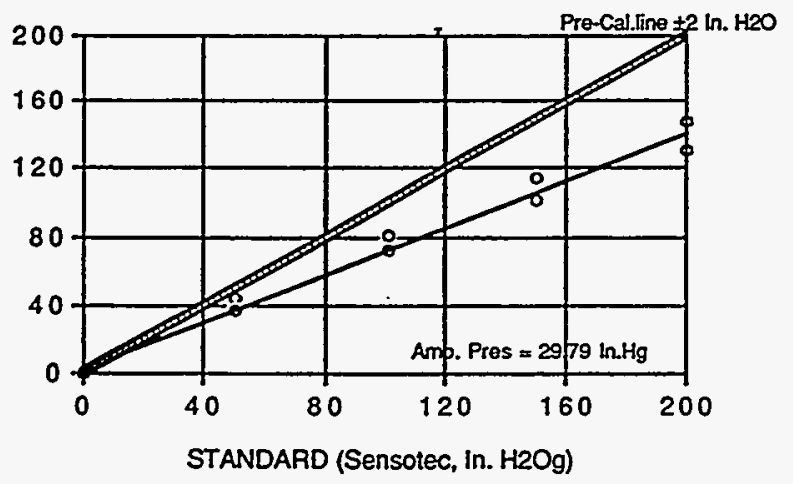

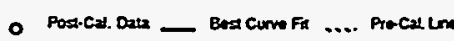

Pre-test Calibration: 10-15-96

Post-test Calibration: 03-12-97 Evaluation Date: 03-21-97

Pre-test Calibration Results

A cursory check before testing showed that all gauges indicated within \pm 2 in. $\mathrm{H} 2 \mathrm{O}$ of a standard.

Therefore the Pre-Cal. Data Relation is:

Noshoh = $1 \times$ (Standard), \pm 2 In. $\mathrm{H} 2 \mathrm{O}$

fit: Standard, In.H2Og = bO + b1x(Noshok, In. H2Og)

\begin{tabular}{|l|l|}
\hline b0 & -2.083811 \\
\hline b1 & 1.425461 \\
\hline corr.coef. & 0.992745 \\
\hline
\end{tabular}

fit: Noshok, In. $\mathrm{H} 2 \mathrm{Og}=\mathbf{a 0}+$ atx(Standard, In. $\mathrm{H} 2 \mathrm{Og})$

\begin{tabular}{|l|l|}
\multicolumn{2}{c}{ for statistics } \\
\hline a0 & 2.4787887 \\
\hline a1 & 0.6913847 \\
\hline corr.coef. & 0.9927448 \\
\hline
\end{tabular}

POST CALIBRATION STATISTICALDATA

\begin{tabular}{|l|l|}
\hline 2 & 2.47878866 \\
\hline$b$ & 0.69138473 \\
\hline SEI & 700.67369 \\
\hline MSE & 38.9263158 \\
\hline SXX & 99918.9177 \\
\hline
\end{tabular}

\begin{tabular}{ll|}
\hline $\operatorname{sum}\left(X i^{\wedge} 2\right)$ & 300977.545 \\
\hline
\end{tabular}

\begin{tabular}{|l|l|}
\hline $\operatorname{avg}(X)$ & 100.2643075 \\
\hline
\end{tabular}

Degrees Freedom 18

(95\% confidence) 2.101

\begin{tabular}{ll} 
Test Statistic, $T$ & \\
\hline
\end{tabular}

W\&T: Uncert.Wy low 14.063 in.H2O

W\&T: Uncert.,Wy high 14.057 In.H2O

Curve Fit: Uncert.,We 20.331 In.H2O

Cal. Equip. Uncert.,Wc 4.000 In.H2O

Total Uncertainty, Wt 20.72 In.H2O

i.e. Uncentainty in Post Cal. Cunee Fit:21 In.H2O

Figure D17: Uncertainty Analysis, Air Pressure Gauge AP3 
Final Report: Full-scale Test of DWPF Advanced Liquid-level and

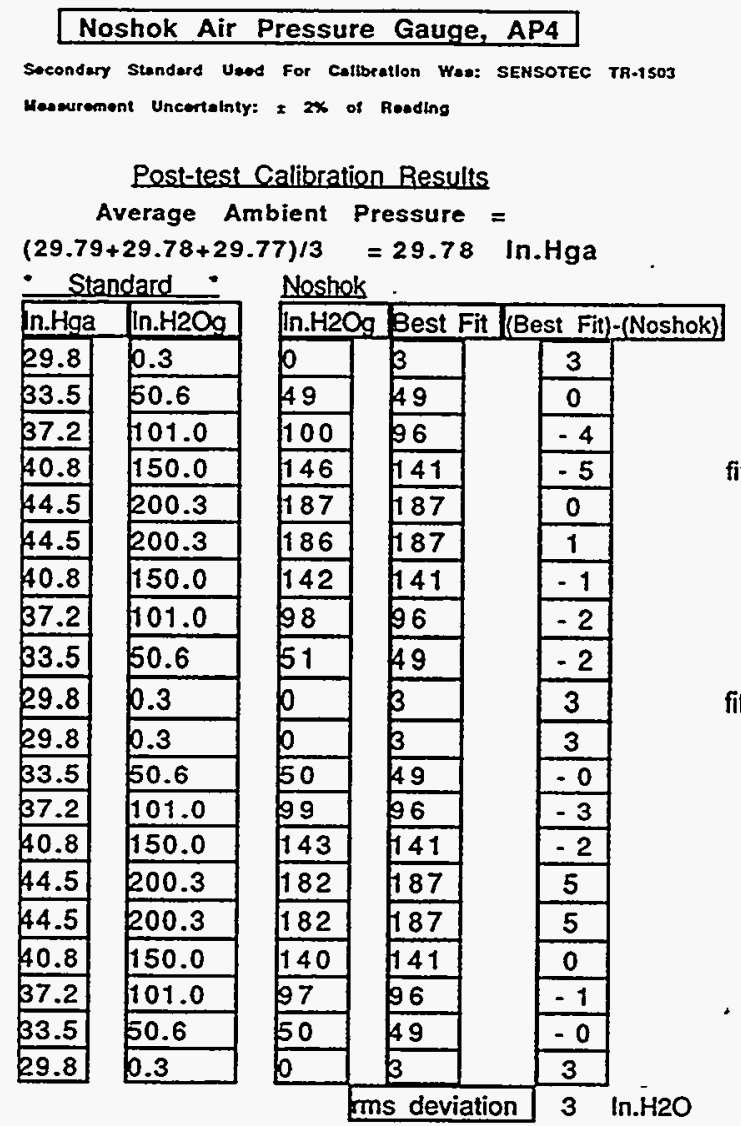

RESPONSE (Noshok, In. H2Og)

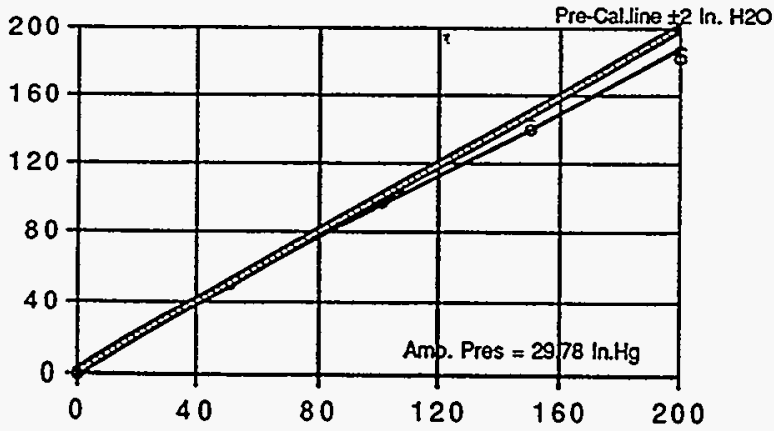

STANDARD (Sensotec, In. H2Og)

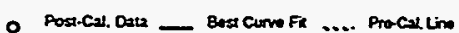

\section{Pre-test Calibration: 10-15-96 \\ Post-test Calibration: 03-12-97 Evaluation Date: 03-21-97}

Pre-test Calibration Results A cursory check before testing showed that alt gauges indicated within \pm 2 in. $\mathrm{H} 2 \mathrm{O}$ of a standard.

Therefore the Pre-Cal. Data Relation is: Noshoh $=1 \times$ (Standard), \pm 2 In.H2O

fit: Standard, $\ln . \mathrm{H} 2 \mathrm{Og}=\mathrm{bO}+\mathrm{b} 1 \times($ Noshok, $\ln \cdot \mathrm{H} 2 \mathrm{Og})$

\begin{tabular}{|l|l|}
\multicolumn{2}{c}{ for DAS } \\
\hline bo & 2.337290 \\
\hline 01 & 1.080670 \\
\hline corr.coef. & 0.999042 \\
\hline
\end{tabular}

fit: Noshok, In. $\mathrm{H} 2 \mathrm{Og}=\mathrm{a} 0+\mathrm{a} 1 \times($ Standard, In. $\mathrm{H} 2 \mathrm{Og})$

\begin{tabular}{|l|l|}
\multicolumn{2}{c}{ for statistics } \\
\hline $\mathrm{a} 0$ & 2.3407114 \\
\hline $\mathrm{a} 1$ & 0.9235807 \\
\hline corr.coef. & 0.9990425 \\
\hline
\end{tabular}

POST CALIBRATION STATISTICALDATA

\begin{tabular}{|c|c|c|c|}
\hline a & \multicolumn{2}{|l|}{2.34071140} & \\
\hline 5 & \multicolumn{2}{|l|}{0.92358067} & \\
\hline Sex & \multicolumn{2}{|l|}{163.23423} & \\
\hline MSE & \multicolumn{2}{|l|}{9.0685686} & \\
\hline $5 x x$ & \multicolumn{2}{|l|}{99782.4633} & \\
\hline $\operatorname{sum}\left(X i^{\wedge} 2\right)$ & \multicolumn{2}{|l|}{301523.918} & \\
\hline $\operatorname{avg}(X)$ & \multicolumn{2}{|l|}{100.43442} & \\
\hline \multicolumn{2}{|c|}{ Degrees Freedom } & \\
\hline \multicolumn{2}{|c|}{ (95\% confidence) } & \\
\hline \multicolumn{2}{|c|}{ Test Statistic, $T$} & 96.880 & \\
\hline \multicolumn{2}{|c|}{ W\&T: Uncert. Wy low } & 6.787 & In. $\mathrm{H} 2 \mathrm{O}$ \\
\hline \multicolumn{2}{|c|}{ W\&T: Uncert.,Wy high } & 6.785 & In. $\mathrm{H} 2 \mathrm{O}$ \\
\hline \multicolumn{2}{|c|}{ Curve Fit: Uncert.We } & 7.346 & In. $\mathrm{H} 2 \mathrm{O}$ \\
\hline \multicolumn{2}{|c|}{ Cal. Equip. Uncert.,Wc } & 4.000 & In. $\mathrm{H} 2 \mathrm{O}$ \\
\hline \multicolumn{2}{|c|}{ Total Uncertainty, Wt } & 8.36 & $\ln .420$ \\
\hline
\end{tabular}

i.e. Uncertainty in Pest Cal. Curve Fit: 9 ln.H2O

Figure D18: Uncertainty Analysis, Air Pressure Gauge AP4 
Final Report: Full-scale Test of DWPF Advanced Liquid-level and

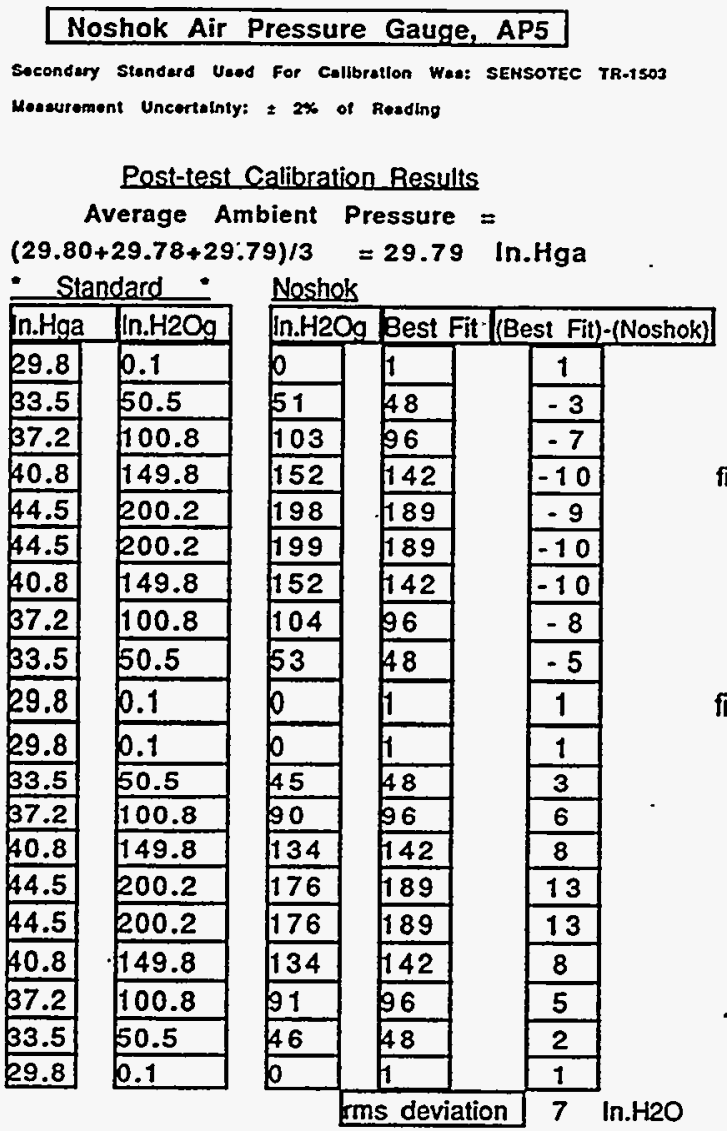

RESPONSE (Noshok, In. $\mathrm{H} 2 \mathrm{Og}$ )

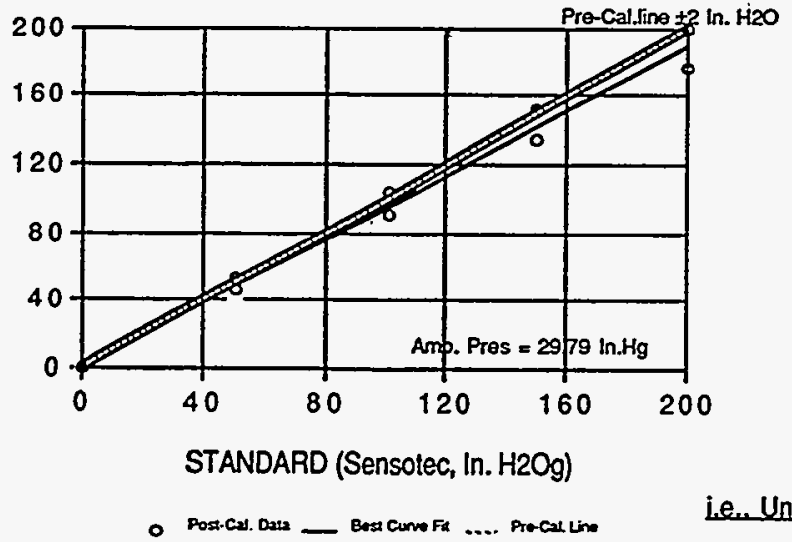

Pre-test Calibration: 10-15-96

Post-test Calibration: 03-12-97 Evaluation Date: 03-21-97

Pre-test Calibration Besults A cursory check before testing showed that al! gauges indicated within \pm 2 in. $\mathrm{H} 2 \mathrm{O}$ of a standard.

Therefore the Pre-Cal. Data Relation is: Noshoh $=1 \times$ (Standard), \pm 2 in. $\mathrm{H} 2 \mathrm{O}$

fit: Standard,In. $\mathrm{H} 2 \mathrm{Og}=\mathrm{bO}+\mathrm{b} 1 \times($ Noshok, In.H2Og)

\begin{tabular}{|l|l|}
\hline \multicolumn{2}{c}{ for DAS } \\
\hline bo & 0.092993 \\
\hline corr.coef. & 0.993931 \\
\hline
\end{tabular}

fit: Noshok, In. $\mathrm{H} 2 \mathrm{Og}=\mathrm{aO}+$ alx(Standard, In. $\mathrm{H} 2 \mathrm{Og})$ for statistics

\begin{tabular}{|l|l|}
\hline \multicolumn{2}{|c|}{ for statistics } \\
\hline a1 & 1.0646816 \\
\hline corr.coef. & 0.9385532 \\
\hline
\end{tabular}

POST CALURATION STATISTICALDATA

\begin{tabular}{|l|l|}
\hline 2 & 1.06468164 \\
\hline$b$ & 0.93855320 \\
\hline MSE & 1076.61365 \\
\hline Sxx & 59.8118695 \\
\hline
\end{tabular}

\begin{tabular}{lll}
\hline $\operatorname{sum}\left(X^{\wedge} 2\right)$ & 300977.563 \\
\hline
\end{tabular}

\begin{tabular}{l|l}
$\operatorname{avg}(X)$ & 100.29833 \\
\hline
\end{tabular}

Degrees Freedom 18

(95\% confidence) 2.101

Test Statistic, $T$

W\&T: Uncert.,Wy low 17.429 in. $\mathrm{H} 2 \mathrm{O}$ W\&T: Uncert. Wy high 17.425 in.H2O Curve Fit: Uncert.We 18.566 In.H2O Cal. Equip. Uncert.Wc 4.000 in. $\mathrm{H} 2 \mathrm{O}$ Total Uncertainty, Wt 18.99 In.H2O 


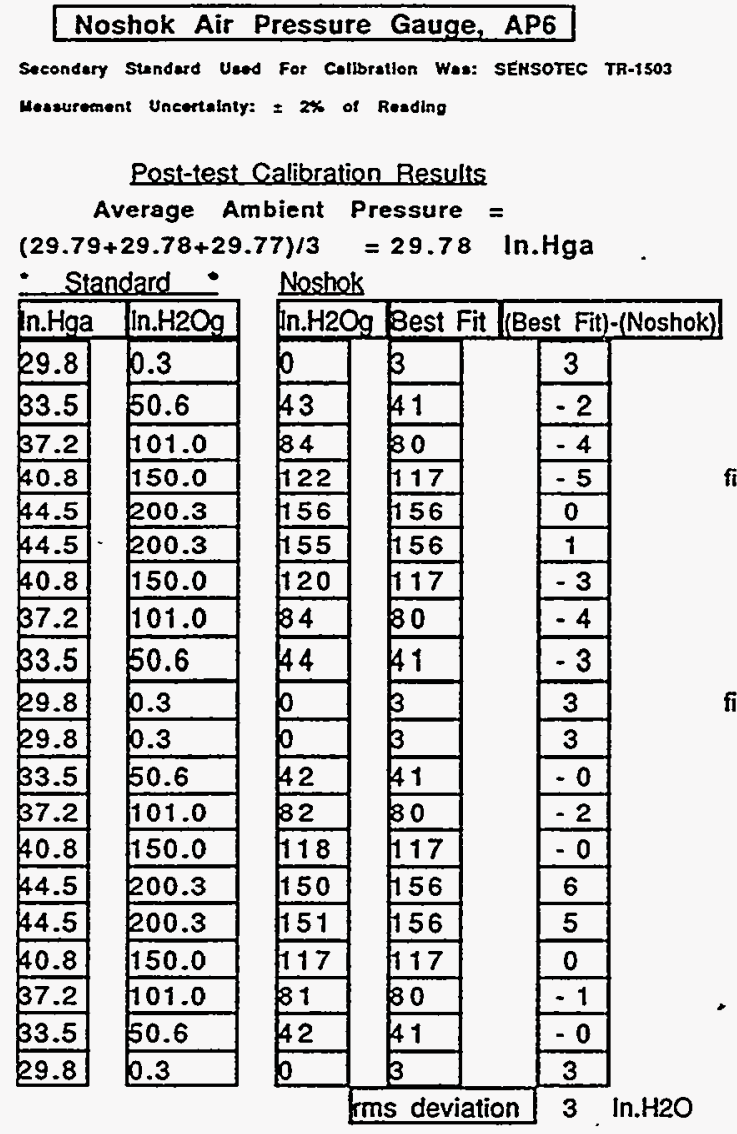

RESPONSE (Noshok, In. H2Og)

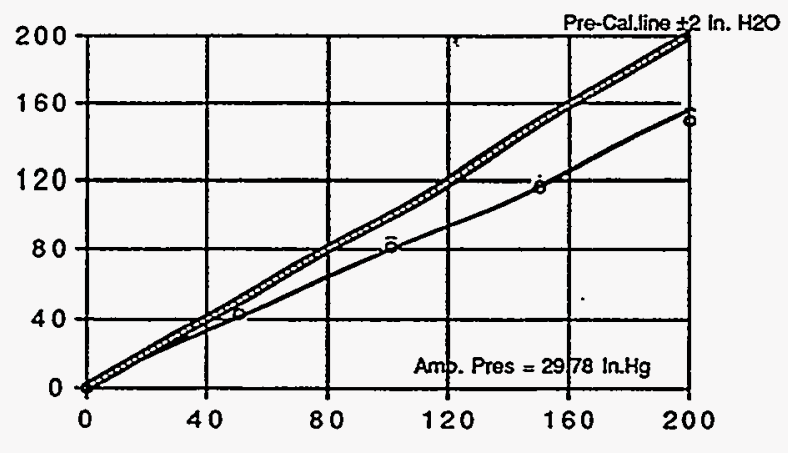

STANDARD (Sensotec, In. $\mathrm{H} 2 \mathrm{Og}$ )

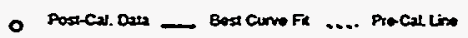

\author{
Pre-test Calibration: 10-15-96 \\ Post-test Calibration: 03-12-97 \\ Evaluation Date: 03-21-97
}

Pre-test_Calibration Results A cursory check belore testing showed that all gauges indicated within \pm 2 in. $\mathrm{H} 2 \mathrm{O}$ of a standard.

Therefore the Pre-Cal. Data Relation is: Noshoh $=1 \times$ (Standard), \pm 2 In. H2O

fit: Standard,In.H2Og = b0 + b1 $\times($ Noshok, In.H2Og)

\begin{tabular}{|l|l|}
\multicolumn{2}{|c|}{ for DAS } \\
\hline bo & 3.127160 \\
\hline b1 & 1.301843 \\
\hline corr.coef. & 0.998548 \\
\hline
\end{tabular}

fit: Noshok, In.H2Og = aO + atx(Standard, In.H2Og) for statistics

\begin{tabular}{|l|l|}
\hline 20 & 2.6260528 \\
\hline 31 & 0.7659122 \\
\hline corr.coef. & 0.9985475 \\
\hline
\end{tabular}

POST CALIBRATION STATISTICALDATA

\begin{tabular}{|l|l|}
\hline $\mathrm{a}$ & 2.62605277 \\
\hline $\mathrm{b}$ & 0.76591220 \\
\hline SEE & 170.41241 \\
\hline MSE & 9.4673562 \\
\hline S $x x$ & 99782.4633 \\
\hline
\end{tabular}

$\operatorname{sum}\left(X^{\wedge} 2\right) 301523.918$ \begin{tabular}{ll}
$\operatorname{avg}(X)$ & 100.43442 \\
\hline
\end{tabular} Degrees Freedom 18 (95\% confidence) 2.101

Test Statistic, $T \quad 78.631$ W\&T: Uncert.Wy low 6.934 in.H2O W\&T: Uncert.Wy high 6.932 in. $\mathrm{H} 2 \mathrm{O}$ Curve Fit: Uncert.We 9.051 in. $\mathrm{H} 2 \mathrm{O}$ Cal. Equip. Uncert.Wc 4.000 in.H2O Total Uncertainty, Wt 9.90 In. $\mathrm{H} 2 \mathrm{O}$ 
Final Report: Full-scale Test of DWPF Advanced Liquid-level and

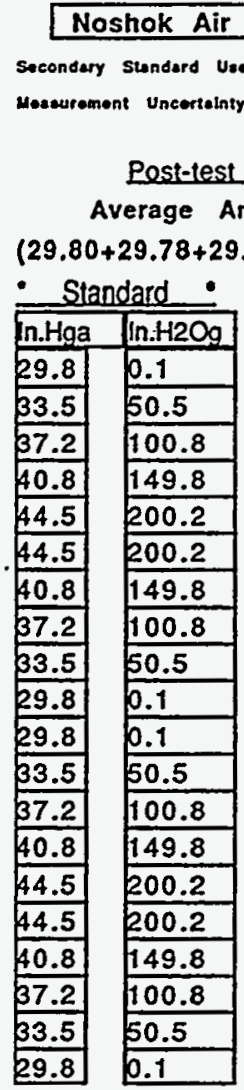

Noshok Air Pressure Gauge, AP7

Socondary Stondard Uied for Calfbrallon Was: SENSOTEC TR.2503

Rest-test Calibration Results

$(29.80+29.78+29.79) / 3=29.79 \quad$ In. Hga .

- Standard - Noshok.

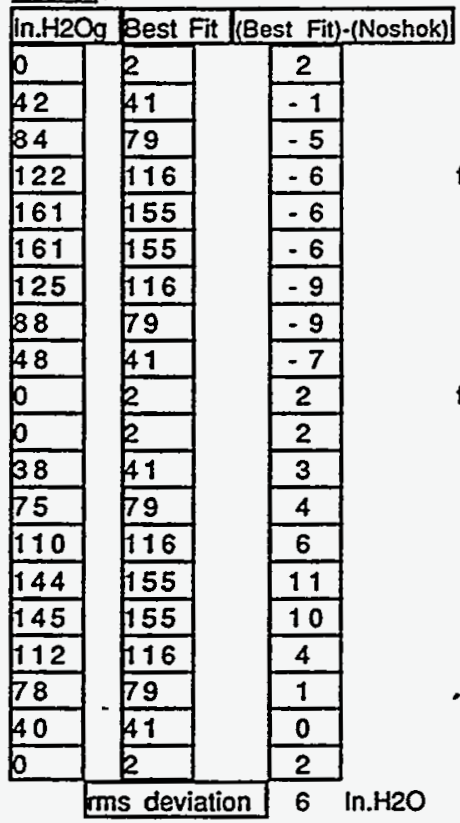

RESPONSE (Noshok, In. H2Og)

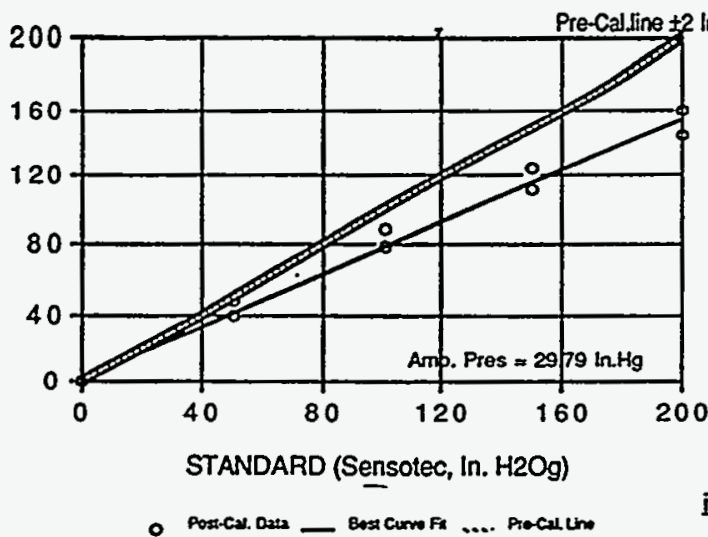

i.e. Uncertainty in Post Cal. Curve Fit: 19 in. H2Q

\author{
Pre-test Calibration: 10-15-96 \\ Post-test Calibration: 03-12-97 \\ Evaluation Date: 03-21-97
}

Ere-test Calibration Results

A cursory check before testing showed that all gauges indicated within \pm 2 in. $\mathrm{H} 2 \mathrm{O}$ of a standard.

Therefore the Pre-Cal. Data Relation is:

Noshoh $=1 \times$ (Standard), \pm 2 In. H2O

fit: Standard,In. $\mathrm{H} 2 \mathrm{Og}=\mathrm{bO}+\mathrm{b} 1 \times($ Noshok, In.H2Og)

\begin{tabular}{|l|l|}
\multicolumn{2}{|c}{ for DAS } \\
\hline bo & -1.699791 \\
\hline b1 & 1.296861 \\
\hline corr.coef. & 0.994350 \\
\hline
\end{tabular}

fit: Noshok, In.H2Og = a0 + a1x(Standard, In.H2Og)

\begin{tabular}{|l|l|}
\multicolumn{2}{c}{ for statistics } \\
\hline 20 & 2.1821188 \\
\hline 21 & 0.7624043 \\
\hline corr.coef. & 0.9943503 \\
\hline
\end{tabular}

POST CALIBRATION STATISTICALDATA

\begin{tabular}{|l|l|}
\hline $\mathrm{E}$ & 2.18211883 \\
\hline $\mathrm{b}$ & 0.76240433 \\
\hline SEI & 660.95908 \\
\hline MSE & 36.7199489 \\
\hline SXX & 99782.4633 \\
\hline
\end{tabular}

sum(Xi^2) 300977.563

\begin{tabular}{l|l}
$\operatorname{avg}(X)$ & 100.29833 \\
\hline
\end{tabular}

Degrees Freedom 18

(95\% confidence) 2.101

Test Statistic. T 39.743

W\&T: Uncert.,Wy low 13.656 in.H2O

W\&T: Uncert.,Wy high 13.653 in. H2O

Curve Fit: Uncert.We 17.908 In.H2O

Cal. Equip. Uncert..Wc 4.000 in.H2O

Total Uncertainty, $W_{t}$ 18.35 In.H2O 
Final Report: Full-scale Test of DWPF Advanced Liquid-level and

Noshok Air Pressure Gauge, APB

Socondary Stendard Uaed For Collbration Was: SEHSOTEC TR-1503

Wezourement Uncortalnty: $=2 \times$ of Resding

Rost-1est Calibration Results

Average Ambient Pressure = $(29.79+29.78+29.77) / 3=29.78 \mathrm{ln} . \mathrm{Hga}$

\begin{tabular}{|l|l|}
\hline \hline In.Hga & in.H2Og \\
\hline 29.8 & 0.3 \\
\hline 33.5 & 50.6 \\
\hline 37.2 & 101.0 \\
\hline 40.8 & 150.0 \\
\hline 44.5 & 200.3 \\
\hline 44.5 & 200.3 \\
\hline 40.8 & 150.0 \\
\hline 37.2 & 101.0 \\
\hline 33.5 & 50.6 \\
\hline 29.8 & 0.3 \\
\hline 29.8 & 0.3 \\
\hline 33.5 & 50.6 \\
\hline 37.2 & 101.0 \\
\hline 40.8 & 150.0 \\
\hline 44.5 & 200.3 \\
\hline 44.5 & 200.3 \\
\hline 40.8 & 150.0 \\
\hline 37.2 & 101.0 \\
\hline 33.5 & 50.6 \\
\hline 29.8 & 0.3 \\
\hline
\end{tabular}

In.H2Og Best Fit (Best Fit)-(Noshok)

\begin{tabular}{l|l|l|l|l|l|l|l|l|}
\hline 0 & 3 & 3 \\
\hline
\end{tabular}

\begin{tabular}{|l|}
\hline 49 \\
\hline 94 \\
\hline 138 \\
\hline 178 \\
\hline 178 \\
\hline 137 \\
\hline 95 \\
\hline 50 \\
\hline 0 \\
\hline 0 \\
\hline 48 \\
\hline 93 \\
\hline 134 \\
\hline 172 \\
\hline 173 \\
\hline 134 \\
\hline 92 \\
\hline 48 \\
\hline 0 \\
\hline
\end{tabular}

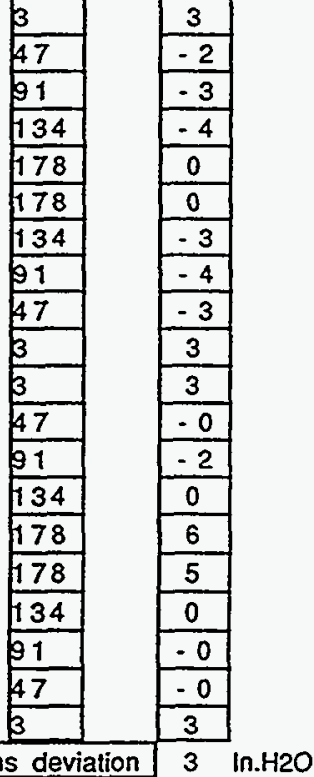

rms deviation 3 in.H2O

RESPONSE (Noshok, In. H2Og)

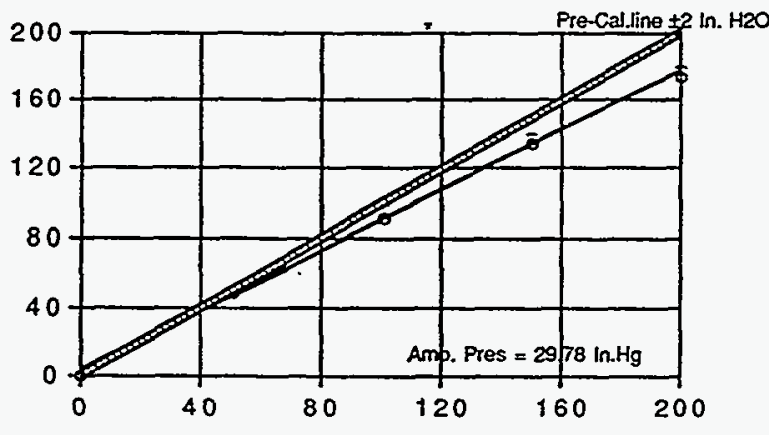

STANDARO (Sensotec, In. H2Og)

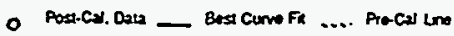

Pre-test Calibration: 10-15-96

Post-test Calibration: 03-12-97

Evaluation Date: 03-21-97

Pre-test Calibration Results

A cursory check before testing showed that all gauges indicated within \pm 2 in. $\mathrm{H} 2 \mathrm{O}$ of a standard.

Therefore the Pre-Cal. Data Relation is: Noshoh $=1 \times$ (Standard), \pm 2 In. $\mathrm{H} 2 \mathrm{O}$

fit: Standard,ln. $\mathrm{H} 2 \mathrm{Og}=\mathrm{b0}+\mathrm{b1} \times($ Noshok, $\ln \cdot \mathrm{H} 2 \mathrm{Og})$

\begin{tabular}{|l|l|}
\multicolumn{2}{|c|}{ for DAS } \\
\hline bo & -2.821545 \\
\hline corr.coef. & 0.998925 \\
\hline
\end{tabular}

fit: Noshok,in. $\mathrm{H} 2 \mathrm{Og}=\mathrm{aO}+\operatorname{a1} \times($ Standard, In. $\mathrm{H} 2 \mathrm{Og})$ for statistics

\begin{tabular}{|l|l|}
\hline $\mathrm{ao}$ & 2.6666276 \\
\hline $\mathrm{a} 1$ & 0.8760281 \\
\hline corr.coef. & 0.9989245 \\
\hline
\end{tabular}

POST CALIBRATIONSTATISTICAL DATA

\begin{tabular}{|l|l|}
\hline & 2.66662757 \\
\hline 0 & 0.87602808 \\
\hline SEI & 164.97288 \\
\hline NSE & 9.1651599 \\
\hline SXX & 99782.4633 \\
\hline
\end{tabular}

sum(Xi^2) 301523.918

\begin{tabular}{l|l|}
\hline $\operatorname{avg}(X)$ & 100.43442 \\
\hline
\end{tabular}

\begin{tabular}{l|l}
\hline Degrees Freedom & 18
\end{tabular}

(95\% confidence) 2.101

\begin{tabular}{l|l}
\hline Test Statistic, $T$ & 91.406
\end{tabular}

W\&T: Uncert.Wy low 6.823 in. $\mathrm{H} 2 \mathrm{O}$

W\&T: Uncert. Wy high 6.821 in. $\mathrm{H} 2 \mathrm{O}$

Curve Fit: Uncert.,We 7.786 In.H2O

Cal. Equip. Uncert.,Wc 4.000 In.H2O

Total Uncertainty, Wt 8.75 in. $\mathrm{H} 2 \mathrm{O}$ 
Final Report: Full-scale Test of DWPF Advanced Liquid-level and Density Measurement Bubblers (U)- WSRC-TR-97-0103, Rev. 0

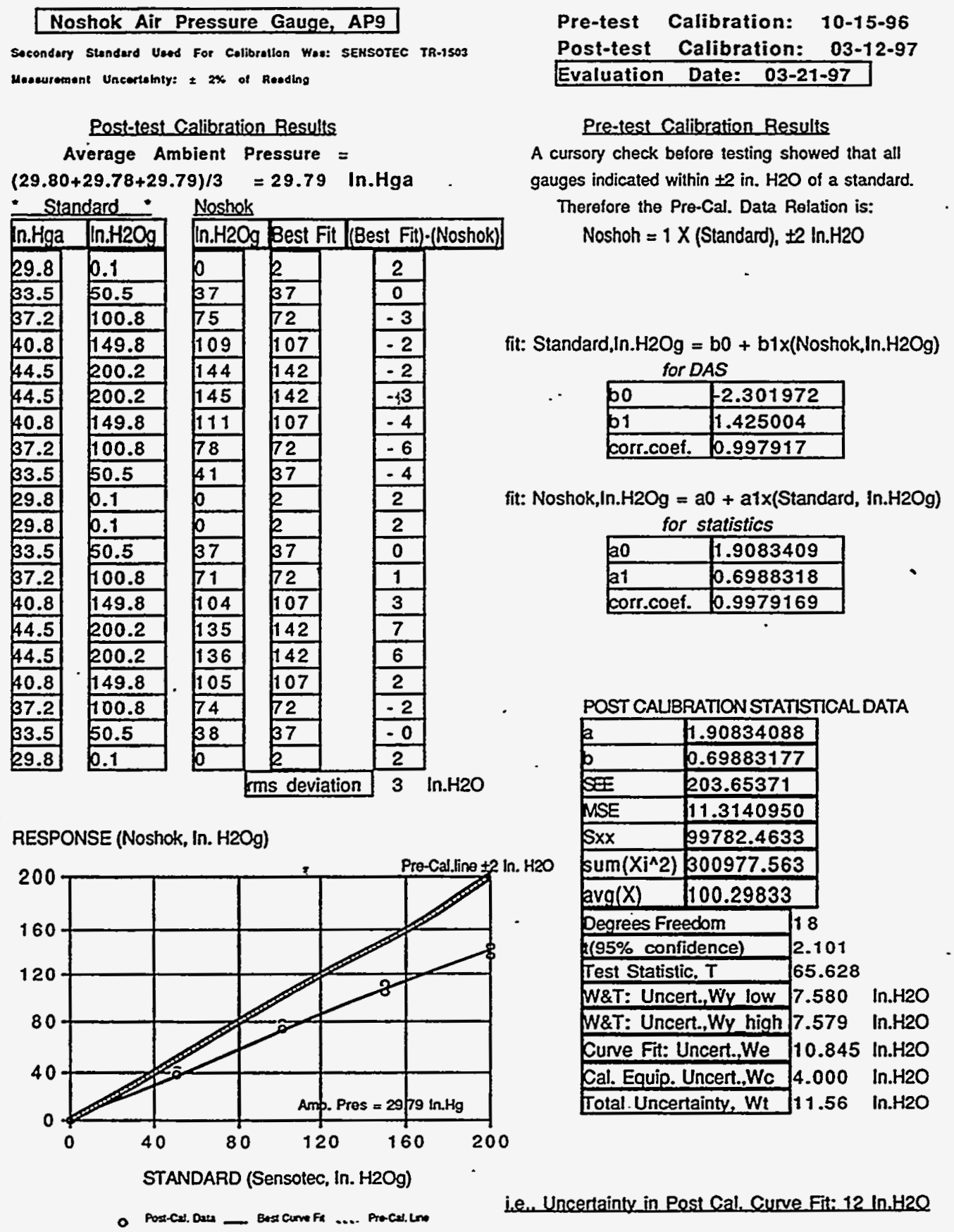

Figure D23: Uncertainty Analysis, Air Pressure Gauge AP9 
Final Report: Full-scale Test of DWPF Advanced Liquid-level and

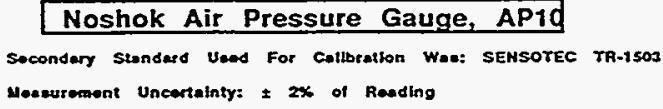

Post-test Calibration Results

Average Ambient Pressure $=$ $(29.79+29.78+29.77) / 3=29.78 \quad$ In. Hga

\begin{tabular}{|c|c|}
\hline in.Hga & In. $\mathrm{H} 2 \mathrm{Og}$ \\
\hline 29.8 & 0.3 \\
\hline 33.5 & 50.6 \\
\hline 37.2 & 101.0 \\
\hline 40.8 & 150.0 \\
\hline 44.5 & 200.3 \\
\hline 44.5 & 200.3 \\
\hline 40.8 & 150.0 \\
\hline 37.2 & 101.0 \\
\hline 33.5 & 50.6 \\
\hline 29.8 & 0.3 \\
\hline 29.8 & 0.3 \\
\hline 33.5 & 50.6 \\
\hline 37.2 & 101.0 \\
\hline 40.8 & 150.0 \\
\hline 44.5 & 200.3 \\
\hline 44.5 & 200.3 \\
\hline 40.8 & 150.0 \\
\hline 37.2 & 101.0 \\
\hline 33.5 & 50.6 \\
\hline 29.8 & 0.3 \\
\hline
\end{tabular}

Noshok

In.H2Og Best Fit (Best Fit)-(Noshok)

\begin{tabular}{|c|c|c|}
\hline 0 & 4 & 4 \\
\hline 44 & 44 & -0 \\
\hline 86 & 84 & -2 \\
\hline 126 & 123 & -3 \\
\hline 161 & 163 & 2 \\
\hline 162 & 163 & 0 \\
\hline 127 & 123 & -4 \\
\hline 90 & 84 & -6 \\
\hline 49 & 44 & -5 \\
\hline 0 & 4 & 4 \\
\hline$e$ & 4 & 4 \\
\hline 44 & 44 & -0 \\
\hline 84 & 34 & -0 \\
\hline 122 & 123 & 0 \\
\hline 156 & 163 & 7 \\
\hline 157 & 163 & 6 \\
\hline 123 & 123 & -0 \\
\hline 87 & 84 & -3 \\
\hline 46 & 44 & -2 \\
\hline 0 & 4 & 4 \\
\hline & is del & 4 \\
\hline
\end{tabular}

RESPONSE (Noshok, In. H2Og)

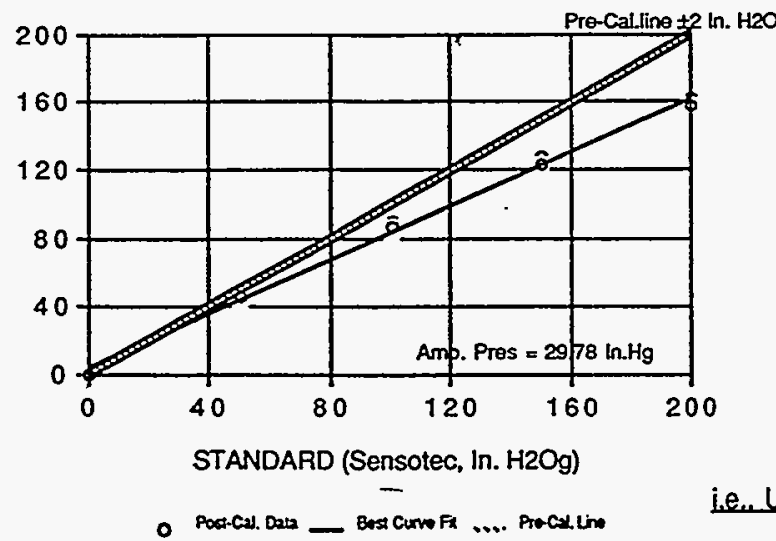

Pre-test Calibration: 10-15-96

Post-test Calibration: 03-12-97. Evaluation Date: 03-21-97

Pre-test_Calibration Results A cursory check before testing showed that all gauges indicated within \pm 2 in. $\mathrm{H} 2 \mathrm{O}$ of a standard. Therefore the Pre-Cal. Data Relation is: Noshoh $=1 \times$ (Standard), \pm 2 in. $\mathrm{H} 2 \mathrm{O}$

fit: Standard,in.H2Og = bo + bix(Noshok, In. H2Og)

\begin{tabular}{|l|l|}
\multicolumn{2}{|c|}{ for DAS } \\
\hline $\mathrm{b0}$ & 3.870497 \\
\hline $\mathrm{b1}$ & 1.253665 \\
\hline corr.coef. & 0.997992 \\
\hline
\end{tabular}

fit: Noshok, In. $\mathrm{H} 2 \mathrm{Og}=\mathbf{2 0}+\mathrm{atx}($ Standard, In.H2Og)

\begin{tabular}{|l|l|}
\multicolumn{2}{c}{ for statistics } \\
\hline ao & 3.4088045 \\
\hline att & 0.7944607 \\
\hline corr.coef. & 0.9979917 \\
\hline
\end{tabular}

POST CAUBRATION STATISTICAL DATA

\begin{tabular}{|l|l|}
\hline \hline & 3.40880453 \\
\hline$b$ & 0.79446066 \\
\hline MSE & 253.72831 \\
\hline SXX & 14.0960172 \\
\hline
\end{tabular}

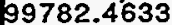

\begin{tabular}{ll}
$\operatorname{sum}\left(X{ }^{\wedge} 2\right)$ & 301523.918 \\
\hline
\end{tabular}

\begin{tabular}{l|l|}
\hline $\operatorname{avg}(X)$ & 100.43442 \\
\hline
\end{tabular}

Degrees Freedom

2.101

Test Statistic, $T$ 66.842

W\&T: Uncert. Wy low 8.461 in.H2O W\&T: Uncert.,Wy high 8.459 in.H2O Curve Fit: Uncert.,We 10.648 in.H2O Cal. Equip. Uncert.Wc 4.000 in.H2O Total Uncertainty, Wt 11.37 in.H2O

Figure D24: Uncertainty Analysis, Air Pressure Gauge AP10 
Final Report: Full-scale Test of DWPF Advanced Liquid-level and Density Measurement Bubblers (U)- WSRC-TR-97-0103, Rev. 0

Noshok Air Pressure Gauge, AP11

Sacondary standerd Uned for Cellibration Woo: SENSOTEC TR-1503

Moseurament Uncortainty: $\pm 2 x$ of Rosding

Post-test Calibration Results

Average Ambient Pressure $=$ $(29.80+29.78+29.79) / 3=29.79 \quad$ In. Hga

- Standard - Noshok

in.Hga in. $\mathrm{H}_{2 \mathrm{Og}}$ in.H2Og Best Fit (Best Fit)-(Noshok

$29.8 \quad 0.1$

$33.5 \quad 50.5$

$37.2 \quad 100.8$

$40.8 \quad 149.8$

$44.5 \quad 200.2$

$44.5 \quad 200.2$

$40.8 \quad 149.8$

$37.2 \quad 100.8$

$33.5 \quad 50.5$

$29.8 \quad 0.1$

29.8

$33.5 \quad 50.5$

$37.2 \quad 100.8$

$40.8 \quad 149.8$

$44.5 \quad 200.2$

$44.5 \quad 200.2$

$40.8 \cdot 149.8$

$37.2 \quad 100.8$

33.5

29.8

50.5

0.1

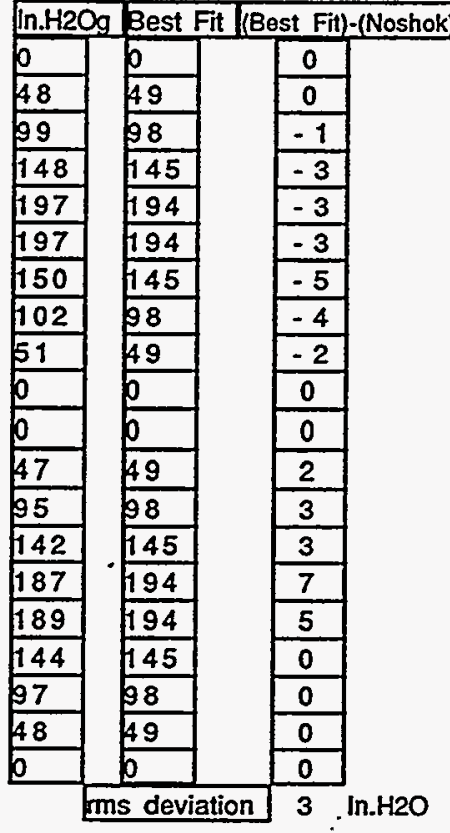

RESPONSE (Noshok, In. H2Og)

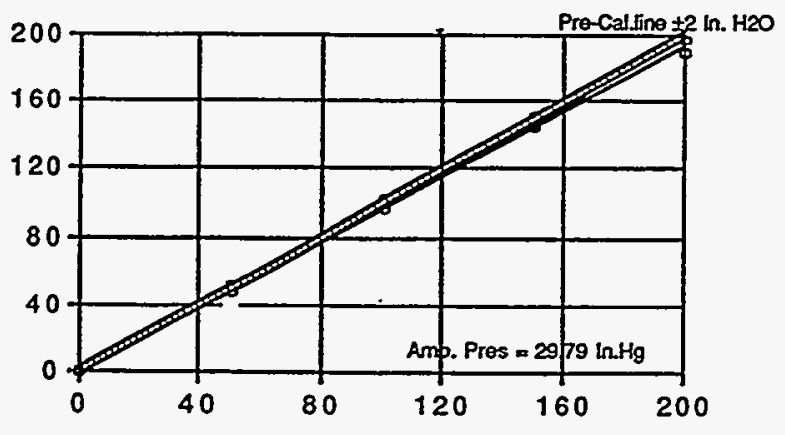

STANDARD (Sensotec, In. H2Og)

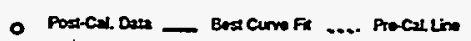

Pre-test Calibration: 10-15-96

Post-test Calibration: 03-12-97

Evaluation Date: 03-21-97

Pre-test_Calibration Results

A cursory check before testing showed that all gauges indicated within \pm 2 in. $\mathrm{H} 2 \mathrm{O}$ of a standard.

- Therefore the Pre-Cal. Data Relation is:

Noshoh $=1 \times$ (Standard), \pm 2 in. H2O

fit: Standard, In. $\mathrm{H} 2 \mathrm{Og}=\mathrm{bO}+\mathrm{b} 1 \times($ Noshok, In. $\mathrm{H} 2 \mathrm{Og})$

\begin{tabular}{|l|l|}
\hline \multicolumn{2}{|c|}{ for DAS } \\
\hline $\mathrm{b} 0$ & 0.022659 \\
\hline corr.coef. & 0.999084 \\
\hline
\end{tabular}

fit: Noshok, ln. $\mathrm{H} 2 \mathrm{Og}=\mathrm{aO}+\mathrm{a1x}($ Standard, $\ln . \mathrm{H} 2 \mathrm{Og})$ for statistics

\begin{tabular}{|l|l|}
\hline $\mathrm{a} 0$ & 0.1558289 \\
\hline $\mathrm{a} 1$ & 0.9660597 \\
\hline corr.coef. & 0.9990840 \\
\hline
\end{tabular}

POST CALBRATIONSTATISTICAL DATA

\begin{tabular}{|l|l|}
\hline$a$ & 0.15582885 \\
\hline$b$ & 0.96605967 \\
\hline MSE & 170.84297 \\
\hline SXX & 9.4912760 \\
\hline
\end{tabular}

\begin{tabular}{ll}
\hline $\operatorname{sum}\left(X i^{\wedge} 2\right)$ & 300977.563 \\
\hline
\end{tabular}

\begin{tabular}{|l|l|}
\hline $\operatorname{avg}(X)$ & 100.29833 \\
\hline
\end{tabular}

\begin{tabular}{l|l} 
Degrees Freedom & 18
\end{tabular}

(95\% confidence) 2.101

Test Statistic. $T$

W\&T: Uncert.Wy low 6.943 in.H2O

W\&T: Uncert..Wy high 6.941 In.H2O

Curve Fit: Uncert.We 7.185 in.H2O

Cal. Equip. Uncert..Wc 4.000 in.H2O

Total Uncertainty, Wt 8.22 In.H2O 
Final Report: Full-scale Test of DWPF Advanced Liquid-level and

\begin{tabular}{|c|c|}
\hline & shok Air \\
\hline conder & Stenderd \\
\hline Mescurreat & Uncortaint \\
\hline & \\
\hline & rerage $A$ \\
\hline$(29.79$ & $29.78+29$ \\
\hline - Sto & dard - \\
\hline In. Hga & In. $\mathrm{H} 2 \mathrm{Og}$ \\
\hline 29.8 & 0.3 \\
\hline 33.5 & 50.6 \\
\hline 37.2 & 101.0 \\
\hline 40.8 & 150.0 \\
\hline 44.5 & 200.3 \\
\hline 44.5 & 200.3 \\
\hline 40.8 & 150.0 \\
\hline 37.2 & 101.0 \\
\hline 33.5 & 50.6 \\
\hline 29.8 & 0.3 \\
\hline 29.8 & 0.3 \\
\hline 33.5 & 50.6 \\
\hline 37.2 & 101.0 \\
\hline 40.8 & 150.0 \\
\hline 44.5 & 200.3 \\
\hline 44.5 & 200.3 \\
\hline 40.8 & 150.0 \\
\hline 37.2 & 101.0 \\
\hline 33.5 & 50.6 \\
\hline 29.8 & 0.3 \\
\hline
\end{tabular}

Pre-test Calibration: 10-15-96 Post-test Calibration: 03-12-97 Evaluation Date: 03-21-97

\section{Pre-test_Calibration Results}

A cursory check before testing showed that all gauges indicated within \pm 2 in. $\mathrm{H} 2 \mathrm{O}$ of a standard.

Therefore the Pre-Cal. Data Relation is:

Noshoh $=1 \times$ (Standard), \pm 2 In. H2O
RESPONSE (Noshok, In. H2Og)

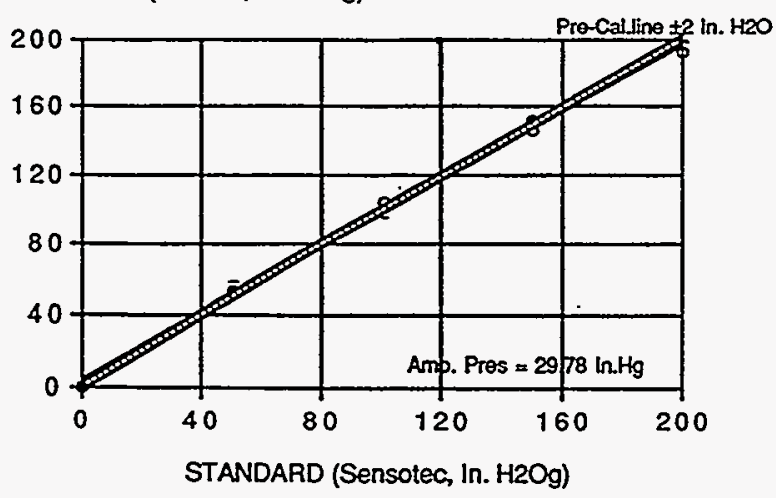

fit: Standard,In.H2Og = b0 + b1x(Noshok,In.H2Og)

\begin{tabular}{|l|l|}
\hline \multicolumn{2}{|c|}{ for DAS } \\
\hline b0 & -2.765482 \\
\hline b1 & 1.034067 \\
\hline corr.coef. & 0.998751 \\
\hline
\end{tabular}

fit: Noshok, In.H2Og = aO + a1x(Standard, In.H2Og) for statistics

\begin{tabular}{|l|l|}
\hline a0 & 2.916816 .1 \\
\hline a1 & 0.9646412 \\
\hline corr.coef. & 0.9987511 \\
\hline
\end{tabular}

POST CALBRATION STATISTICAL DATA

\begin{tabular}{|l|l|}
\hline $\mathrm{a}$ & 2.91681614 \\
\hline $\mathrm{b}$ & 0.96464124 \\
\hline Sex & 232.35202 \\
\hline MSE & 12.9084454 \\
\hline SXX & 99782.4633 \\
\hline
\end{tabular}

\begin{tabular}{ll}
$\operatorname{sum}\left(X i^{\wedge} 2\right)$ & 301523.918 \\
\hline
\end{tabular} \begin{tabular}{lll}
$\operatorname{avg}(X) \quad 100.43442$ \\
\hline
\end{tabular} \begin{tabular}{l|l} 
Degrees Freedom & 18
\end{tabular} (95\% confidence) 2.101 Test Statistic, $T$ W\&T: Uncert.,Wy low 8.097 in.H2O W\&T: Uncert.,Wy high 8.095 in.H2O Curve Fit: Uncert.We 8.392 In.H2O Cal. Equip. Uncert..Wc 4.000 in. $\mathrm{H} 2 \mathrm{O}$ Total Uncertainty, Wt 9.30 In.H2O

- Postaxisata 